
Career Choice of Medical Students and Recent Medical Graduates

Studies on factors of influence in a

longitudinal trajectory

Sophie Querido 


\section{Cover}

Frontside "Pathways"

Career paths of medical students and recent medical graduates with different factors of influence on their way.

Backside: "Balance of elements"

Balance between career and societal needs to satisfy and perception of specialty characteristics.

C) Sophie Querido, 2020

Illustration cover and chapter pages Davine, Levy, Yva, Henri, Sophie

Printed by

ISBN

Ridderprint BV, www.ridderprint.nl

DOI

\section{8-94-6416-180-9}

$10.33540 / 282$

All rights reserved. No part of this thesis may be reproduced, stored in retrieval systems, or transmitted in any form or by any means, electronic, mechanical, photocopying, recording or otherwise without prior permission of the author.

De uitgave van dit proefschrift is mede ondersteund door de Nederlandse Vereniging voor Medisch Onderwijs. 


\title{
Career Choice of Medical Students and Recent Medical Graduates Studies on factors of influence in a longitudinal trajectory
}

Beroepskeuze van geneeskundestudenten en basisartsen Onderzoek naar relevante factoren in longitudinaal perspectief (met een samenvatting in het Nederlands)

\section{Proefschrift}

\author{
ter verkrijging van de graad van doctor aan de \\ Universiteit Utrecht \\ op gezag van de \\ rector magnificus, prof.dr. H.R.B.M. Kummeling, \\ ingevolge het besluit van het college voor promoties \\ in het openbaar te verdedigen op \\ donderdag 21 januari 2021 des middags te 4.15 uur
}

door

Sophia Jaëla Querido

geboren op 21 december 1982

te Utrecht 


\section{Promotor:}

Prof. dr. Th.J. ten Cate

\section{Copromotoren:}

Dr. L. Wigersma

Dr. M.E.J. de Rond 


\section{Table of contents}

Chapter 1 General introduction and thesis outline

Chapter 2 Dynamics of career choice among students in undergraduate medical courses. A BEME systematic review: BEME guide No. 33

Chapter 3

Factors affecting senior medical students'

career choice

Chapter 4

Chapter 5 are reasons related to prior physician experience? 



\section{Chapter 1}

\section{Introduction}

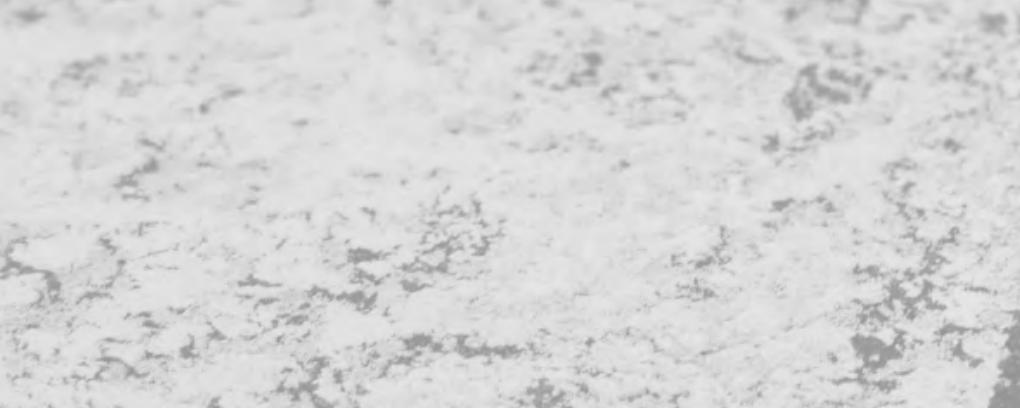

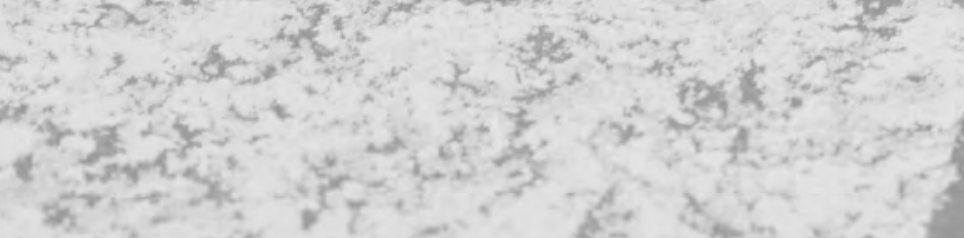

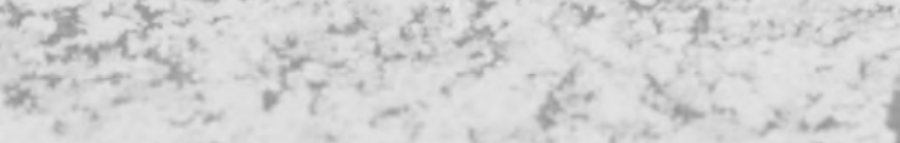

की

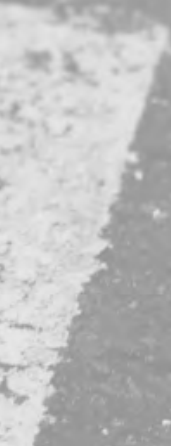


This research resulted from the question why the career choice of medical students does not match the need in society for health care and thus for medical specialists. The consequential question is how this is caused and what can be done about this mismatch.

The purpose of medical school is to train students to become medical doctors and to supply enough doctors available for the needs of society. The density of physicians, the total number per 1.000 population, across the globe shows that over $44 \%$ of WHO Member States report to have less than 1 physician per 1.000 population. ${ }^{1}$ Physicians are distributed unequally worldwide. Countries with the lowest relative need have the highest numbers of physicians, while those with the greatest healthcare needs have a much smaller health workforce. ${ }^{1}$ Even countries with a high density of physicians, such as the western countries, can face shortages of specialists such as family physicians, geriatricians, psychiatrists and surgeons. ${ }^{2-7}$ Medical graduates tend to prefer some specialties over others. This can lead to an imbalance between the needs of western society and the career choices of medical students.

The undergraduate medical education programs in various countries are determined by national rules for example about content, structure, terminology, and duration. ${ }^{8}$ There are many differences between countries worldwide in the structure, terminology, length of medical training, time for full registration and degrees granted. ${ }^{8}$ In most countries, including the Netherlands, graduates can choose their medical career and apply for a residency. ${ }^{8-11}$ However, there is a fixed number of residency positions for each medical specialty training based on the perceived needs of the Dutch society. ${ }^{12}$ Unfortunately, the career choices of Dutch medical students do not match the available residency positions. ${ }^{13-18}$ There is a skewed distribution. ${ }^{12}$ The unpopular specialties suffer from insufficient numbers of doctors to fulfill society needs. ${ }^{12,16}$ To influence students' career choice, we need to investigate what determines that choice. Therefore, this research explores the factors determining career choice and investigates if and how the current imbalance can be corrected. 


\section{Two personal stories of career choice}

To illustrate the process of career choice, the personal considerations of medical students Emily and Zoe are given here. These are text passages of various interviews of this thesis.

\section{Personal story one - Emily}

During her final study year, Emily had two career preferences: family physician and geriatrician. During her physician-not-in-training (PNIT) period, this changed into psychiatrist.

"I thought: I have to look around a little bit more. The care for the elderly was nice, with the somatic and psychiatric elements, but quite heavy with a lot of patients who die. So, I had to look around before I could make my career choice. That is when I went to work as a PNIT in psychiatry, because I really liked that."

Question (of the interviewer): "Why did you like it?"

"It was still in my head. If I become a family physician, it will be useful. It is part of the family physician-education program anyway. And during my emergency care internship my supervisor told me: "I think psychiatry is something for you, because you want to know the story behind the patient, and I would recommend you work there for a period. Even if you want to be in family medicine, it is good to have this experience. And maybe you will really like it." Maybe he was right. So, I went to work as a PNIT in psychiatry, and I am still here and I am so enthusiastic. This is my number one career preference now."

One and a half year later Emily started as a resident in psychiatry.

\section{Personal story two - Zoe}

At the start of her final study year, Zoe had three career preferences: neurologist, rehabilitation or family physician. At the end of the final year, her preferences were family physician, rehabilitation or neurologist. During her PNIT period, these changed again to neurologist and family physician.

"I was uncertain for a long period, but I made my choice to go for a residency position neurology. Now I am working as a PNIT in neurology, I really like it. It is such a broad specialty. I am the only PNIT in neurology in this hospital, so I am in the position to do a lot--to diagnose and set up therapy for complicated patients, sort things out, and talk with other small departments in the region. It is nice to do all this.

One and a half year later Zoe started as a resident in neurology. 


\section{Dutch medical career choice}

An important question that has to be answered in order to establish a balanced workforce of physicians is how they make their career choice. For medical students, choosing a specialty is a complex process. Many students enter medical school with a career plan or preference ${ }^{19}$, but few actually start a residency in the early domain of preference. ${ }^{20}$ A reason for that is that medical students appear to have misconceptions about the medical profession. ${ }^{21,22}$ As students gain experience during medical school, their career plans and preferences shift.

This chapter provides a general overview of Dutch undergraduate medical education, states what is known about the medical career choice process, describes conceptualizations and identifies gaps in the literature. It also addresses the consequences of the mismatches that occur because of inadequate career choices. Finally, it introduces the body of work that comprises this thesis, presents a conceptual framework and outlines the following chapters.

\section{Transition from undergraduate to graduate medical school in the Netherlands}

Most students are admitted to medical school directly from secondary school. ${ }^{8,10}$ Dutch undergraduate medical education takes six years, consisting of a bachelor phase and a master phase of three years each. ${ }^{9}$ The master years consist of clerkships, and the final year is called "transitional year," which is meant to provide a smooth transition from undergraduate to postgraduate training. ${ }^{10,23}$ In this year there are periods, from 6 to 18 weeks, of rotations at different departments, chosen by the students, they learn the area and supervisors get to know the students who may be future residents. ${ }^{10,23,24}$ Medical students use the transitional year electives to focus on their preferences, i.e. for orientation and to strengthen their curriculum vitae with their preferred specialty. ${ }^{25}$ This is a crucial time for students' career choice as it lets them experience how the demands of the specialty match with their career preferences. ${ }^{10}$ During the final-year rotations, students take on an increased level of responsibility in patient care, as they are expected to participate as a junior doctor, under strict supervision. ${ }^{10,23}$ In this last year of undergraduate training, medical students in most Dutch medical schools are called semi-physicians. ${ }^{8}$ Such an educational model is not limited to the Netherlands. Other medical training models have implemented similar transitional periods for the transition from undergraduate to graduate studies. For example, a foundation doctor in the UK and sub-intern or intern in the USA also have a final year in which medical students experience a period of clinical placements before their final exam to be licensed as a medical doctor, Figure $1 .^{8}$ Wijnen-Meijer et al. created a classification of six different educational routes to the medical 
degree worldwide. ${ }^{8}$ They explain how systems in various countries differ regarding medical school entry, curriculum length and structure, residency selection and postgraduate training structure.

The Dutch program duration and availability of residency positions is as follows. Medical schools start their programs with large cohorts (300-400 at each medical school) in September and students graduate six to eight years later, in small cohorts throughout the year. ${ }^{9}$ Graduates are allowed to perform supervised clinical work before their residency, start a $\mathrm{PhD}$-trajectory or directly start a residency. Most graduates take an interval period of months to years to gain clinical or research experience before starting a residency. Dutch graduates are free to make their career choice and they apply for a residency in an open job market system. ${ }^{8-11}$ The Netherlands has three categories of medical specialties: general practice (including family physician, elderly care specialist and intellectual disability physician), clinical specialties and public health medicine. Throughout the year, approximately 2.400 graduates become eligible to start residency. ${ }^{12}$ There is no nationally coordinated placement, like in the USA and Canada, where medical graduates immediately continue in a residency through a national residency matching program. ${ }^{26,27}$ 
- Chapter 1

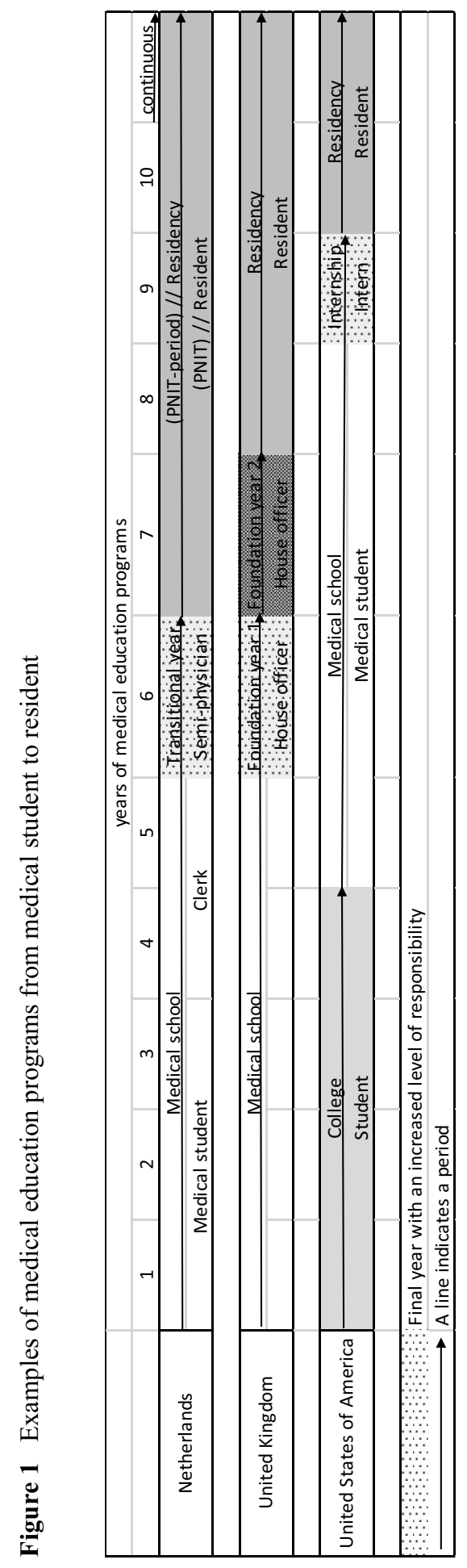




\section{Mismatch of available graduates and available residency positions}

Of the Dutch medical graduates, $20 \%$ want to start residency directly after medical school. ${ }^{16}$ Most of the graduates start with a period to gain clinical experience, to perform research to require a $\mathrm{PhD}$ degree (both to enhance their chances on a successful application later on) or take a time-out. They search and apply for a residency position later. This is the so-called interval-period. ${ }^{12}$ The time between really searching, choosing and starting a residency, the so-called searching time, averages 16.7 months in $2019 .{ }^{12,16}$ Nevertheless, the data of searching time are retrospectively collected through a survey among residents by the Dutch Registration Committee and therefore it can be somewhat biased. ${ }^{12}$ The total duration between graduation of medical school and starting residency averages 34.2 months in 2019 . This is the sum of the interval-period and searching time. ${ }^{16}$ The duration of both periods has increased in recent years, ${ }^{12-16}$ as shown in Table 1.

Table 1 Time between graduation and start search, between start search and start residency and between graduation and start residency

\begin{tabular}{|l|c|c|c|c|}
\hline & $\mathbf{2 0 0 9}$ & $\mathbf{2 0 1 2}$ & $\mathbf{2 0 1 6}$ & $\mathbf{2 0 1 9}$ \\
\hline $\begin{array}{l}\text { Average time graduation to start search residency (interval } \\
\text { period, in months) }\end{array}$ & 8.6 & 14.3 & 14.0 & 17.5 \\
\hline $\begin{array}{l}\text { Average time start search residency to start residency } \\
\text { (searching time in months) }\end{array}$ & 18.2 & 14.2 & 16.6 & 16.7 \\
\hline Average time graduation to start residency (in months) & 26.8 & 28.5 & 30.6 & 34.2 \\
\hline
\end{tabular}

Of the graduates who wait, $28 \%$ want to start sooner. ${ }^{16}$ Most Dutch graduates must, and want to, wait before starting residency training. The interruption period of their education has increased in the last ten years as the waiting time between medical school and residency increases. Also, residency programs started to weigh the experience as a physician-not-intraining (PNIT) obtained in the waiting period in their selection criteria. Some graduates filled this time by accepting a paid position as a clinical researcher in doctoral training, which also started to count in the selection criteria. These enhanced selection criteria have now become a significant reason for graduates to postpone residency and to aim at meeting the higher entrance criteria in the competition with their peers to increase their chances to obtain a residency position. ${ }^{9,28}$ In 2019, there were 6.765 graduates in this waiting period, while there was space for 2.920 residents to start. ${ }^{12,16}$ An overview of the available residency positions and the pool of graduates of the last ten years is presented in Table 2. ${ }^{12,29-31}$ 
Table 2 Number of residency positions and graduates with the wish for a residency position

\begin{tabular}{|l|c|c|c|c|}
\hline & $\mathbf{2 0 0 9}$ & $\mathbf{2 0 1 2}$ & $\mathbf{2 0 1 6}$ & $\mathbf{2 0 1 9}$ \\
\hline Available residency positions & 1.820 & 2.711 & 2.348 & 2.920 \\
\hline Pool of graduates & 3.719 & 4.670 & 5.102 & 6.765 \\
\hline Ratio & 2.0 & 1.7 & 2.1 & 2.3 \\
\hline
\end{tabular}

The pool of graduates needed for fluctuations in available residency positions (increase of availability or drop out of graduates) should ideally be 1.5 times the number of residency positions. ${ }^{12}$ The pool of graduates wanting a residency position increased in recent years up to 2.1 in 2016 and even up to 2.3 in 2019 the number of available residency positions, as seen in Table 2. This increase occurred for three main reasons: 1 . Too many medical students started undergraduate training compared to the number recommended by the Advisory Committee on Medical Manpower Planning. This can lead to more graduates into the pool. 2. More graduates dropped out of residency and most of these graduates wanted to start another residency and therefore they returned to the pool of graduates. As residency positions are assigned yearly, when a graduate drops-out a position cannot be reused. This will be a loss of residency capacity and 3 . While the available residency positions in some of the popular specialties decreased, graduates are willing to wait for one of these positions and therefore stay longer in the pool of graduates.

In the meantime, the elderly care specialist and public health residency positions are not fulfilled. ${ }^{12,32,33}$ This will lead to a future shortage of these health professionals. Research of the Dutch Medical Student Association among 2.920 Dutch medical students found that $71 \%$ prefer a career choice in one of the clinical specialties, primarily in pediatrics, internal medicine, surgery and gynecology. Also, 16\% had family medicine as their first choice, and $23 \%$ had it as their second choice in case they did not get a clinical residency position. ${ }^{17,18} \mathrm{~A}$ study by Van der Velde et al. among 6.049 graduates found similar findings. Most of them prefer a clinical specialty, such as internal medicine, surgery, pediatrics and gynecology. Of the graduates, $24 \%$ preferred family medicine as their first and $29 \%$ as their second choice. ${ }^{16}$ Medical students shape their career preferences during their undergraduate education. These preferences are influenced by many factors, such as type of work (content), experience as an intern, work-life balance, patient contact and salary. ${ }^{7,34-38}$ Which factors affect the final career choice? Can this choice be influenced to fill all available residency positions and to supply sufficient health care professionals to answer the needs of society? 


\section{Factors that determine medical career choice and dropout}

Multiple studies assessing the factors associated with specialty career choice have been performed among medical students worldwide. ${ }^{19,38,47-49,39-46}$ The main factors of influence on career choice mentioned in the literature are: salary, status, work-life balance, specialty content, challenging work, altruism, experiences by rotations, experiences otherwise, opinion of others and chance to obtain a residency position. ${ }^{19,38,47-49,39-46}$

Part of the literature on specialty choice focuses on specific specialties, such as surgery ${ }^{50,51}$, psychiatry $3,34,52$ or general practice..$^{7,38,53,54}$ Because of their limitations as specialty-specific studies, most of this research is performed because of shortages of physicians in the context of decreased interest in some specialties instead of the broad scope of what influences general interest of medical students to make their career choice. Some specialty-specific studies in this context did set up an intervention, such as a workshop event, film-festival or publicspeaking competition, to identify important factors of influence that may contribute to more interest in this specific specialty. ${ }^{7,55-58}$ Other studies just investigated a single factor, such as gender $^{36,59,60}$, salary/debt ${ }^{61,62}$, clinical experience ${ }^{7,50,63}$ or role models. ${ }^{64,65}$

Factors that determine career choice can also be gleaned from residents who drop out of residency. Previous studies provide insight in factors related to dropping out, which are often related to prior career choices. The main factors of influence on dropout mentioned in the literature are: uncontrollable lifestyle, disturbed work-life balance, change in career plans, health/family reasons, job content other than expected and insufficient knowledge. ${ }^{66-71}$ Several studies assessed dropping out worldwide. This field also has specialty-specific studies, such as emergency medicine ${ }^{69}$, family medicine ${ }^{71}$, orthopedics ${ }^{66}$, plastic surgery ${ }^{72}$, surgery ${ }^{68,70,73-75}$ and hospital specialties ${ }^{67}$ Most studies show relevance of preparing the future residents, by providing them with personal guidance and support before they make their career choice and to continue this support during residency to prevent drop outs. ${ }^{67,70,73,75}$ Residents with realistic expectations of what it takes to become a medical specialist may be more likely to complete training. ${ }^{67,70,73,75}$ 
- Chapter 1

\section{Longitudinal study}

Although previous studies provide valuable information about factors affecting career preferences and career choice, they were rarely based on a conceptual or theoretical framework, and there is a lack of longitudinal studies while there is a need for such research. ${ }^{7,19,41,76,77}$ Previous Dutch research advised to improve manpower planning and career choice of medical students and graduates by performing longitudinal research during medical school, about the preferences students have and the needs of the health care field. ${ }^{77} \mathrm{~A}$ longitudinal study would provide a more nuanced understanding of how medical students develop an interest in a specialty and which factors affect this decision over time. It also allows to determine the stability of the career preferences of medical students and graduates. Furthermore, knowledge of factors associated with career choice may create opportunities for career guidance, enabling better career decisions and preventing dropout. This is needed to achieve better workforce planning.

\section{Conceptual model}

There are multiple theories and models which can be used as a conceptual model. Decision theory ${ }^{37}$ helps to understand how career decisions are made, estimates the quality of decisions, and improves the decision-making process. ${ }^{37}$ Social cognitive career theory ${ }^{78}$ highlights the interplay of social cognitive variables (such as self-efficacy) with other key person, contextual, and experiential-learning factors, such as gender, culture and support systems.

This theory-building complements and bridges certain aspects of existing career theories. ${ }^{78}$ Social cognitive career theory is broader and more general than decision theory, without a specific medical perspective focus. Because of the typical characteristics of the medical career choice process, we used a more adjusted medical perspective model. Several of the studies referenced in this thesis used a model of career choice proposed in 1995 by Bland et al. ${ }^{79}$ This model provides insight into the career choice process. It shows how career choice results from a balance between the students' career desires and their perception of the characteristics of a specialty. The Bland model shows the medical career choice process with multiple factors of influence. Overview of these theories in Table 3. 
Table 3 Overview of decision theories/models

\begin{tabular}{|c|c|c|c|}
\hline & Decision theory $^{37}$ & $\begin{array}{c}\text { Social cognitive career } \\
\text { theory }^{78}\end{array}$ & Bland model $^{79}$ \\
\hline Summary & $\begin{array}{l}\text { an approach to } \\
\text { understand how } \\
\text { decisions are } \\
\text { made, providing } \\
\text { information about } \\
\text { the quality of the } \\
\text { decision and } \\
\text { improving the } \\
\text { decision-making } \\
\text { process }\end{array}$ & $\begin{array}{l}\text { a theory about } \\
\text { people's capacity to } \\
\text { influence their own } \\
\text { development and } \\
\text { surroundings. } \\
\text { interests are typically } \\
\text { related to the choices } \\
\text { that people make and } \\
\text { the actions they take to } \\
\text { implement their } \\
\text { choices }\end{array}$ & $\begin{array}{l}\text { provides an } \\
\text { overview of many } \\
\text { institutional and } \\
\text { student } \\
\text { characteristics that } \\
\text { result in a medical } \\
\text { career choice }\end{array}$ \\
\hline Strengths & $\begin{array}{l}\text { good way to help } \\
\text { students to make } \\
\text { wise decisions }\end{array}$ & $\begin{array}{l}\text { emphasis on the } \\
\text { learning experiences } \\
\text { that shape people's } \\
\text { occupational interests, } \\
\text { values, and choices } \\
\text { - empirical support for } \\
\text { the theory } \\
\text { - clear model }\end{array}$ & 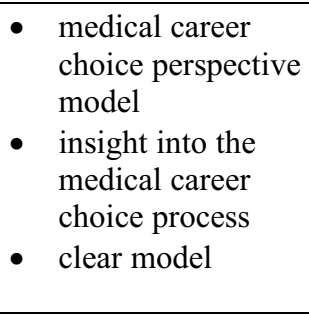 \\
\hline Weaknesses & $\begin{array}{l}\text { - no medical career } \\
\text { choice perspective } \\
\text { - a theory, no model }\end{array}$ & $\begin{array}{l}\text { no medical career } \\
\text { choice perspective } \\
\text { a theory, no model }\end{array}$ & $\begin{array}{l}\text { - } \text { applied to primary } \\
\text { care only } \\
\text { - } \text { not tested as a } \\
\text { theoretical model }\end{array}$ \\
\hline
\end{tabular}

\section{Bland model}

We used this model to examine how the balance between needs and perceptions evolves over time and influences specialty career choice. Although the Bland model has been cited in many studies, it has not yet been tested. This is remarkable, as research of career preferences of medical students has been criticized for its lack of a theoretical basis. ${ }^{80-82} \mathrm{We}$ used the model of Bland to determine a student's choice for a specialty, for this study ${ }^{79}$, in Figure 2. 
- Chapter 1

Figure 2 Model of the variables that determine medical students' choices of specialties by Bland et al. ${ }^{79}$

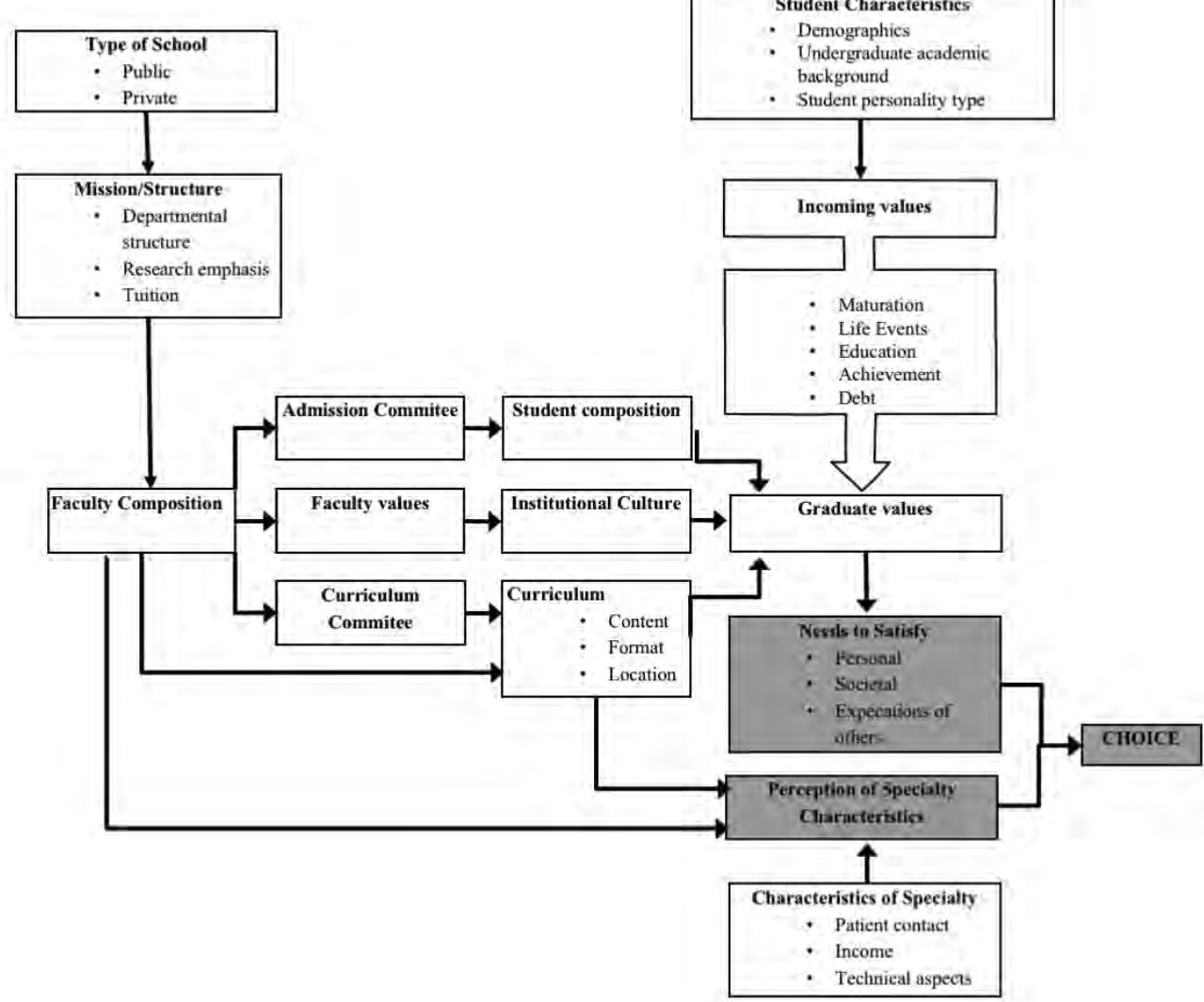




\section{Research aim}

Our research aims to explore the factors that determine career choice of medical students and recent graduates in the Netherlands to improve academic understanding of the development of career preferences during the period of undergraduate medical education and after graduation. It also aims to clarify which preferences change or become determinate during a period directly after graduation and before residency, when clinical or research experience is often obtained and final career choices are often made. The results can be used to learn how and when specialty choice is shaped during and after medical education. The knowledge gained can be used to support medical students and graduates in their career planning considerations. And can also be used to help medical schools to develop programs to support students in career choice, in order to obtain a balance between the needs of society and students' career preferences.

\section{Objectives}

This research investigates the following questions:

1. What is known from the literature about factors associated with career preferences and career choice?

2. Which factors determine the career choice of medical students during the final phase of medical school?

3. What is the impact of working as a physician not in training (PNIT) between medical school and residency on career preferences and choice?

4. Why do residents drop out? Which factors influence their career choice?

5. How is the career choice stability of medical students over a period of time?

Overall, our research aims to describe career preference(s) and related factors of medical students and new graduates, specifically the crucial factors for their career choice.

\section{Methods}

A variety of methods was used to address the research questions.

To answer the first research question, we started with a literature review. The purpose of this review was to relate the topic to the larger, ongoing dialogue in the literature, filling in gaps and extending prior studies. ${ }^{83}$ It provides an overview of recent studies and points out the need for more longitudinal and qualitative research on career choice (Chapter 2). To answer 
the second and third research questions, a qualitative longitudinal research approach was used. ${ }^{83,84}$ This is a phenomenological study, as we describe the experiences of medical students about the phenomenon of career choice, as explained by themselves. ${ }^{83,85}$ This description provides a better understanding of the essence of these lived experiences and thereby of the factors influencing medical career choice.

To gain insight into the concept of career choice by medical students over a period of time, we used a longitudinal interview study. We used one-on-one interviews, as this data collection process was ideal for our participants who are articulate and can speak comfortably about their ideas. ${ }^{84}$ For the best structure we used an interview protocol and developed a semistructured questionnaire about career preferences. ${ }^{84}$ The overall theme of the questionnaire was to explore considerations of students to identify factors that affect career choice (see Appendix 2) Our study population consisted of medical students at University Medical Center Utrecht in the Netherlands. We conducted a longitudinal study among our study population with four intervals: at the beginning of the final study year of medical school, at the end of the final study year, one year after graduation and 2,5 years after graduation, an overview in Figure 3.

Figure 3 Interview moments

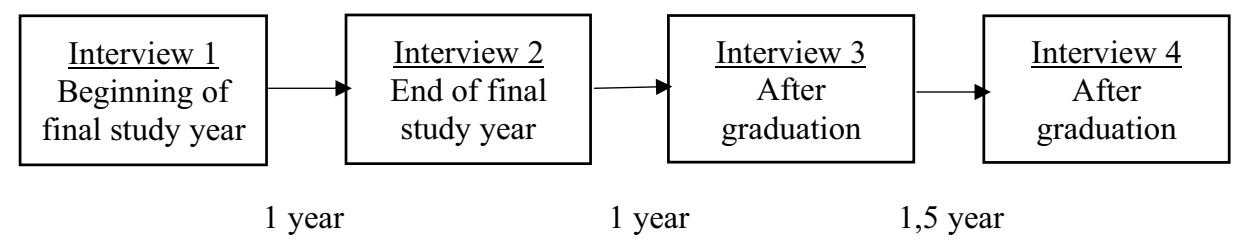

We deliberately started with participants who were in their final study year, the transitional year, as they have clerkships and have the opportunity to work with increased responsibilities in clinical practice. ${ }^{86}$ This is a crucial time for students' career choice, as it is the period in which they experience if and how the demands of the specialty match with their career preferences. ${ }^{10}$ The last interview examined how career preferences evolve over time and the impact of working as a doctor.

After data collection, we prepared the data for analysis. This brought us to our main findings and we integrated these using the Bland model. ${ }^{79}$ (Chapter 3). Next, we focused on one particular theme that emerged from the data of the first three interviews, the results of 
experience (Chapter 4). In Chapters 3 and 4 we used quotes from the participants to strengthen the findings.

The fourth research question was addressed using a survey among a large group of graduates who dropped out of residency in all specialties. ${ }^{84}$ In collaboration with the Dutch Medical Registration Board, an online survey was sent to all graduates who dropped out during a twoyear period between 1 September 2017 and 1 September 2019 (see Appendix 3). As the board registers all graduates in the Netherlands, they could sent the survey to all graduates who dropped out in the selected period of our proposal. The selected sample was $100 \%$ of the population. The survey was developed using a recommended seven-step process for survey design by Artino et al. ${ }^{87}$

The studies were approved by the Netherlands Association for Medical Education Ethical Review Board and by the Ethical Commission of the Dutch Medical Registration Board. The topics examined in the survey concerned experience as a physician working not in residency training (PNIT), any career preferences during the period of making the career choice and current and desired working position. Further, they were asked to indicate on a 5-point Likert scale the weight of various reasons for dropping out of their residency. The results were analyzed by a process including developing a codebook for every variable and correcting all missing data ${ }^{84}$ Next, a descriptive analysis was performed, and results were analyzed using IBM SPSS ${ }^{\circledR}$ software version 26 . The results are presented for the complete group

\section{(Chapter 5).}

Finally, for the fifth research question, we investigated the career paths of the study population to determine stability of career choice. The data of the four sessions interview study with medical students were used. From each participant with sufficient information, the first and second career preferences were analyzed to interpret career preference stability scores. This brought a longitudinal view into stability of career preferences (Chapter 6).

\section{Outline of the thesis}

To address our research questions, this thesis is structured chronologically with interviews about student career choice process during the different phases of undergraduate and graduate medical education ending with a survey among physicians who dropped out of residency. 
- Chapter 1

Finally, we sketch characteristic career paths of our study population and attempt to interpret the stability of career choice.

Chapter 2 presents the results of a systematic review of studies focusing on factors related to career preference and career choice in countries with a similar educational system to the Netherlands. It places the outcomes of today's research in the light of the Bland model of the process of career choice and the factors influencing this choice. ${ }^{79}$ It was important to find out how career choices are developed and influenced over the years. Therefore, we conducted a review to provide insight into recent literature.

Chapter 3 presents the results of the first interview series with medical students at the beginning of the final year of medical school about how they establish career preference and their perspective into their future career choice. The sensitizing concepts from the literature were used in the thematic analysis of the interview data.

Chapter 4 focuses on what influences students' career preference during the final study year and the PNIT period. The interviews focused on how students establish career preferences, the impact of clinical responsibility, and how preferences evolve over time.

Chapter 5 presents the results of a national survey among dropped out graduates during residency and the personal considerations that led to dropping out.

Chapter 6 describes the different career paths of medical students that predict stability in their career choice over time.

Finally, chapter 7 summarizes and discusses the findings from each study. Implications of the research results and recommendations on how to support medical students and recent graduates to make their career choice are presented and future research directions are discussed.

Note: This thesis is a collection of articles. Each chapter was written as stand-alone article. Therefore, repetition and overlap across chapters are inevitable. 


\section{References}

1. WHO WHO. Global Health Observatory (GHO) data.

https://www.who.int/gho/health_workforce/physicians_density/en/. Published 2019.

2. Holveck C., Wick JY. Addressing the shortage of geriatric specialists. Consult Pharm. 2018;33(3):130-138. doi:10.4140?TCP.n.2018.130.

3. Goldenberg MN, Sc M, Williams DK, Ph D, Spollen JJ. Stability of and Factors Related to Medical Student Specialty Choice of Psychiatry. 2017;(September):859-866. doi:10.1176/appi.ajp.2017.17020159.

4. Kirch DG, Medical A, Petelle K. Addressing the Physician Shortage The Peril of Ignoring Demography. Jama. 2017;317(19):1947-1948. doi:10.1001/jama.2017.2714.

5. Lambert TW, Smith F, Goldacre MJ, Lambert TW. Career specialty choices of UK medical graduates of 2015 compared with earlier cohorts : questionnaire surveys. Postgrad Med J. 2018;94(1110):191-197. doi:10.1136/postgradmedj-2017-135309.

6. Olsson C, Järnbert-pettersson H, Ponzer S, Dahlin M, Bexelius T. Swedish doctors choice of medical speciality and associations with cultural capital and perceived status : a cross- sectional study. BMC Med Educ. 2019;19(online):1-9. doi:10.1186/s12909019-1691-y.

7. Pfarrwaller E, Sommer J, Chung C, et al. Impact of Interventions to Increase the Proportion of Medical Students Choosing a Primary Care Career: A Systematic Review. J Gen Intern Med. 2015;30(9):1349-1358.

8. Wijnen-Meijer M, Burdick W, Alofs L, Burgers C, ten Cate O. Stages and transitions in medical education around the world: clarifying structures and terminology. Med Teach. 2013;35(4):301-307.

9. Hoff R, Imhof S, Frenkel F, ten Cate OTJ. Flexibility in Postgraduate Medical Training in the Netherlands. Acad Med. 2018;93(3):S33-6.

10. Ten Cate O. Medical education in The Netherlands. Med Teach. 2007;29(8):752-757.

11. van der Vleuten C, Scherpbier A. AM Last Page: medical education in the Netherlands. Acad Med. 2009;84(7):973.

12. Advisory Committee on Medical Manpower Planning. Medical Manpower Planning Main Report [In Dutch]. Utrecht; 2019.

https://capaciteitsorgaan.nl/app/uploads/2020/02/2020_02_12-Capaciteitsplan-20212024-Hoofdrapport-DEFINITIEF-EN.pdf.

13. Velde F van der, Verijdt F, Smeets RCKC. Loopbanen En Loopbaan- Wensen van Basisartsen [In Dutch]. Utrecht. Prismant; 2009.

14. Van der Velde F, Abbink-Cornelissen M, Bloemendaal I, Van der Kwartel A. Loopbanen En Loopbaanwensen van Basisartsen, Meting 2012/2013 [In Dutch]. Utrecht, KIWA; 2013.

15. Van der Velde F, Wierenga M. Loopbanen En Loopbaanwensen van Basisartsen. Herhaling van Het Onderzoek Onder Basisartsen 2009 En 2012 [In Dutch]. Utrecht. KIWA; 2016.

16. Velde F van der, Leemkolk B van de, Lodder A. Loopbanen En Loopbaanwensen van Basisartsen Meting 2019 [In Dutch]. Utrecht. Prismant; 2019. 
- Chapter 1

17. The medical student association. Research Report Career Choice 2014 [in Dutch]. Utrecht; 2014. https://degeneeskundestudent.nl/nieuws-en-standpunten/onderwerpenstandpunten/beroepskeuze.

18. The medical student association. Underexposed Residencies [in Dutch]. Utrecht; 2018. https://degeneeskundestudent.nl/nieuws-en-standpunten/onderzoeksrapporten-2018.

19. Cleland JA, Johnston PW, Anthony M, Khan N, Scott NW. A survey of factors influencing career preference in new-entrant and exiting medical students from four UK medical schools. BMC Med Educ. 2014;14(1):151. doi:10.1186/1472-6920-14-151.

20. Kaur B, Carberry A, Hogan N, Roberton D, Beilby J. The medical schools outcomes database project : Australian medical student characteristics. BMC Med Educ. 2014;14:180-190.

21. Soethout MBM, Heymans MW, ten Cate OTJ. Career preference and medical students' biographical characteristics and academic achievement. Med Teach. 2008;30(1):e15e22. doi:10.1080/01421590701759614.

22. Underwood MJ, Thompson M, McCaskie A. Insight of first-year medical students into their future working conditions. Med Educ. 1990;24(3):210-211. doi:10.1111/j.13652923.1990.tb00002.x.

23. Jonker G, Hoff RG, Max S, Kalkman CJ, ten Cate O. Connecting undergraduate and postgraduate medical education through an elective EPA-based transitional year in acute care: an early project report. GMS J Med Educ. 2017;34(5):1-6.

24. ten Cate OTJ, Borleffs JCC, Van Dijk M, Westerveld T. Training Medical Students for the 21st Century: Rationale and Development of the Utrecht Curricullum "CRU+." Med Teach. 2018;40(5):461-466.

25. van den Broek WES, Wijnen-Meijer M, Ten Cate O, van Dijk M. Medical students' preparation for the transition to postgraduate training through final year elective rotations. GMS J Med Educ. 2017;34(5):Doc65.

26. CaRMS. The Canadian Resident Matching Service. https://www.carms.ca. Published 2020 .

27. The Match. National Residency Matching Program: Residency. www.nrmp.org. Published 2020.

28. ten Cate O. Medical education in the Netherlands. Med Teach. 2007;29(8):752-757. doi:10.1080/01421590701724741.

29. Advisory Committee on Medical Manpower Planning. Medical Manpower Planning Main Report 2008 [In Dutch]. Utrecht; 2009. https:/capaciteitsorgaan.nl/app/uploads/2015/06/Capaciteitsplan-2008.pdf.

30. Advisory Committee on Medical Manpower Planning. The 2013 Recommendations for Medical Specialist Training [In Dutch]. Utrecht; 2013. https://capaciteitsorgaan.nl/app/uploads/2016/01/DEFINITIEF-2013-hoofdrapportengels-compl.pdf.

31. Advisory Committee on Medical Manpower Planning. The 2016 Recommendations for Medical Specialist Training [in Dutch]. Utrecht; 2016. https://capaciteitsorgaan.nl/app/uploads/2016/10/2016_10_21-Revisie-3.0Capaciteitsplan-2016-Hoofdrapport-DEFINITIEF.pdf. 
32. Advisory Committee on Medical Manpower planning. Medical Manpower Planning Subreport Elderly Care Specialist [in Dutch]. Utrecht; 2019.

https:/capaciteitsorgaan.nl/app/uploads/2019/12/Capaciteitsplan-2021-2024Deelrapport-5-SO.pdf.

33. Advisory Committee on Medical Manpower Planning. Medical Manpower Planning Subreport Public Health [in Dutch]. Utrecht; 2019.

https:/capaciteitsorgaan.nl/app/uploads/2019/12/Capacitietsplan-2021-2024Deelrapport-4-SG.pdf.

34. Baller FE, Ludwig K V, Kinas-Gnadt Olivares CL, Graef-Calliess I-T. Exploring the ideas and expectations of German medical students towards career choices and the speciality of psychiatry. Int Rev Psychiatry. 2013;25(4):425-430. doi:10.3109/09540261.2013.823384.

35. Berger AP, Giacalone JC, Barlow P, Kapadia MR, Keith JN. Choosing surgery as a career: Early results of a longitudinal study of medical students. Surgery. 2017;161(6):1683-1689. doi:10.1016/j.surg.2016.12.016.

36. Diderichsen S, Johansson EE, Verdonk P, Lagro-Janssen T, Hamberg K. Few gender differences in specialty preferences and motivational factors: a cross-sectional Swedish study on last-year medical students. BMC Med Educ. 2013;13(1):39. doi:10.1186/1472-6920-13-39.

37. Reed V., Jernstedt CG, Reber E. Understanding and Improving Medical Student Specialty Choice: A Synthesis of the Literature Using Decision Theory as a Referent, Teaching and Learning in Medicine: An Int J. 2001;13(2):117-129.

38. Shadbolt N, Bunker J. Choosing general practice: A review of career choice determinants. Aust Fam Physician. 2009;38(1-2):53-55.

39. Burack J, Irby D, Carline J, Ambrozy D, Ellsbury K, Stritter F. A study of medical students' specialty-choice-pathways: trying on possible selves. Acad Med. 1997;72(6):534-541.

40. Compton MT, Frank E, Elon L, Carrera J. Changes in U.S. Medical Students ' Specialty Interests over the Course of Medical School. J Gen Intern Med. 2008;23(7):1095-1100.

41. Goel S, Angeli F, Dhirar N, Singla N, Ruwaard D. What motivates medical students to select medical studies : a systematic literature review. BMC Med Educ. 2018;18(16):110. doi:10.1186/s12909-018-1123-4.

42. Goldacre MJ, Laxton L, Lambert TW. Medical graduates' early career choices of specialty and their eventual specialty destinations: UK prospective cohort studies. $B M J$. 2010;340(c3199):1-9.

43. Heikkilä TJ, Hyppölä H, Vänskä J, et al. Factors important in the choice of a medical career: a Finnish national study. BMC Med Educ. 2015;15(1):169. doi:10.1186/s12909015-0451-X.

44. Hou J, Xu M, Kolars JC, et al. Career preferences of graduating medical students in China: a nationwide cross-sectional study. BMC Med Educ. 2016;16(1):136. doi:10.1186/s12909-016-0658-5.

45. Huda N, Yousuf S. Career preference of final year medical students of Ziauddin Medical University. Educ Heal Chang Learn Pract. 2006;19(3):345-353. doi:10.1080/13576280600984087. 
- Chapter 1

46. Ibrahim M, Fanshawe A, Patel V, et al. What factors influence British medical students' career intentions? Med Teach. 2014;36(12):1064-1072. doi:10.3109/0142159X.2014.923560.

47. Jolly P, Erikson C, Garrison G. U.S. Graduate Medical Education and Physician Specialty Choice. Acad Med. 2013;88(4):468-474. doi:10.1097/ACM.0b013e318285199d.

48. Soethout M, Ten Cate TJ, van der Wal G. Factors associated with the nature, timing and stability of the specialty career choices of recently graduated doctors in European countries, a literature review. Med Educ Online. 2004;9(24):1-9. doi:10.3402/meo.V9i.4360.

49. Takeda Y, Morio K, Snell L, Otaki J, Takahashi M, Kai I. Characteristic profiles among students and junior doctors with specific career preferences. BMC Med Educ. 2013;13(1):125. doi:10.1186/1472-6920-13-125.

50. Goldin SB, Schnaus MJ, Horn G, et al. Surgical interest and surgical match for thirdyear students: Results of a prospective multivariate longitudinal cohort study. $J \mathrm{Am}$ Coll Surg. 2012;215(5):599-606.

51. Tambyraja AL, McCrea CA, Parks RW, Garden OJ. Attitudes of medical students toward careers in general surgery. World J Surg. 2008;32(6):960-963. doi:10.1007/s00268-008-9529-5.

52. Andlauer O, Guicherd W, Haffen E, et al. Factors influencing french medical students towards a career in psychiatry. Psychiatr Danub. 2012;24(SUPPL. 1):185-190.

53. Kiolbassa K, Miksch A, Hermann K, et al. Becoming a general practitioner--which factors have most impact on career choice of medical students? BMC Fam Pract. 2011;12(1):25. doi:10.1186/1471-2296-12-25.

54. Lahad A, Bazemore A, Petek D, Phillips WR, Merenstein D. How can we change medical students' perceptions of a career in family medicine? Marketing or substance? Isr J Health Policy Res. 2018;7(52):1-5.

55. Agyapong VIO, McLoughlin D. Promoting Psychiatry as a Career Option for Ghanaian Medical Students Through a Public-Speaking Competition. Acad Psychiatry36. 2012;36(3):229-232.

56. Ahmed K, Bennett DM, Halder N, Byrne P. Medfest : the Effect of a National Medical Film Festival on Attendees ' Attitudes to Psychiatry and Psychiatrists and Medical Students 'Attitudes to a Career in Psychiatry. Acad Psychiatry. 2015;39(3):335-338. doi:10.1007/s40596-014-0184-x.

57. Avinashi $\mathrm{V}$, Shouldice $\mathrm{E}$. Increasing interest in family medicine. CMAJ. 2006;174(6):761-762.

58. Bridgeman A, Findlay R, Devnani A, Lim D, Loganathan K. Inspiring the next generation of Cardiothoracic Surgeons : an easily reproducible, sustainable event increases UK undergraduate interest in the specialty. Interact Cardiovasc Thorac Surg. 2016;22(October 2015):106-108. doi:10.1093/icvts/ivv280.

59. Drinkwater J, Tully MP, Dornan T. The effect of gender on medical students' aspirations: A qualitative study. Med Educ. 2008;42(4):420-426. doi:10.1111/j.13652923.2008.03031.x. 
60. Heiligers PJ. Gender differences in medical students $\underset{\not}{ }$ motives and career choice. $B M C$ Med Educ. 2012;12(1):82. doi:10.1186/1472-6920-12-82.

61. Dezee KJ, Maurer D, Colt R, et al. Effect of financial remuneration on specialty choice of fourth-year U.S. medical students. Acad Med. 2011;86(2):187-193.

62. Rohlfing J, Navarro R, Maniya OZ, Hughes BD, Rogalsky DK. Medical student debt and major life choices other than specialty. Med Educ Online. 2014;11(19):1-10.

63. Coffeng LE, Visscher AJE, Ten Cate OTJ. The influence of early clinical experiences on career preference of male and female medical students. 2009;31:e323-e326. doi: $10.1080 / 01421590802650084$.

64. Otis G, Fe S. Medical Specialty Selection: How well can students predict their choice ? 2018;(August). doi:10.13140/RG.2.2.22989.28646.

65. Passi V, Johnson N. The impact of positive doctor role modeling. Med Teach. April 2016:1-7. doi:10.3109/0142159X.2016.1170780.

66. Bauer JM, Holt GE. National Orthopedic Residency Attrition : Who Is At Risk? J Surg Educ. 2016;73(5):852-857. doi:10.1016/j.jsurg.2016.03.010.

67. Bustraan J, Dijkhuizen K, Velthuis S, et al. Why do trainees leave hospital-based specialty training? A nationwide survey study investigating factors involved in attrition and subsequent career choices in the Netherlands. BMJ Open. 2019;9:1-8. doi:10.1136/bmjopen-2018-028631.

68. Khoushhal Z, Hussain M, Greco E, et al. Prevalence and Causes of Attrition Among Surgical Residents A Systematic Review and Meta-analysis. JAMA Surg. 2017;152(3):265-272. doi:10.1001/jamasurg.2016.4086.

69. Lu DW, Hartman ND, Druck J, Carolina N. Why Residents Quit : National Rates of and Reasons for Attrition Among Emergency Medicine Physicians in Training. West J Emerg Med. 2019;20(March):351-356. doi:10.5811/westjem.2018.11.40449.

70. Ottenhausen M, Anetsberger S, Kleffmann J, et al. Risk factors for dropping Out of NeurosurgIcal resideNcy programs - The RONIN Survey. World Neurosurg. 2018. doi:10.1016/j.wneu.2018.07.195.

71. Vermeulen MI, Kuyvenhoven MM, Zuithoff P, Graaf Y, Pieters R. Attrition and poor performance in general practice training: age, competence and knowledge play a role. Ned Tijdschr Geneeskd. 2011;155(A2780):1-7.

72. Yang MK, Meyerson JM, Pearson GD. Resident Attrition in Plastic Surgery A National Survey of Plastic Surgery Program Directors. Ann Plast Surg. 2018;81(3):360-363. doi:10.1097/SAP.0000000000001526.

73. Abelson J, Sosa J, Symer M, et al. Association of Expectations of Training With Attrition in General Surgery Residents. JAMA Surg. 2018;153(8):712-717. doi:10.1001/jamasurg.2018.0611.

74. Siotos C, Payne RM, Mirdad A, et al. Failure-to-Progress Through Surgical Residency : A 9-Year Analysis. J Surg Educ. 2020;77(1):178-188. doi:10.1016/j.jsurg.2019.07.017.

75. Yeo H, Bucholz E, Ann Sosa J, et al. A National Study of Attrition in General Surgery Training. Which Residents Leave and Where Do they Go? Trans. Meet Am Surg Assoc. 2010;252(3):529-536. doi:10.1097/SLA.0b013e3181f2789c. 
- Chapter 1

76. Querido SJ, Vergouw D, Wigersma L, Batenburg RS, De Rond MEJ, Ten Cate OTJ. Dynamics of career choice among students in undergraduate medical courses. A BEME systematic review: BEME Guide No. 33. Med Teach. 2015;38(1):18-29. doi:10.3109/0142159X.2015.1074990.

77. Soethout M. Career preference of medical students and career choice of recent graduates general and in public health in particular [doctoral dissertation]. 2007.

78. Lent R, Brown S, Hackett G. Social cognitive career theory. In: Brown D, ed. Career Choice and Development. fourth. San Francisco: Jossey-Bass; 2002:255-311.

79. Bland C, Meurer L, Maldona G. Determinants of primary care specialty choice; A nonstatistical meta-analysis of the literature. 1995:70(7):620-641.

80. Cook DA, Bordage G, Schmidt HG. Description, justification and clarification: A framework for classifying the purposes of research in medical education. Med Educ. 2008;42(2):128-133.

81. Lawson SR, Hoban JD, Mazmanian PE. Understanding primary care residency choices: a test of selected variables in the Bland-Meurer model. Acad Med. 2004;79(10 Suppl):S36-9. doi:10.1097/00001888-200410001-00011.

82. Wolf FM. Methodological quality, evidence, and Research in Medical Education (RIME). Acad Med. 2004;79(10 Suppl):S68-S69.

83. Creswell JW. Research Design: Qualitative, Quantitative, and Mixed Methods Approaches. Fourth. Michigan: Sage Publications Inc.; 2014.

84. Creswell JW. Educational Research. Planning, Conducting and Evaluating Quantitative and Qualitative Research. fourth. (Smith P, ed.). Boston: Pearson; 2016.

85. O’Brien BC, Harris IB, Beckman TJ, Reed DA, Cook DA. Standards for reporting qualitative research: A synthesis of recommendations. Acad Med. 2014;89(9):12451251.

86. Watling CJ, Lingard L. Grounded theory in medical education research: AMEE Guide No. 70. Med Teach. 2012;34(10):850-861.

87. Artino A, Rochelle JS La, Dezee KJ, et al. Developing questionnaires for educational research : AMEE Guide No. 87. Med Teach. 2014;36(6):463-474. doi:10.3109/0142159X.2014.889814. 




\section{Chapter 2}

\section{Dynamics of career choice among students in undergraduate}

medical courses. A BEME systematic review: BEME Guide No. 33

\section{Published as:}

Dynamics of career choice among students in undergraduate medical courses. A BEME systematic review: BEME Guide No. 33. Medical Teacher 2015;38(1):18-29. doi: $10.3109 / 0142159 X .2015 .1074990$ 
- Chapter 2

\begin{abstract}
Introduction

Due to the lack of a theoretically embedded overview of the recent literature on medical career decision-making, this study provides an outline of these dynamics. Since differences in educational routes to the medical degree likely affect career choice dynamics, this study focuses on medical career decision-making in educational systems with a Western European curriculum structure.
\end{abstract}

\title{
Methods
}

A systematic search of electronic databases (Medline, Embase) was conducted from January 2008 to November 2014. A panel of seven independent reviewers performed the data extraction, quality assessment and data synthesis using the Bland model of medical specialty choice as a reference.

\section{Results}

Fifty-seven studies met the inclusion criteria for the review. Factors associated with specialty preference or career choice can be classified in five main categories: (1) medical school characteristics (e.g., curriculum structure), (2) student characteristics (e.g., age, personality), (3) student values (e.g., personal preference), (4) career needs to be satisfied (e.g., expected income, status, work-life balance), and (5) perception of specialty characteristics (e.g., extracurricular or curricular experiences). Especially career needs and perceptions of specialty characteristics are often associated with medical career decision-making.

\section{Conclusion}

Our results support that medical career decisions are formed by a matching of perceptions of specialty characteristics with personal needs. However, the process of medical career decision-making is not yet fully understood. Besides identifying possible predictors, future research should focus on detecting interrelations between hypothesized predictors and identify the determinants and interrelations at the various stages of the medical career decision-making process. 


\section{Introduction}

For graduating doctors planning to specialize, choosing a residency is a major career decision and a defining phase in their professional life. Many enter medical school with a career plan or preference ${ }^{1}$, but few actually start a residency of that early preference. ${ }^{2}$ One reason is that enrolling medical students appear to have misconceptions about the medical profession. ${ }^{3-5}$ As students progress through medical school, career plans and preferences tend to shift. These shifts are determined by the medical curriculum that usually does not expose students to the wide variety of specialties. Initial student preference for specialty training usually does not align with the health care workforce demands and with available residency vacancies. ${ }^{6-11}$ As a result, specialties may either experience a shortage of residency applicants' primary choices, while the competition for other more popular specialties can be fierce. Students who cannot obtain the residency position of their first choice might switch to a less desirable training post; other may postpone their residency commencement and wait for the opportunity of their first choice. Furthermore, not well-informed students may start a residency that leads to distress, possible reallocation or dropout. ${ }^{12,13}$ The understanding of the medical career decision-making process is important to aid career counseling and thus prevent wrong choices, support medical graduates in their choice and promote faster choices.

Career choice research has predominantly been performed in North America (United States and Canada), Australia and the United Kingdom. Wijnen-Meijer et al. showed how different the educational routes to the medical degree are, as systems in various countries differ regarding medical school entry, curriculum length and structure, residency selection and postgraduate training structure. ${ }^{14}$ These differences likely affect career choice dynamics and consequently impedes the comparison of results from studies performed in different educational systems. Therefore, we are particularly interested to explore the dynamics of medical career decision-making in educational systems with a curricular structure that is most common in Western European countries; students enter medical school directly after secondary school without a prior tertiary or college entry-level medical education program. Thus, a long integrated, one-tier undergraduate medical course. Furthermore, postgraduate specialty training follows directly after medical school or after a period of non-mandatory practice. This educational structure corresponds with the routes 1 and 2 (i.e., a medical school programme with students directly admitted from high school or primary school that is directly followed by postgraduate specialty training) from the classification by Wijnen-Meijer et al., as opposed to North-American structures. ${ }^{14}$ 
Medical career preferences and determinants of medical career choice have been addressed abundantly in the literature, indicating that medical career decision-making is a dynamic, complex and multifactorial process. ${ }^{15,16}$ The Bland model of medical specialty choice captures the most comprehensive outline of medical student career decision-making to date. ${ }^{17}$ This framework, which originates from a non-statistical meta analysis, suggests that medical specialty choice emerges from the matching of perceptions of specialty characteristics with personal and social needs. Perceptions and needs which, in turn, are expected to be mediated by faculty and student characteristics as well as student values. Although the model was introduced two decades ago, suggested mediating influences and interrelations between hypothesized predictors are seldom explored. Most research only investigates the direct association of career choice with one or a few variables which hampers the interpretation of individual study results in relation to all hypothesized predictive variables.

Data of individual studies on career choice have often been synthesized. ${ }^{16,18-23}$ Most overviews limit their focus on (1) a single medical specialty ${ }^{21,22},(2)$ a single theme or a limited number of potential predictors ${ }^{18-20}$, or (3) do not theoretically underpin the result. ${ }^{23}$ The only overview that we have identified not suffering from these three limitations is almost fifteen years old. ${ }^{16}$

Because of the lack of a theoretically embedded overview of the recent literature presenting the dynamics of medical career choice, our study aims to provide such an outline by using the Bland model as a reference. This literature synthesis was conducted to address the following research questions:

1. What factors have been studied that may be associated to medical career decisionmaking in undergraduate medical students?

2. How can the associated factors be embedded in a theoretical framework to explain career choice dynamics?

\section{Methods}

A systematic literature review (SLR) was undertaken to explore the factors influencing preferences and choices for a medical career by synthesizing data from qualitative and quantitative methodologies. 


\section{Search}

A search of Embase and Medline, 1 January 2008 to 1 November 2014, was undertaken to identify studies focusing on career preferences and choices of medical students. We developed a search strategy which is shown in Table 1. Search terms had to be present in title or abstract. In addition, the reference lists of all included studies were hand searched for supplementary relevant studies.

Table 1 Search terms and strategy for health-related databases

\begin{tabular}{|l|l|}
\hline $\begin{array}{l}\text { medical students } \\
\text { students health occupations } \\
\text { or students public health } \\
\text { or medical students } \\
\text { or premedical students } \\
\text { or first year students } \\
\text { or final year students } \\
\text { or medical school student } \\
\text { or junior doctor }\end{array}$ & $\begin{array}{l}\text { and career preference/ choice } \\
\text { career choice } \\
\text { or career choices } \\
\text { or career preference } \\
\text { or career preferences }\end{array}$ \\
\hline $\begin{array}{l}\text { Sources: Medline, Embase } \\
\text { Limits: January 2008 - November } 2014\end{array}$ \\
\hline
\end{tabular}

\section{Inclusion and exclusion}

Inclusion and exclusion criteria are presented in Table 2. The inclusion criteria were: (1) a study had to report results regarding factors associated with undergraduate medical students' career preferences or undergraduate medical students' professional choices, (2) a study had to have an observational design, i.e., retrospective or prospective cohort studies, or crosssectional studies, (3) students had to be enrolled in a one-tier undergraduate medical course The first step of the selection was the initial screening of titles and abstracts for appropriateness by two researchers independently (SQ and DV). Results were compared and in case of disagreement reassessed and discussed to reach consensus. Selected papers were then obtained in full-text, independently read by two researchers, and assessed for relevance (SQ and DV). In case of disagreement, these results were also reassessed and discussed to reach consensus. When a mutually shared decision could not be reached, a third researcher (LW) reassessed the paper and results were again discussed to reach consensus. 
- Chapter 2

Table 2 Inclusion and exclusion criteria applied to potentially relevant studies to determine the suitability for data synthesis

\begin{tabular}{|l|l|l|}
\hline Population & Inclusion criteria & Exclusion criteria \\
\hline Outcome & $\begin{array}{l}\text { One-tier undergraduate course } \\
\text { according to routes 1 and 2* }\end{array}$ & $\begin{array}{l}\text { Study of factors associated } \\
\text { other than medical } \\
\text { Wedical courses with other } \\
\text { preferences or choices } \\
\text { routes* }\end{array}$ \\
\hline Study type & $\begin{array}{l}\text { Studies that did not investigate } \\
\text { associations with career } \\
\text { preferences or choices (e.g., } \\
\text { evaluation of educational } \\
\text { programs, reasons for burn-out } \\
\text { of medical students) }\end{array}$ \\
\hline Scientific articles & $\begin{array}{l}\text { Articles in the Dutch, English, } \\
\text { or German language }\end{array}$ & $\begin{array}{l}\text { Editorials, comments, or opinion } \\
\text { pieces } \\
\text { Articles in other languages }\end{array}$ \\
\hline
\end{tabular}

\section{Data extraction and quality assessment}

A data extraction was performed by dividing the selected papers among a panel of seven assessors (SQ, DV, OtC, LW, MdR, PH and RB). Each paper was assessed by two researchers, independently synthesizing data regarding study design, study characteristics, methodological quality, and findings, using a data extraction form. Disagreements were first analyzed again and discussed by the two researches. If necessary, a third researcher was consulted and the article was assessed and discussed again by three researchers to reach consensus.

Levels of methodological quality were defined according to Soethout et al. ${ }^{24}$; and previously used by Ariens et al. ${ }^{25}$ The content is a seven category list of criteria: (a) study purpose, (b) study design, (c) response rate, $d$. nature of the survey, e. number of investigated factors (associated factors and career factors), (f) career or professional, and (g) statistical analysis. Four items (a, b, f, and g) could be awarded 0 or 2 points and three items (c, d, and e) could be awarded 0 to 3 points, depending on the match between content and the criteria. Individual quality items were summed to calculate a total quality score with a minimum rate of 0 and a maximum of 17 points. The methodical quality was taken into account when analyzing the results. The results from studies with a low methodical quality are properly expected more uncertain and should be interpreted carefully. 


\section{Results}

\section{Selection of papers}

A flow chart of the selection of appropriate papers is provided in Figure 1.

The search strategy identified 1483 unique results in Medline and 76 in Embase, resulting in a total of 1559 papers. After screening titles and abstracts for relevance, 1274 articles were excluded. The main reasons for exclusion were an irrelevant study sample (e.g. midwifes or nurses) or non-empirical research paper (e.g. opinion or editorial). A consensus meeting was not needed. A total of 284 papers was obtained in full-text. After full-text evaluation 225 papers were excluded because they did not fit the inclusion criteria, being (1) factors did not relate to preference or choice for a medical career, (2) the sample group concerned residents who were not retrospectively inquired about experiences during undergraduate training or, (3) the study was not performed in route 1 or 2 of the undergraduate course. ${ }^{14}$ The additional check of the reference lists of all identified papers yielded three supplementary papers that were not identified by searching the electronic databases. Therefore, final selection included 57 papers suitable for data synthesis.

Figure 1 Flow diagram of literature search and paper selection

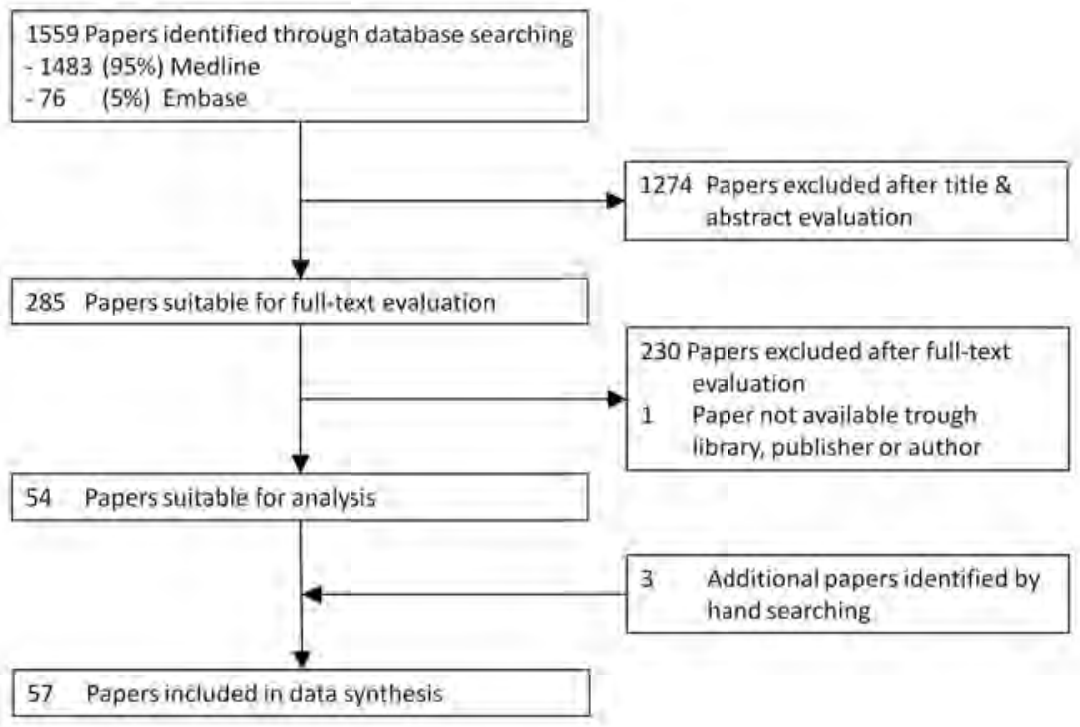


- Chapter 2

\section{Origin and nature of the studies}

An overview of the characteristics of the identified studies including their methodological quality score is provided in Table 3.

All of the 57 included and analyzed papers dealt with a sample group of medical students. Most of the studies were cross-sectional surveys $(\mathrm{N}=47)$. Ten longitudinal studies; four of which used a pre-post design ${ }^{26-29}$, five used a prospective cohort ${ }^{30-34}$, and one used a retrospective cohor ${ }^{35}$ and there were three qualitative studies. ${ }^{36-38}$

Most of the identified studies regard the United Kingdom ( $\mathrm{N}=20,35 \%)$. Other studies were performed in Germany $(\mathrm{N}=11,19 \%)$, Australia $(\mathrm{N}=7,12 \%)$, the Netherlands $(\mathrm{N}=5,9 \%)$, France $(\mathrm{N}=4,7 \%)$, India $(\mathrm{N}=3,5 \%)$, Saudi-Arabia $(\mathrm{N}=2,4 \%)$ and Sweden, Denmark, Italy, Japan, or Spain ( $\mathrm{N}=1,2 \%)$. Almost all studies clearly described the purpose of the study $(\mathrm{N}=55,96 \%)$ and the study design $(\mathrm{N}=48,84 \%)$. Two thirds $(\mathrm{N}=36,63 \%)$ presented data collected at one university in a local survey with varying samples sizes (13 to 5400 subjects). A total of $47(82 \%)$ studies investigated a limited number of ( $\geq$ three) factors associated with the choice of medical specialty, six studies investigated two, and four studies investigated only factor for an association with medical specialty choice.

Six studies (10\%), (two UK, two French, one German and one Japanese) each with a total score of 16 or 17 , can be regarded as high quality. ${ }^{24}$ Quality scores of 13 through 15 were found in 31 (54\%) studies, nineteen studies (33\%) showed a score in the range $8-12$, and two studies $(3 \%)$ had quality scores of $5-7$, predominantly showing lack of information. 
Table 3 Study characteristics and methodological quality of included studies

\begin{tabular}{|c|c|c|c|c|}
\hline No & References & Design & Resp. (\%) & $\begin{array}{l}\text { Meth. } \\
\text { quality }\end{array}$ \\
\hline 1 & Cleland et al. (2012) & CS & 88 & 17 \\
\hline 2 & Takeda et al. (2013) & $\mathrm{CS}$ & $80 / 70$ & 17 \\
\hline 3 & Cleland et al. (2014) & $\mathrm{CS}$ & $80 / 81$ & 16 \\
\hline 4 & Lefèvre et al. (2010a) & $\mathrm{CS}$ & 67 & 16 \\
\hline 5 & Lefèvre et al. (2010b) & $\mathrm{CS}$ & 67 & 16 \\
\hline 6 & Lempp et al. (2012) & $\mathrm{CS}$ & 94 & 16 \\
\hline 7 & Bindal et al. (2011) & $\mathrm{CS}$ & 97 & 15 \\
\hline 8 & Coulston et al. (2012) & $\mathrm{CS}$ & 100 & 15 \\
\hline 9 & Diderichsen et al. (2013) & $\mathrm{CS}$ & 87 & 15 \\
\hline 10 & Lampe et al. (2010) & $\mathrm{CS}$ & 93 & 15 \\
\hline 11 & Kuhnigk et al. (2019) & $\mathrm{CS}$ & 87 & 15 \\
\hline 12 & Malhi et al. (2011) & $\mathrm{CS}$ & 99 & 15 \\
\hline 13 & Tambyraja et al. (2008) & $\mathrm{CS}$ & 87 & 15 \\
\hline 14 & Tay et al. (2009) & $\mathrm{CS}$ & 83 & 15 \\
\hline 15 & van Tongeren-Alers et al. (2011) & $\mathrm{CS}$ & 94 & 15 \\
\hline 16 & Coffeng et al. (2009) & LRC & 99 & 14 \\
\hline 17 & Davis et al. (2010) & LPP & 77 & 14 \\
\hline 18 & Deutsch et al. (2014) & LPC & 64 & 14 \\
\hline 19 & Gibis et al. (2012) & $\mathrm{CS}$ & 16 & 14 \\
\hline 20 & Heiligers (2012) & $\mathrm{CS}$ & 36 & 14 \\
\hline 21 & Heinz \&Jacob (2012) & CS & 16 & 14 \\
\hline 22 & Hughes et al. (2008) & $\mathrm{CS}$ & $99 / 88$ & 14 \\
\hline 23 & Kumar \& Dhaliwal (2011) & $\mathrm{CS}$ & 79 & 14 \\
\hline 24 & Maiorova et al. (2008) & LPC & 89 & 14 \\
\hline 25 & Mehmood et al. (2013) & $\mathrm{CS}$ & 92 & 14 \\
\hline 26 & Ravindra \& Fitzgerald (2011) & $\mathrm{CS}$ & 65 & 14 \\
\hline 27 & Svirko et al. (2013) & $\mathrm{CS}$ & 52 & 14 \\
\hline 28 & Soethout et al. (2008a) & $\mathrm{CS}$ & 77 & 14 \\
\hline 29 & Thapper \& Roussou (2013) & $\mathrm{CS}$ & - & 14 \\
\hline 30 & Budd et al. (2011) & $\mathrm{CS}$ & - & 13 \\
\hline 31 & Deutsch et al. (2013) & LPP & 95 & 13 \\
\hline 32 & Rabadan \& Hildago (2010) & LPP & $54 / 97$ & 13 \\
\hline 33 & Gedrose et al. (2012) & $\mathrm{CS}$ & 48 & 13 \\
\hline 34 & Hermann et al. (2012) & $\mathrm{CS}$ & 11 & 13 \\
\hline 35 & Kiolbassa et al. (2011) & $\mathrm{CS}$ & 11 & 13 \\
\hline 36 & Maudsley et al. (2010) & LPC & - & 13 \\
\hline 37 & Robertson et al. (2009) & LPP & 11 & 13 \\
\hline 38 & Steinhäuser et al. (2013) & $\mathrm{CS}$ & 11 & 13 \\
\hline 39 & Abdulghani et al. (2013) & $\mathrm{CS}$ & 67 & 12 \\
\hline 40 & Al-Nuaimi et al. (2008) & $\mathrm{CS}$ & 20 & 12 \\
\hline 41 & Andlauer et al. (2012) & $\mathrm{CS}$ & 37 & 12 \\
\hline 42 & Ibrahim et al. (2014) & $\mathrm{CS}$ & 12 & 12 \\
\hline 43 & Subba et al. (2012) & $\mathrm{CS}$ & 75 & 12 \\
\hline 44 & Tavakol et al. (2011) & $\mathrm{CS}$ & 68 & 12 \\
\hline 45 & Pedersen et al. (2011) & $\mathrm{CS}$ & 57 & 11 \\
\hline 46 & Wigney \& Parker (2008) & Q & 100 & 11 \\
\hline 47 & Baller et. Al (2013) & $\mathrm{CS}$ & 17 & 10 \\
\hline
\end{tabular}




\begin{tabular}{|l|l|lll|}
\hline No & References & Design & Resp. (\%) & $\begin{array}{l}\text { Meth. } \\
\text { Quality }\end{array}$ \\
\hline 47 & Baller et al. (2013) & CS & 17 & 10 \\
48 & Clark et al. (2013) & LPC & 55 & 10 \\
49 & Drinkwater et al. 2008) & Q & 3 & 10 \\
50 & Ferrai et al. (2013) & CS & 47 & 10 \\
51 & Halder et al. (2013) & CS & - & 10 \\
52 & Robbins et al. (2011) & CS & 4 & 10 \\
53 & Firth \& Wass (2011) & LPC & $48 / 72$ & 9 \\
54 & Thislewaite et al. (2008) & Q & 100 & 9 \\
55 & Mulla et al. (2012) & CS & 29 & 8 \\
56 & Andlauer et al. (2013) & CS & - & 7 \\
57 & Praharai et al. (2013) & CS & - & 5 \\
\hline
\end{tabular}

\section{Factors associated with career preference and career choice}

To provide an insightful overview of the factors significantly associated with specialty preference or career choice, Figure 2 presents an overview of these factors classified in five categories according to the Bland model. ${ }^{17}$ The original model consists of variables that determine medical students' specialty choice. We arranged the variables we found following the Bland model: (1) medical school characteristics, (2) student characteristics, (3) student values (incoming-graduate), (4) needs to satisfy, and (5) perception of specialty characteristics. In the Bland model specialty choice is suggested to be essentially established by matching perceptions of specialty characteristics to personal and social needs. Needs that originate from the values that a student holds, which in turn are affected by many student characteristics, faculty characteristics, and personal developments during education. For the inclusion of factors in Figure 2, such interrelations did not necessarily have to be examined. Factors that are assumed to be directly associated with the process of career decision-making are presented by Figure 2 as well. 
Figure 2 The factors identified by the data synthesis as associated with medical specialty preference or medical career choice ordered according to the Bland model of medical career choice ${ }^{17}$ Reference numbers relate to the identification of studies from Table 3, in which studies are ordered according to their methodological quality (high quality: references 1-6, moderate quality: references 7-38, and low methodological quality: references 39-57).

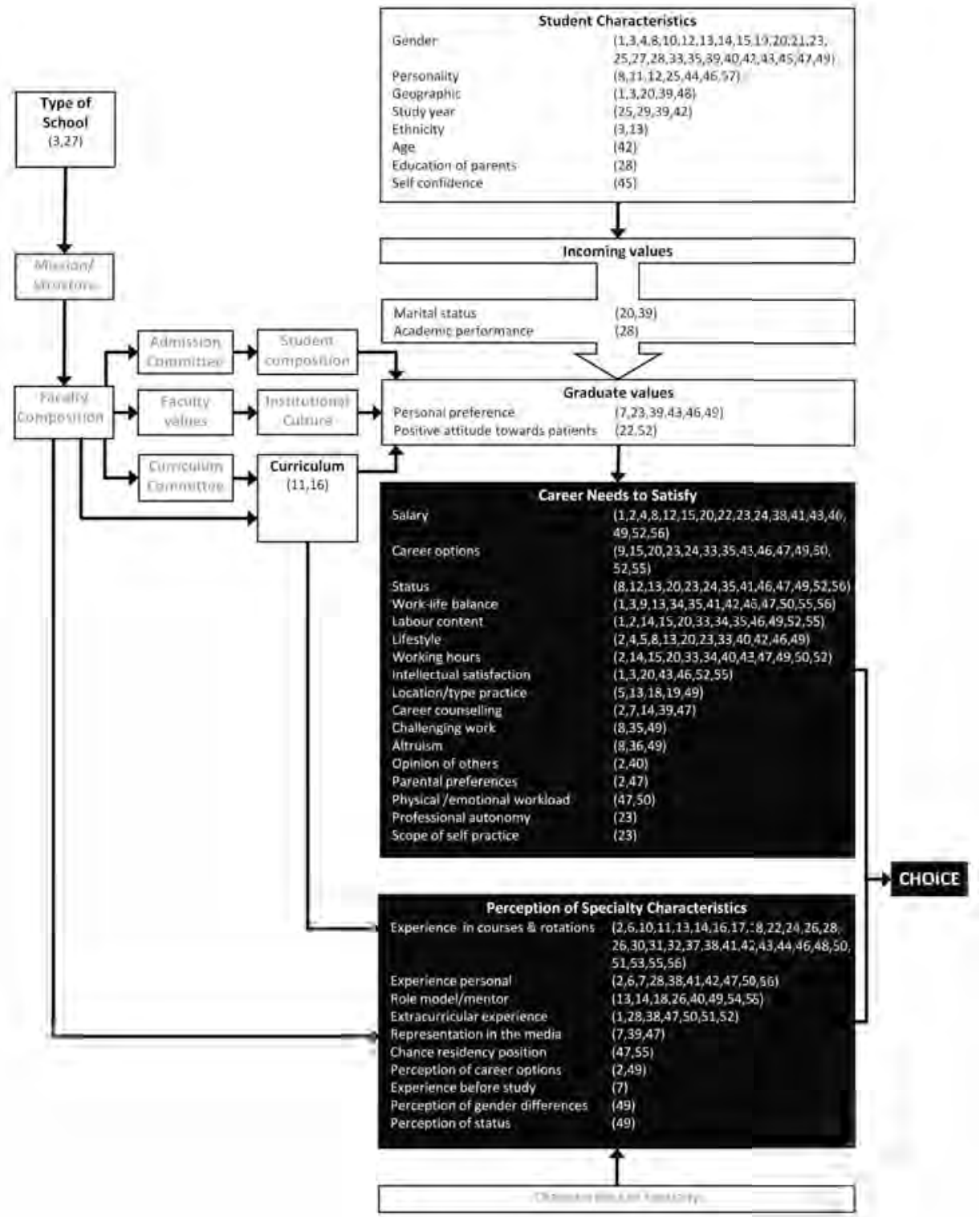




\section{Medical school characteristics}

Medical school characteristics are suggested to affect career choice by influencing the students' personal values and their perceptions of specialty characteristics. When applying to medical school, students may take their impressions of a school such as its ownership (private or public), mission, and orientation/structure into account. Furthermore, the selection of students may differ between medical schools because of policies that favor student characteristics or because of indirect influences of the selection committee. During medical school, students' perceptions and preferences may be influenced by the faculty values and institutional culture. The curriculum format and content, as determined by the curriculum committee, might as well influence students' career preferences and choices.

Two unique studies revealed that career choices differed between students from different medical schools. ${ }^{1,11}$ While Svirko et al. showed a regional difference, Cleland et al. showed that differences relate to both student variables and variation in medical school education and culture. ${ }^{1,11}$

Two other studies provided insight on the influence of habitus (variation in medical school education and culture) by showing that the sequencing of clinical rotations ${ }^{27}$ or curricular design (traditional versus problem based) affect (the development of) career preferences. ${ }^{39}$

\section{Student characteristics}

Several studies suggest that student characteristics affect career choice through the values that people hold, which influences their needs in fulfilling a career. Half $(\mathrm{N}=28,49 \%)$ of the included studies find an association between specialty choice and student characteristics. Inherent student characteristics (i.e., gender, personality, and age) as well as environmental student characteristics (i.e., geographic, study year, ethnicity and education of parents) have been associated with career choice. However, the factors age and background were only associated with career choice in two studies which we identified to be of a low methodological quality (12 points)..$^{30,40}$

One third of all the studies report gender as a direct determinant or a factor associated with medical career choice. Females appear more attracted to work with chronic patients, palliative care and a controllable lifestyle. Male students were more inclined to technology-oriented work, acute patients and prestige. In contrast, three studies found no gender differences in career preferences. ${ }^{41-43}$ Swedish male and female final year medical students opted for similar specialties and did not differ in motivational factors. ${ }^{41}$ A Dutch study ${ }^{43}$ found a bivariate association between gender and the preference for general practice. However, after correction 
for other variables (i.e., background characteristics, patients and type of work preference, and self-assessed likelihood of becoming a general practitioner) this relationship did not hold. Comparable results were obtained by another Dutch study in which the gender association disappeared when correcting for living with a partner. ${ }^{42}$

\section{Student values}

Most medical students start medical school with initial values which may evolve because of maturation, life events, and financial debt during medical training. ${ }^{17}$

Three studies found associations between factors that may affect student values (i.e., marital status and academic performance) and medical career preference in incoming students and for final year students. A study by Abdulghani et al. showed that marital status is associated with career choice. ${ }^{44}$ Heiligers suggests that students who are married, or live with a partner, may have other priorities, because of family related issues and spouse expectations. ${ }^{42}$ Academic achievement is, according to Soethout et al., weakly associated with medical student career preferences. $^{4}$

Eight studies present direct associations between actual student values and career choice. A positive attitude towards the patient group of the specialty and a personal preference for a medical career are associated with the medical career choice of graduating students. However, five of the studies in which such an association was identified, were regarded as being of a low methodological quality ( $<13$ points).

\section{Satisfying (personal) career needs}

Medical students have (personal) career needs that they wish to fulfill in their future career and their professional lives. Half of the included studies show an association between career choice and career needs. These can be classified as personal needs, societal needs and expectations of others. Personal needs are most frequently associated with career choice. Associated personal needs are expected salary $(\mathrm{N}=17)$, career options $(\mathrm{N}=14)$, status $(\mathrm{N}=32)$, work-life balance $(\mathrm{N}=12)$, the labor content (e.g., type of patients or medical procedures) $(\mathrm{N}=12)$, lifestyle $(\mathrm{N}=12)$ e.g. habits, attitudes, economic level, etc., that together constitute the mode of living of an individual or group). Most studies however do not clearly define the factor lifestyle; it usually refers to concerns about raising a family, alongside professional demands. ${ }^{45}$ Other frequently associated personal needs with career choice are working hours $(\mathrm{N}=12)$, intellectual satisfaction $(\mathrm{N}=7)$ (e.g., the fulfillment of intellectual needs), location/type of work $(\mathrm{N}=5)$, and challenging work $(\mathrm{N}=3)$. The factors physical and emotional 
workload, professional autonomy and scope of self-practice are respectively found in two studies of low methodological quality ( $\leq 10$ points) and two studies with a moderate methodological quality ( $\leq 14$ points). Societal needs (i.e., the wish to serve society) and expectations of others have much less often been associated with career choice than personal needs. Three studies particularly report an association of the societal need of altruism to career choice. Altruism being meant as 'the wish to make a difference to people' or 'wanting to help people. ${ }^{29}$ Other factors associated with career decision-making that relate to the expectations of others are: the opinion of others, career counselling and parental preferences.

\section{Perception of specialty characteristics}

According to the Bland model specialty choice is essentially established by a matching of personal career needs with student perceptions of specialty characteristics. Actual student perceptions are rarely inquired by the selected studies. Only two studies associated an actual student perception (i.e., the perception of the likelihood to obtain a residency position) with career choice. According to Baller et al. significant differences were seen among female students who mentioned that the competition regarding a residency position was of influence. ${ }^{46}$ These studies however, were identified as being of a low methodological quality ( $\leq 10$ points).

More than half $(\mathrm{N}=35,61 \%)$ of all identified studies found a direct association between experiences during medical school that are expected to influence student's perception of a specialty and career choice. Curricular experiences such as (clinical) courses, rotations, electives, lectures, performing medical procedures, and contact with a patient group were most often associated with career choice. These experiences contribute to the level of interest and therefore of influence on their medical career choice.

However, extracurricular experiences (e.g. voluntary or paid work ${ }^{47}$ ) are also mentioned as an important experience, as well as experiences in a student's personal life. For example, a psychiatric family member or acquaintances, positively influences a career choice for psychiatry. ${ }^{46,48}$ Or illness yourself as a child ${ }^{49}$, and the influence of a role model or mentor may affect your preference, this could be in a positive or negative way. Evidence for the influence of these experiences is limited since they are associated with career choice in a single or two studies; specialty representation in the media or internet, perception of career options, experiences prior to medical school, perception of gender differences, and perception of status. Especially for the last three of these, the studies in which these associations were identified are of a low methodical quality ( $\leq 12$ points). 


\section{Discussion}

In this research, we provide a theoretically embedded overview of the recent literature on the dynamics of medical career decision-making in educational systems with a Western European curriculum structure. Based on the 57 studies selected from a SLR, our results, as summarized in Table 4, show that factors often associated with medical career decision-making in studies with methodological quality are: perceptions of specialty characteristics gained from curricular, extracurricular and personal experiences in health care, personal career needs (e.g., expected income, career options, status, work-life balance, labor content, lifestyle, working hours) and gender. Although recent literature prevalently focusses on student characteristics, we found indications that medical school characteristics such as curriculum design are also associated with career decision-making. Research into these influences is however still scarce.

Table 4 Summary of findings; the number of studies with a high, moderate or low methodological quality in which a factor is associated with medical career decision-making

\begin{tabular}{|c|c|c|c|c|}
\hline \multirow{2}{*}{\multicolumn{2}{|c|}{$\begin{array}{l}\text { Factors associated with medical career } \\
\text { preference / choice }\end{array}$}} & \multicolumn{3}{|c|}{ Methodological quality } \\
\hline & & High & Moderate & Low \\
\hline $\begin{array}{l}\text { Medical school } \\
\text { characteristics }\end{array}$ & $\begin{array}{l}\text { type of school } \\
\text { curriculum }\end{array}$ & $\begin{array}{l}1 \\
-\end{array}$ & $\begin{array}{l}1 \\
2 \\
\end{array}$ & $\begin{array}{l}- \\
-\end{array}$ \\
\hline $\begin{array}{l}\text { Student } \\
\text { characteristics }\end{array}$ & $\begin{array}{l}\text { gender } \\
\text { personality } \\
\text { geographic } \\
\text { study year } \\
\text { ethnicity } \\
\text { age } \\
\text { education of parents } \\
\text { self confidence }\end{array}$ & $\begin{array}{l}3 \\
- \\
2 \\
- \\
1 \\
- \\
- \\
-\end{array}$ & $\begin{array}{l}15 \\
4 \\
1 \\
2 \\
1 \\
- \\
1 \\
-\end{array}$ & $\begin{array}{l}7 \\
3 \\
2 \\
2 \\
- \\
1 \\
- \\
1\end{array}$ \\
\hline Student values & $\begin{array}{l}\text { personal preference } \\
\text { positive attitude towards } \\
\text { patients } \\
\text { marital status } \\
\text { academic performance }\end{array}$ & $\begin{array}{l}- \\
- \\
- \\
-\end{array}$ & $\begin{array}{l}2 \\
1 \\
1 \\
1 \\
1\end{array}$ & $\begin{array}{l}4 \\
1 \\
1 \\
-\end{array}$ \\
\hline Personal needs & $\begin{array}{l}\text { salary } \\
\text { career options } \\
\text { status } \\
\text { work-life balance } \\
\text { labor content } \\
\text { lifestyle }\end{array}$ & $\begin{array}{l}3 \\
- \\
- \\
3 \\
2 \\
3\end{array}$ & $\begin{array}{l}8 \\
7 \\
7 \\
3 \\
6 \\
5\end{array}$ & $\begin{array}{l}6 \\
7 \\
6 \\
7 \\
4 \\
4\end{array}$ \\
\hline
\end{tabular}




\begin{tabular}{|l|l|lll|}
\hline & working hours & 1 & 5 & 6 \\
& intellectual satisfaction & 2 & 1 & 4 \\
& location/type practice & 1 & 3 & 1 \\
career counseling & 1 & 2 & 2 \\
challenging work & - & 2 & 1 \\
& altruism & - & 2 & 1 \\
opinion of others & 1 & - & 1 \\
parental preferences & 1 & - & 1 \\
physical/emotional workload & - & - & 2 \\
\hline professional autonomy & - & 1 & - \\
\hline Perception of & scope of self practice & - & 1 & - \\
characteristics & experience in courses \& & 2 & 17 & 11 \\
& rotations & & 3 & 5 \\
experience personal & 2 & 4 & 4 \\
role model/mentor & - & 2 & 4 \\
extracurricular experience & 1 & 1 & 2 \\
& representation in the media & - & - & 2 \\
chance residency position & - & - & 1 \\
& perception of career options & 1 & 1 & - \\
experience before study & - & - & 1 \\
perception of gender & - & - & 1 \\
\hline
\end{tabular}

Based on our data synthesis we support that students rationally match perceptions of different specialties' characteristics against a checklist of personal needs to form their specialty preference or medical career choice. ${ }^{17}$ The interrelations between hypothesized predictors and the needs and perceptions trade-off are however barely described as the literature mainly investigates direct associations between predictors and medical career decision-making. Within the literature, only the interrelation between gender and medical career choice has received much attention. Male and female career decision-making is known to differ. 1,9,33,40,42,50-57 Male students appear more externally motivated by salary, status and the opportunity to implement technical activities and probably therefore more often opt for technical and instrumental oriented specialties (e.g., surgery). ${ }^{42}$ Female students, on the other hand, are more intrinsically motivated by patient related activities, humanistic and altruistic reasons and opt for relationship-oriented specialties (e.g., family medicine and pediatrics). ${ }^{1,42,52,54,57}$ Furthermore, compared to men, women expect their careers to be negatively influenced by their future family lives. ${ }^{52}$ Because of the higher compatibility with family life, women tend to prefer primary care careers over a medical specialty. ${ }^{42,50,58}$ 
However some studies suggest that this is no longer only a female issue because family arguments seem to become more important among men as well. ${ }^{41,42,55}$

Whether such interrelations also exist for factors as personality, ethnicity or incoming career preference is unclear. Studies reporting survey data have so far not identified many conflicts between student values and career decision-making. This may indicate that, after decades of research, we still do not fully understand the process of career decision-making. In this light, qualitative research may provide more insight into the differences between groups of students and the possible causes and interrelations among hypothesized predictors.

Most studies involve surveys. To obtain more elaborate insight in choice mechanisms, qualitative studies, such as interviews, are needed. Interviews can prompt subjects to explain motives more deeply and help to understand relationships between various factors. Even more insightful may be longitudinal interview studies to monitor students' changes in career argumentation.

To structure the data synthesis, we used the outline of the Bland model of medical specialty choice as a reference. However, in the identified studies career preference and career choice are ambiguously used as dependent variables, as these terms appoint to different stages in the career decision-making process. ${ }^{59-61}$ During medical school career decision-making is assumed to evolve. Students first are likely to have one or more non-committal career preferences which are expected to be purely influenced by the perception of the content of work. As students' progress through medical school and gain experience, they are likely to become more pragmatic. Possible barriers to residency selection (e.g., work-life balance, job opportunities) are assumed to play an important role in coming to a more binding career choice. ${ }^{59,61}$ Since many of the studies included in our review inquired the interest of medical students, it was often unclear whether preferences or choices were reported. This makes it difficult to distinguish predictors for medical career preference and medical career choice. We hypothesize that while students' progress through their studies, career preferences, guided by intrinsic factors of genuine content interest become gradually supplemented or replaced by extrinsic factors that limit their scope of choice options. An indication for this hypothesis is found when a subgroup analysis compared four studies performed among first-year students ${ }^{1,52,62,63}$, with 13 studies performed among final-year medical students. ${ }^{9}, 11,32,41,43,49,54,56,64-68$

Factors solely associated with specialty preferences in first-year medical students appear more personal oriented (e.g., geography, self-confidence, positive attitude toward patient population) compared to factors solely associated in final-year students which appear to be 
more specialty oriented (e.g., lifestyle, status, workload, specialty representation by media, personal experiences in specific specialty). To provide more insight into career decisionmaking and the interrelation among predictors in the different stages of this process, longitudinal studies that follow career preferences during undergraduate medical training are necessary. Most of the performed research is based on cross-sectional design inventorying career decision-making on a single time point or retrospective with the risk of distortion of memory about earlier preferences.

\section{Strengths and limitations}

Other than just enumerating predictive factors, our study provides a theoretically embedded overview of the recent literature on the dynamics of career choice using the Bland model. By doing so, we provided information on which hypothesized predictors are identified in recent research and how these factors are possibly related to each other and explain career choice dynamics. This shows what is currently known and what the gaps in the current knowledge of medical career decision-making are. Thus, providing direction for future research.

Since the differences in educational routes around the world likely affect career choice dynamics, we chose to only synthesize data from studies in educational settings comparable to the one-tier undergraduate medical course as commonly adopted in Western European countries. This provides a more comprehensible interpretation for researchers and career counselors from countries adopting such an undergraduate educational system. However, even countries which we included may differ in terms of social and cultural background. These differences should still be accounted for when interpreting the results to a specific setting. The recently introduced two-cycle bachelor and master model in some European countries do not seem to have affected student career considerations. ${ }^{69,70}$

Although we included the most prevalently used educational system worldwide ${ }^{14}$, our choice led to the exclusion of studies performed in North America. Due to this choice, we might have missed some hypothesized predictors as a substantial part of the medical career decisionmaking research originates from the United States and Canada. A comparison between our results and those of a review that did not restrict the inclusion of North American studies ${ }^{21}$ indeed showed some discrepancies. Faculty composition, medical school admission, students' socio-economic and academic background, and indebtedness are factors that, as opposed to our data synthesis, were associated with medical career decision-making in North American studies. Whether these factors are general predictors is unclear. It might very well be that the 
known social, cultural and educational differences between North America and other countries explain why these factors were not denoted as predictors in our data synthesis. What might have led to omission of some hypothesized predictors is that our data synthesis only included recent studies (2008-2014). Generally acknowledged predictors could have been ignored by recent studies in search of new associations. However, when we compare our findings with those from earlier published reviews ${ }^{16,17,22}$, we found two additional predictors (i.e., the probability of obtaining a residency position, and the perception of emotional workload). In these additional predictors, the current shortage on the labor market might be reflected.

The exclusion of articles published in languages other than Dutch, English, or German led to the omission of $66(4,2 \%)$ of the 1559 initially through database searching identified papers. Since original articles written in languages such as French, Spanish, Hebrew, Hungarian, Swedish, Danish, and Portuguese were omitted from the initial selection of papers, potential predictors might have been absent in the presented overview. The same holds for employing the search strategy to only two literature databases (Medline and Embase). Although an additional reference screening was undertaken, recent grey literature may still have been missed.

For all studies included in the data synthesis, the levels of methodological quality was, regardless of study design, assessed by a criteria list provided by Soethout et al. ${ }^{24}$ These criteria however slightly favor quantitative studies over qualitative studies. Because of their non-statistical nature, qualitative studies can only obtain a maximum score of 15 where quantitative studies can obtain a maximum of 17 points. As a consequence, the current methodological quality of the study by Wigney $\&$ Parker $^{38}$ is regarded as low (11 points), while correcting for study design would make it a study with moderate methodological quality (13 points).

In our overview, we presented factors with a known association with medical career decisionmaking in general. We did not discriminate between factors associated to specialty-specific career preferences. Some factors in our overview are presented as generally applicable while in the individual studies they were specifically associated to a particular specialty choice or preference. The generalizability was our inference. 
- Chapter 2

\section{Conclusion and recommendations}

There is a significant amount of medical career decision-making literature that provides the following factors as predictors of medical career decision-making: perceptions of specialty characteristics gained from curricular, extracurricular and personal experiences in health care, personal career needs (e.g., expected income, career options, status, work-life balance, labor content, lifestyle, working hours) and gender. However, the data synthesis using the Blandmodel as a reference shows that the process of medical career decision-making is not yet fully understood. Besides identifying possible predictors, future research should also focus on detecting interrelations between hypothesized predictors and identify the determinants and interrelations at the various stages of the medical career decision-making process. Since medical career decision-making is a dynamic, complex and multifactorial process, qualitative research is expected to provide useful insights into this process. Next to recommendations for further research, the data synthesis appears to support practical recommendations. Medical school leadership and curriculum committees should be aware of the impact of school characteristics such as curriculum organization and design on career decision-making processes. Furthermore, career counseling should stimulate students to gain (clinical) experiences in different specialties, to discover their personal career needs, and the matching of career needs to specialty perceptions. 


\section{References}

1. Cleland J, Johnston PW, French FH, Needham G. Associations between medical school and career preferences in Year 1 medical students in Scotland. Med Educ. 2012;46(5):473-484. doi:10.1111/j.1365-2923.2012.04218.x.

2. Kaur B, Carberry A, Hogan N, Roberton D, Beilby J. The medical schools outcomes database project : Australian medical student characteristics. BMC Med Educ. 2014;14:180-190.

3. Nieuwhof MG, Rademakers JJ, Kuyvenhoven MM, Soethout MB, ten Cate TJ. Students' conceptions of the medical profession; an interview study. Med Teach. 2005;27(8):709-714. doi:10.1080/01421590500271159.

4. Soethout MBM, Ten Cate OTJ, Van Der Wal G. Correlations of knowledge and preference of medical students for a specialty career: A case-study of youth health care. BMC Public Health. 2008;8(4):1-7. doi:10.1186/1471-2458-8-14.

5. Underwood MJ, Thompson M, McCaskie A. Insight of first-year medical students into their future working conditions. Med Educ. 1990;24(3):210-211. doi:10.1111/j.13652923.1990.tb00002.x.

6. Avinashi $\mathrm{V}$, Shouldice E. Increasing interest in family medicine. CMAJ. 2006;174(6):761-762.

7. Fukuda Y, Harada T. Gender differences in specialty preference and mismatch with real needs in Japanese medical students. BMC Med Educ. 2010;10(15):1-7. doi:10.1186/1472-6920-10-15.

8. Goldacre MJ, Laxton L, Lambert TW. Medical graduates' early career choices of specialty and their eventual specialty destinations: UK prospective cohort studies. BMJ.2010;340(c3199):1-9.

9. Lefevre JH, Roupret M, Kerneis S, Karila L. Career choices of medical students: A national survey of 1780 students. Med Educ. 2010;44(6):603-612. doi:10.1111/j.13652923.2010.03707.x.

10. Pugno PA, Mcgaha AL, Schmittling GT, de Vilbiss Bieck AD, Crosley PW, Ostergaard DJ. Results of the 2010 National Resident Matching Program: Family medicine. Fam Med. 2010;42(8):552-561.

11. Svirko E, Goldacre MJ, Lambert T. Career choices of the United Kingdom medical graduates of 2005, 2008 and 2009: Questionnaire surveys. Med Teach. 2013;35(5):365375. doi:10.3109/0142159X.2012.746450.

12. Dodson T, Webb T. Why do residents leave general surgery? The hidden problem in today's programs. Curr Surg. 2005;62(1):128-131.

13. Vermeulen MI, Kuyvenhoven MM, Zuithoff P, Graaf Y, Pieters R. Attrition and poor performance in general practice training: age, competence and knowledge play a role. Ned Tijdschr Geneeskd. 2011;155(A2780):1-7.

14. Wijnen-Meijer M, Burdick W, Alofs L, Burgers C, ten Cate O. Stages and transitions in medical education around the world: clarifying structures and terminology. Med Teach. 2013;35(4):301-307. 
15. Burack J, Irby D, Carline J, Ambrozy D, Ellsbury K, Stritter F. A study of medical students' specialty-choice-pathways: trying on possible selves. Acad Med. 1997;72(6):534-541.

16. Reed V., Jernstedt CG, Reber E. Understanding and Improving Medical Student Specialty Choice: A Synthesis of the Literature Using Decision Theory as a Referent, Teaching and Learning in Medicine: An Int J. 2001;13(2):117-129.

17. Bland C, Meurer L, Maldona G. Determinants of primary care specialty choice; A nonstatistical meta-analysis of the literature. 1995:70(7):620-641.

18. Borges NJ, Savickas ML. Personality and medical specialty choice: A literature review and integration. J Career Assess. 2002;10(3):362-380. doi:10.1177/10672702010003006.

19. Borges N, Navarro A, Grover A, Hodan J. How, when and why do physicians choose career in academic medicine? A literature review. Acad Med. 2010;85(4):680-686.

20. Campos-Outcalt D, Senf J, Watkins A, Bastacky S. The effect of medical school curricula, faculty role models, and biomedical research support on choice of generalist physician careers: a review and quality assessment of the literature. Academic Med. 1995;70(7):611-619.

21. Senf JH, Kutob R, Campos-Outcalt D. Which Primary Care Specialty? Factors that Relate to a Choice of Family Medicine, Internal Medicine, Combined Internal Medicine-Pediatrics, or Pediatrics. Fam Med. 2004;36(2):123-130.

22. Shadbolt N, Bunker J. Choosing general practice: A review of career choice determinants. Aust Fam Physician. 2009;38(1-2):53-55.

23. Straus SE, Straus C, Tzanetos K. Career choice in academic medicine: Systematic review. J Gen Intern Med. 2006;21(12):1222-1229. doi:10.1111/j.15251497.2006.00599.x.

24. Soethout M, Ten Cate TJ, van der Wal G. Factors associated with the nature, timing and stability of the specialty career choices of recently graduated doctors in European countries, a literature review. Med Educ. 2004;9(24):1-9.

25. Ariens GAM, Van Mechelen W, Bongers PM, Bouter LM, Van der Wal G. Psychosocial risk factors for neck pain: A systematic review. Am J Ind Med. 2001;39(2):180-193. doi:10.1002/1097-0274(200102)39:2<180::aidajim1005>3.0.co;2-\%23.

26. Budd S, Kelley R, Day R, Variend H, Dogra N. Student attitudes to psychiatry and their clinical placements. Med Teach. 2011;33(11):e586-592. doi:10.3109/0142159X.2011.610836.

27. Coffeng LE, Visscher AJE, Ten Cate OTJ. The influence of early clinical experiences on career preference of male and female medical students. 2009;31:e323-e326. doi:10.1080/01421590802650084.

28. Deutsch T, Hönigschmid P, Frese T, Sandholzer H. Early community-based family practice elective positively influences medical students' career considerations - A Prepost-comparison. BMC Fam Pract. 2013;14(24):1-6. doi:10.1186/1471-2296-14-24.

29. Maudsley G, Williams L, Taylor D, Maudsley G, Williams LYN, Taylor D. Medical students' and prospective medical students' uncertainties about career intentions: Cross-sectional and longitudinal studies. 2010;32(3):e143-e151. 
30. Clark T, Freedman S, Croft A, et al. Medical graduates becoming rural doctors: rural background versus extended rural placement. Med J Aust. 2013;199(11):779-782.

31. Davis CR, O'Donoghue JM, McPhail J, Green AR. How to improve plastic surgery knowledge, skills and career interest in undergraduates in one day. J Plast Reconstr Aesthetic Surg. 2010;63(10):1677-1681. doi:10.1016/j.bjps.2009.10.023.

32. Firth A, Wass V. The impact of general practice attachments on Foundation Doctors: Achieving the goals of Modernising Medical Careers. Educ Prim Care. 2011;22(5):314-320. doi:10.1080/14739879.2011.11494025.

33. Kiolbassa K, Miksch A, Hermann K, et al. Becoming a general practitioner--which factors have most impact on career choice of medical students? BMC Fam Pract. 2011;12(1):25. doi:10.1186/1471-2296-12-25.

34. Kumar R, Dhaliwal U. Career choices of undergraduate medical students. Natl Med J India. 2011;24(3):166-169.

35. Tavakol S, Dennick R, Tavakol M. Empathy in UK medical students: Differences by gender, medical year and specialty interest. Educ Prim Care. 2011;22(5):297-303. doi:10.1080/14739879.2011.11494022.

36. Drinkwater J, Tully MP, Dornan T. The effect of gender on medical students' aspirations: A qualitative study. Med Educ. 2008;42(4):420-426. doi:10.1111/j.13652923.2008.03031.x.

37. Thistlethwaite J, Kidd MR, Leeder S. Enhancing the choice of general practice as a career. Aust Fam Physician. 2008;37(11):964-968.

38. Wigney T, Parker G. Factors encouraging medical students to a career in psychiatry: Qualitative analysis. Aust N Z J Psychiatry. 2008;42(6):520-525. doi:10.1080/00048670802050637.

39. Kuhnigk O, Hofmann M, Böthern AM, Haufs C, Bullinger M, Harendza S. Influence of educational programs on attitudes of medical students towards psychiatry: Effects of psychiatric experience, gender, and personality dimensions. Med Teach.

2009;31(7):e303-310. doi:10.1080/01421590802638048.

40. Ibrahim M, Fanshawe A, Patel V, et al. What factors influence British medical students' career intentions? Med Teach. 2014;36(12):1064-1072. doi:10.3109/0142159X.2014.923560.

41. Diderichsen S, Johansson EE, Verdonk P, Lagro-Janssen T, Hamberg K. Few gender differences in specialty preferences and motivational factors: a cross-sectional Swedish study on last-year medical students. BMC Med Educ. 2013;13(1):39. doi:10.1186/1472-6920-13-39.

42. Heiligers PJ. Gender differences in medical students $;$ motives and career choice. $B M C$ Med Educ. 2012;12(1):82. doi:10.1186/1472-6920-12-82.

43. Maiorova T, Stevens F, Zee J Van Der, Boode B, Scherpbier A. Shortage in general practice despite the feminisation of the medical workforce: A seeming paradox? A cohort study. BMC Health Serv Res. 2008;8(262):1-8. doi:10.1186/1472-6963-8-262.

44. Abdulghani HM, Al-Shaikh G, Alhujayri AK, et al. What determines the selection of undergraduate medical students to the specialty of their future careers? Med Teach. 2013;35:S25-30. doi:10.3109/0142159X.2013.765548. 
45. Coulston C, Vollmer-Conna U, Malhi G. Female medical students: Who might make the cut? Psychiatry Res. 2012;200(2-3):457-463. doi:10.1016/j.psychres.2012.06.019.

46. Baller FE, Ludwig K V, Kinas-Gnadt Olivares CL, Graef-Calliess I-T. Exploring the ideas and expectations of German medical students towards career choices and the speciality of psychiatry. Int Rev Psychiatry. 2013;25(4):425-430. doi:10.3109/09540261.2013.823384.

47. Robbins T, Crocker-Buque T, Forrester-Paton C, Cantlay A, Gladman J, Gordon A. Geriatrics is rewarding but lacks earning potential and prestige: responses from the national medical student survey of attitudes to and perceptions of geriatric medicine. Age Ageing. 2011;40(3):401-405. doi:10.1093/ageing/afr033.

48. Lempp T, Neuhoff N, Renner T, et al. Who Wants to Become a Child Psychiatrist? Lessons for Future Recruitment Strategies From a Student Survey at Seven German Medical Schools. Acad Psychiatry. 2012;36(3):246-251. doi:10.1176/appi.ap.10120173.

49. Bindal T, Wall D, Goodyear HM. Medical students' views on selecting paediatrics as a career choice. Eur J Pediatr. 2011;170(9):1193-1199. doi:10.1007/s00431-011-1467-9.

50. Mehmood SI, Khan MA, Walsh KM, Borleffs JCC. Personality types and specialist choices in medical students. Med Teach. 2013;35(1):63-68. doi:10.3109/0142159X.2012.731104.

51. Soethout MBM, Heymans MW, ten Cate OTJ. Career preference and medical students' biographical characteristics and academic achievement. Med Teach. 2008;30(1):e15e22. doi:10.1080/01421590701759614.

52. van Tongeren-Alers M, van Esch M, Verdonk P, Johansson E, Hamberg K, LagroJanssen T. Are new medical students' specialty preferences gendered? Related motivational factors at a Dutch medical school. Teach Learn Med. 2011;23(3):263-268. doi:10.1080/10401334.2011.586928.

53. Cleland JA, Johnston PW, Anthony M, Khan N, Scott NW. A survey of factors influencing career preference in new-entrant and exiting medical students from four UK medical schools. BMC Med Educ. 2014;14(1):151. doi:10.1186/1472-6920-14-151.

54. Gedrose B, Wonneberger C, Jünger J, et al. Haben Frauen am Ende des Medizinstudiums andere Vorstellungen über Berufstätigkeit und Arbeitszeit als ihre männlichen Kollegen? Dtsch Medizinische Wochenschrift. 2012;137(23):1242-1247. doi:10.1055/s-0032-1304872.

55. Gibis B, Heinz A, Jacob R, Müller CH. The Career Expectations of Medical Students. Dtsch Arztebl Int. 2012;109(18):327-332. doi:10.3238/arztebl.2012.0327.

56. Lefèvre JH, Karila L, Kerneis S, Rouprêt M. Motivation of French medical students to pursue surgical careers: results of national survey of 1742 students. J Visc Surg. 2010;147(3):e181-e186. doi:10.1016/j.jviscsurg.2010.08.004.

57. Malhi GS, Coulston CM, Parker GB, et al. Who picks psychiatry? Perceptions, preferences and personality of medical students. Aust N Z J Psychiatry. 2011;45(10):861-870. doi:10.3109/00048674.2011.604301.

58. Heinz A, Jacob R. Medizinstudenten und ihre Berufsperspektiven.

Bundesgesundheitsblatt - Gesundheitsforsch - Gesundheitsschutz. 2012;55(2):245-253. doi:10.1007/s00103-011-1413-z. 
59. Matteson M, Smith S. Selection of medical specialties: preferences versus choices. $J$ Med Educ. 1977;52(7):548-554. doi:10.1097/00001888-197707000-00002.

60. Nieman L, Holbert D, Bremer C, Nieman L. Specialty Career Decision Making of Third-year Medical Students. Fam Med. 1989;21(5):359-363.

61. Vroom V. Work and Motivation. Oxford: Wiley; 1964.

62. Hughes N, Soiza R, Chua M, et al. Medical students attitudes toward older people and willingness to consider a career in geriatric medicine. J Am Geriatr Soceity. doi:10.1111/j.1532-5415.2007.01552.x

63. Pedersen LT, Bak NH, Dissing AS, Petersson BH. Gender bias in specialty preferences among Danish medical students: A cross-sectional study. Dan Med Bull. 2011;58(9):A4304.

64. Ferrari S, Reggianini C, Mattei G, Rigatelli M, Pingani L, Bhugra D. International study of student career choice in psychiatry (ISoSCCiP): Results from Modena, Italy. Int Rev Psychiatry. 2013;25(4):450-459. doi:10.3109/09540261.2013.804402.

65. Halder N, Hadjidemetriou C, Pearson R, et al. Student career choice in psychiatry: Findings from 18 UK medical schools. Int Rev Psychiatry. 2013;25(4):438-444. doi:10.3109/09540261.2013.824414.

66. Ravindra P, Fitzgerald JEF. Defining surgical role models and their influence on career choice. World J Surg. 2011;35(4):704-709. doi:10.1007/s00268-011-0983-0.

67. Andlauer O, Guicherd W, Haffen E, et al. Factors influencing french medical students towards a career in psychiatry. Psychiatr Danub. 2012;24(SUPPL. 1):185-190.

68. Andlauer O, Van Effenterre A, Haffen E, et al. Encouraging French medical students to choose a career in psychiatry: How and why? Int Rev Psychiatry. 2013;25(4):460-465. doi:10.3109/09540261.2013.821404.

69. van den Broek S, Ten Cate O, Wijnen-Meijer M, Van Dijk M. Effect of the Bologna bachelor degree on considerations of medical students to interrupt or terminate their medical training. Med Teach. December 2013:1-6. doi:10.3109/0142159X.2013.857012.

70. van den Broek S, Muller B, Dekker N, Bootsma A, Cate O Ten. Effect of the new Bologna bachelor degree on career considerations of medical students in one medical school. Med Teach. 2010;32(12):997-1001. doi:10.3109/0142159X.2010.498487. 



\section{Chapter 3}

\section{Factors Affecting Senior Medical Students' Career Choice}

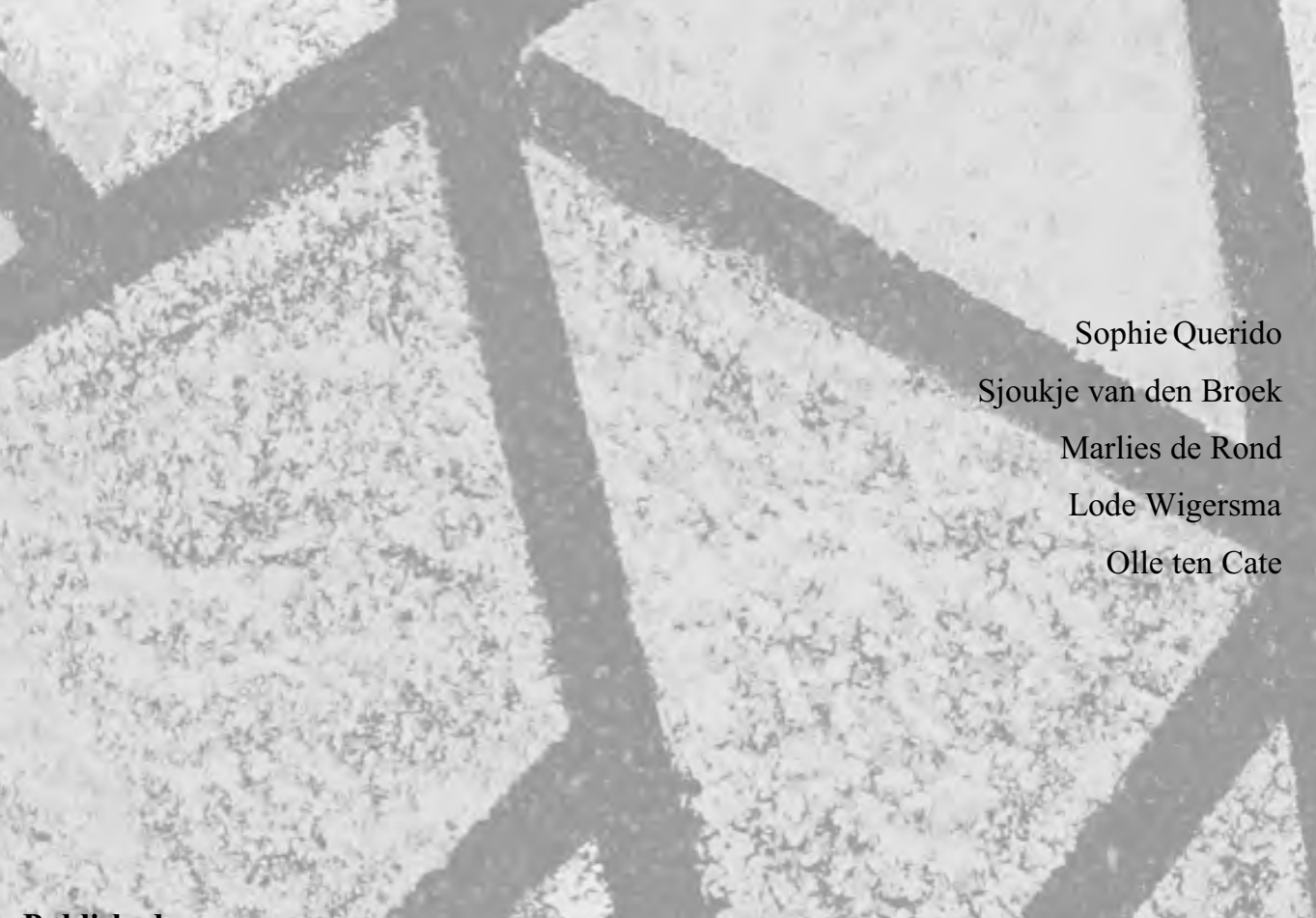

\section{Published as:}

Factors affecting senior medical students' career choice. International Journal of Medical

Education 2018;9:332-339. doi: 10.5116/ijme.5c14.de75 
- Chapter 3

\begin{abstract}
Objectives

To gain insight into factors affecting career preference and career choice during the final phase of medical school, above and beyond a model that was presented by Bland and colleagues in 1995, the 'Bland model'.
\end{abstract}

\title{
Methods
}

A qualitative study was conducted. One-hour semi-structured interviews were conducted with final-year medical students about career preference and the factors influencing preference and choice. The interviews were transcribed and a thematic analysis was applied, to identify patterns and interrelationships in the data and to compare and contrast these with the Bland model.

\section{Results}

Twenty-four students participated. Three critical sets of factors, not present in the Bland model, emerged from the interviews: (a) factors arising from student-initiated information collection, (b) patient population characteristics of a specialty domain, and (c) the characteristics of teams and colleagues within a specialty.

\section{Conclusions}

Students appear to actively match and calibrate perceptions of different specialty characteristics with their current personal needs and expected future needs, and to include cues from self-initiated information collection about a specialty. This agency aligns with Billett's workplace learning theory. Next, specialty patient population features appear to be taken into account; this was not unexpected but not included in the Bland model. Finally, the characteristics of teams and colleagues of a specialty were stressed in the interviews. These three components broaden the applicability of the Bland model--originally created for primary-care careers--to medical specialties in general. 


\section{Introduction}

Thinking about medical career choice starts during undergraduate medical education. "What specialist should I become?" is a question all medical students face and must answer. ${ }^{1}$ Most students start medical school with some idea about specialty choice ${ }^{2,3}$, but first preferences are rarely realized. ${ }^{3-5}$ At the beginning of medical school, many students have vague images and misconceptions of the medical profession. ${ }^{6-8}$ Even for those with a strong preference at the start of medical school, career preference is subject to changes during undergraduate training. ${ }^{6-8}$ Choosing a postgraduate career path is an important choice that is often difficult to reverse once in residency training. Students' career choices shape the landscape of human resources in health care, and a better understanding of the process of career choice can help to create a better match of students' preferences with specialty needs.

After medical school, most graduates start residency training. Switching specialty careers during or after postgraduate training is usually difficult and often causes financial and emotional stress for residents. ${ }^{9}$ To change or quit a residency is, therefore, unusual among residents. ${ }^{10}$ This puts pressure on students to choose the right specialty for a lifetime career. The decision, in turn, has a significant impact on career satisfaction and personal well-being later in life. ${ }^{9,11-15}$ Specialty choice is not only crucial for the individual but also for society at large, as populations must be served with an adequate mix of medical specialties. Medical students generally determine career preferences without attending to societal needs. Some specialities suffer because they cannot attract enough graduates. A skewed distribution of graduates across the specialties leads to shortages in some specialties and competition in others. Guidance in making the best suitable career choice should, therefore, be part of the medical education, and from this point of view, career preference dynamics are a relevant object of study in medical education.

\section{Bland model of career choice}

Career choice is a process with many interacting factors. A literature review published in 1995 by Bland and colleagues, and recently updated, ${ }^{16}$ features among the most comprehensive summaries of this process to date for medical career choice. ${ }^{17}$ It shows how the process of career choice is essentially a balance between expected future career needs and the perception of the characteristics of a specialty. Career needs are determined by the preferences and values of a student, affected by student characteristics and educational program characteristics. The stronger the perceived similarity between career needs and the perceived characteristics of a specialty, the stronger the desire for this specialty as a career 
choice. ${ }^{17}$ These career needs change during medical school under the influence of personal development, curriculum, life experience and specialty experience. ${ }^{16,17}$ Although this model provides valuable information about the relationship between factors affecting decision and preference of specialty, it was designed to address shortages and geographic maldistribution, which were predicted in the wake of a decrease in the number of medical school graduates entering primary care in the United States in the early 1990s. Secondly, the model was proposed more than two decades ago, and its current applicability is unclear. Nevertheless, the model still provides a valuable lens to investigate factors that influence career choice.

\section{Aim and research question}

Most career preference and choice studies in medicine are specialty specific. ${ }^{18-21}$ Moreover, many take a quantitative approach ${ }^{22}$ and lack deep insight into students' perspectives on career choice.

This study aims to provide insight into the factors that influence career choice specifically during the final phase of medical school. To reach a deeper understanding of the participants' views, a qualitative approach was chosen. ${ }^{23,24}$ The research question we attempted to answer is: which factors affect career choice of medical students in their final study year?

\section{Method}

\section{Study design}

An exploratory qualitative study was conducted using thematic analysis. Qualitative methodology was used since this study focuses on the experiences and perceptions of medical students; highlighting how this is affected by multiple factors and therefore how their career preferences might be influenced. We conducted 24 individual in-depth interviews to explore senior medical students' opinions about their career preferences and to relate this to the Bland model. ${ }^{25,26}$.

\section{Setting}

The Dutch educational model allows for variation in study timelines, and graduations in medical schools occur several times per year. During the final-year rotations, students assume increased levels of responsibility in patient care, as they are expected to participate as a junior doctor under strict supervision. In this last year of undergraduate medical training, the medical student in most Dutch medical schools is called a 'semi-physician', somewhat similar to a foundation doctor in the UK system or a sub-intern or intern in the USA. ${ }^{27}$ However, 
successful completion of this year does not guarantee a residency position in a preferred specialty. Dutch graduates need to apply for a residency in an open job market.

\section{Participants}

The study was conducted at University Medical Center (UMC) Utrecht in the Netherlands with two groups of final-year medical students. The duration of UMC Utrecht's undergraduate medical curriculum is six years, and the final year is created as a transitional year towards residency, and contains predominantly elective clinical and science rotations..$^{28,29}$ Each sub-cohort starts with a six-week non-clinical block, with the starting dates for these blocks spread out over the final year. The study was explained during lectures in the first week of two such sub-cohorts, once in May and once in October. The lectures were attended by a total of 67 students and all these students were sent a follow-up information email and were offered the opportunity to sign up for the study. After one week, a reminder was sent to all non-responders. This convenience sample included all students starting in these two modules. ${ }^{24}$ The study was approved by the Netherlands Association for Medical Education Ethical Review Board (ERB number 308). The participants were informed that participation was voluntary, that confidentiality was secured and that non-participation would not be held against them. They could withdraw from the study at any time without giving a reason. Written informed consent was obtained from all the participants. To preserve anonymity, every participant was asked to choose a pseudonym that was used for data storage and analysis.

\section{Data collection}

We conducted semi-structured, in-depth interviews stimulating respondents to talk freely about sensitive matters. The interviews were held in a quiet studio at UMC Utrecht and lasted one hour. The interviews were planned following participants' availability options. The first interviews were conducted by two researchers (SQ and SB), to encourage similar interview styles in subsequent ones. Furthermore, the interviews were equally divided among the two researchers and were performed face to face. All interviews were audio recorded and during the interview field notes were made for the purpose of reference during the interview. To further increase the study's credibility, member validation was performed by writing summaries of each interview and sharing them with the participants. ${ }^{24}$ This did not lead to essential changes; three students made minor changes at sentence and linguistic level. The topic-list with questions that guided the interviews was based on what was known from the 
literature on career choice. The list was piloted with six medical students, and was refined prior to the interviews with the sample group subjects. The items focused on the participants' career preferences and included questions such as, what are your career preferences? Can you explain these? How familiar are you with these specialties? Which are your electives during the transitional year and why did you choose these? Follow-up questions were used to probe explanations of the answers more deeply.

\section{Data analysis}

The researchers (SQ and SB) had several meetings to discuss the developing analysis. This promoted alignment of the researchers' individual interpretations and enhanced reflection. ${ }^{26,30,31}$ The interviews were transcribed verbatim using a transcription company with participants' personal data being de-identified. All transcripts were checked against audio recordings by the first (SQ) or second (SB) author.

Both authors read each transcript twice to familiarize themselves with the contents. The authors analysed all data using the lens of the Bland model. The known "student factors" (as opposed to factors that are determined by the educational institution, i.e., status, salary, worklife balance, interesting work, altruism, experiences, role models ${ }^{16}$ ) formed the basis for a coding template for describing factors influencing medical career choice. ${ }^{32,33}$ The quotations were first identified as expressions of a particular factor and further categorised into the subthemes (e.g. incoming values, career needs to satisfy). The raw data were coded line by line in an open coding process to identify any factor that seemed to influence a student's medical career choice. ${ }^{32,33}$ Coding and analysis of all interviews were performed by the first researcher (SQ). For analytical rigor, the second researcher (SB) also performed an analysis of four interviews selected to reflect variation in gender, transitional-year start date (May or October), and career preference (intramural or extramural medical specialties). Thus, both researchers were familiar with all different codes and themes.

The coding scheme, as well as the themes, were discussed with the researchers' team (SQ, $\mathrm{SB}, \mathrm{MdR}, \mathrm{LW}, \mathrm{OtC}$ ) during several meetings throughout the analysis. This allowed for alignment of the researchers' individual interpretations and enhanced reflection, to increase credibility in the interpretations of the data. ${ }^{30,31}$ The Bland model was used as a starting point for analysis to understand factors of influence for medical career choice, both to provide guidance and to be supplemented with new findings during the process. Data analysis continued by importing all data in a qualitative software application (Dedoose) ${ }^{34}$ With the 
number of interviews, saturation was reached to understand the range of considerations of medical students with respect to their career preferences.

\section{Reflexivity}

The two researchers (SQ, SB) who conducted the interviews were both trained in interview methods. SQ has a Master of Science degree in Health Care Management and was a policy advisor at the Royal Dutch Medical Association. She was not known to the participants and could work primarily as a researcher with an outsider perspective, with knowledge of career options, curricula and the theoretical framework. SB graduated from medical school at Utrecht University and works as a medical educator and researcher at University Medical Center Utrecht. She was not acquainted with any of the participants but had inside knowledge of the Utrecht medical education program from her own experience. Two co-researchers (MdR and LW) had an outsider perspective, not being involved with University Medical Center Utrecht's medical school, and one co-author (OtC) had an insider view, being the director at the Center for Research and Development of Education at University Medical Center Utrecht at the time. All three supervising researchers (MdR, LW, OtC) have theoretical knowledge of career choice, to ensure there was consensus for the use of the codebook. This insider/outsider status of the researchers allowed us to understand and interpret the scope of career options as well as the way they emerge in clinical education.

\section{Results}

Senior medical students participating in the study ranged in age from 23 to 26 and included 20 women and 4 men. There were no married or divorced students, and none had children.

Sixteen students had a partner, 6 were single and of 2 the relationship status was unknown.

Major interview themes and sub-themes were identified using the Bland model as a tool for analysis. Three main themes were classified: Student characteristics, Needs to be satisfied and Perception of specialty characteristics. All three themes have a diversity of subthemes. These are listed in Table 1 and further elaborated upon in the subsections below. 
Table 1 Overview of factors mentioned by interviewees

\begin{tabular}{|l|l|}
\hline Theme & Sub-theme \\
Geography \\
Needs to be satisfied & Parental profession \\
Personality \\
Personal needs \\
- career counselling \\
- career options \\
- lifestyle \\
- location/type of practice \\
- opinion of others \\
- parental preferences \\
- status \\
- working hours \\
- work-life balance \\
Societal needs \\
Perception of speciality \\
characteristics
\end{tabular} \mid \begin{tabular}{l} 
- altruism \\
Content interest needs \\
- characteristics of team and colleagues \\
- intellectual satisfaction \\
- interesting nature of work \\
- patient characteristics \\
Experience with the specialty \\
- experience before study \\
- experience in courses \& rotations \\
- extracurricular experience \\
- experience with role model or mentor \\
- personal experience \\
Information about the specialty \\
- representation in the media \\
- student-initiated information collection \\
Market dynamics of the specialty \\
- chances to obtain a residency position \\
\hline
\end{tabular}

\section{Student characteristics}

The students talked about various personal aspects such as where they live, their age, their personality, their relationship status, and so on. With the Bland model in mind, we categorized these under the theme of student characteristics. We identified three student characteristics of note in the interviews: geographic origin, parental education and personality. 
Geography

Where to live during and/or after residency appeared of critical relevance for some students. Some wanted to stay in a particular city while others wanted to go back to their family, for example. For some, geographic considerations weighed strongly in making a career choice. “...That is really important for me. I definitely do not want to leave Amsterdam. I am prepared to travel, but I'd rather not. I probably will have to, but I'd rather not travel more than one hour per day." (no. 18, female).

Parental profession

Some interviewees explained how parents' or close family-members' medical professions affected their career preference.

“...I think that my preference indirectly has something to do with my father's specialty, but I cannot really explain how. At first, I just did not want the same, but it's in my mind all the time, and I think that played a role. Now I also want to be a gynaecologist, just like my father." (no. 16, female).

Personality

Some students elaborated on why their personality would fit with their career choice.

“...I am really interested in people. I also think that is important for an intellectual disability physician or general practitioner [which I consider as career options]. I am always very interested in my friends, how they really are feeling. I think it is important to be sincerely interested and not pretend. I think that my communication skills fit well with these two specialties." (no. 13, female).

\section{Needs to be satisfied}

All medical students have needs that they wish to fulfill in their future careers and their professional lives and these differ from person to person. These needs may be categorized in three: (1) personal: features that match personal desires around lifestyle, location/type of practice, working hours and work-life balance. Also included here are career features that are important to students because they line up with preferences of other people important to students, sub-themes are career counselling, career options, opinion of others and parental preferences; (2) features that match broader societal needs, the students mentioned altruism and (3) features that align with the content and habits of the specialty, such characteristics of 
- Chapter 3

team and colleagues, intellectual satisfaction, interesting work and patient characteristics. Some examples are described below.

Personal needs

Work-life balance

Many students (both men and women) mentioned the need for a work-life balance.

“... the work-life balance weighs for me. If you want children and a wife then part-time work is attractive. I would like to work hard, but for me it is important that at some time the working day ends. I want to finish at the end of the day and go home and not be called in again. That consideration influences my career preference at the moment."(no 17, male).

There are also students who notice a work-life imbalance, but are willing to accept this because of others factors that are more important such as the content of the work they expect to be doing. An example is:

“... I think about cardiology. It is sort of the only preference I have, although I also think of general practice as an option. Basically, I would like to focus on cardiology. ... I think working hours will be heavy, but I do not think that is a reason to lose interest. It will be of big impact on my life, but I am willing to sacrifice that for it." (no. 24, female).

\section{Career options}

Most interviewees weighed advantages and disadvantages of preferences to continue searching for the best fit with a specialty and shared these considerations with family, partners, friends or student counsellors.

“...Okay this is the situation, I think I will fit in. Well hhhmm... It is just a process which I can share with my family and best friends and talk about it... about my considerations and so...I am a person of self-reflection and hhhmm... I contrast pros and cons and figure things out for myself." (no.15 male).

\section{Opinion of others}

Some students expressed influences by parents or friends (sub-theme "opinion of others"):

"My boyfriend, well yeah..., he is not so happy with my preference for psychiatry."

Question: "Why?"

"Because he thinks it will be very heavy. And also, because he thinks it is not so cool. He literally said that." 
Question: "What does his opinion mean for you?"

"Yes, hhhmm, on the one hand I makes it difficult for me, but on the other hand not so much, I think I love psychiatry. You know, I find it difficult when important people around me reject it." (no.5, female).

“...My mother does not care what I end up choosing. She says:” You started medicine, just finish it." My father tries to restrain himself, but I know he really would love for me to become a medical specialist; sometimes he is a bit pushy. He does not refer to a particular specialty, but he thinks it is important that I choose one with good job opportunities. So, I feel need to go for a hospital speciality." (no.14 male).

Societal needs

Altruism

Some students explain about the wish to help people or to be a difference to people.

"Actually, if I want to combine my social commitment with my job and really want to help, I can choose one of those two preferences." (no.2, female)

Content interest needs

Characteristics of team and colleagues

The characteristics of team and colleagues appeared to be important, i.e. students sought to be part of the team, to participate in the teamwork, to have colleagues and to identify with the features of colleagues.

“...Yes, this specialty really got me, I liked that. I am attracted by a nice team and this was a nice team." [..] Yes, the entire team, the gynaecologists and the residents together. I did not experience that before, where people respectfully work together and at the same time enjoy work and are not too serious all day. I feel at home with them. [...] I do like doing things on my own, but I really want to work in a team, definitely." (no.6, female).

"...I think it is also the colleagues that I see, they are like me. So, it is the combination of the specialty and the colleagues." (no.20, female).

\section{Patient characteristics}

Patient population characteristics appeared also important. This includes frequency of patient contacts, duration of patient contacts, type of relationship with patients and type of patients 
- Chapter 3

(e.g., children or elderly).

“...I just like old people. As a student, I worked a year in elderly care and that really brought me pleasure. I enjoy being in contact with those old people." (no.2, female).

\section{Perception of specialty characteristics}

When asked about previous knowledge and experiences interviewees recalled what they had experienced or heard and how this influenced their image of the speciality. The perception of specialty characteristics may be categorized in three: (1) Experience with the specialty, such experience before study, experience in courses \& rotations, extracurricular experience, experience with role model or mentor and personal experience; (2) Information about the specialty such representation in the media and student-initiated information collection and (3) Market dynamics of the specialty as chances to obtain a residency position. Some examples are described below.

Experience with the specialty Experience in courses and rotations

All students referred to previous experiences during courses and rotations. “...I took a clerkship in gynaecology in Africa. That went very well. I was in the fourth year and I had already done a gynaecology block and with this clerkship I really found out that I like this. During my first block, here in the hospital, I was not allowed to do much, just to watch. In Africa, I was allowed to do more and I think that this confirmed my interest ...this could be it for me." (no.16, female).

"Without an internship, you don't know exactly what it contains. Yes, and when I started my rotations, that was the rotation, which I enjoyed most. Yeah, that is, hhhmm that is it." (no.1, female).

Experience with role model or mentor

Clinicians from a desired specialty would sometimes be influential as an acting role model or mentor.

"One of the general practitioners during my internship, she was a role model for me. How she treated and communicated with her patients, her knowledge, everything she did. I really saw an example in her and I want to be like her when I become a general practitioner myself." (no.14, male) 


\section{Personal experience}

Some students had experienced health care as a patient or had witnessed a close family member to be a patient.

“...my niece is mentally retarded. She also lives in a special hospital. She enjoys my visits, as do the other patients of her group... And I really enjoy it myself; it is very nice. That is also how I noticed my interest in this specialty." (intellectual disability physician) (no.13, female).

Information about the specialty

\section{Student-initiated information collection}

Another factor we labelled "student-initiated information collection", signifying extracurricular activities medical students proactively undertake to gather information to make a career choice, such as voluntarily shadowing doctors in a preferred specialty, visiting medical career events or workshops, participate in a medical career event committees, et cetera. These activities provide them with more information or the possibility to check their personal questions with someone with more knowledge or experience within the specialism.

One student seeking to explore her match contacted two gynaecologists to ask questions and experience a working day with them.

“...I shadowed gynaecologists for two days and had multiple conversations with them saying 'this is who I am and these are my plans'. I asked for their opinions and suggestions... I'd much rather hear this from gynaecologists themselves directly. It was really useful to have them "precept" my plans and to receive information about what to do and how to present myself if I were to apply for a residency position." (no.22, female).

And another student explained:

"Once a year there is a career event of tropical medicine. The stories and the experiences of these doctors, yes, they really got me." (no.23, male).

Market dynamics of the specialty

\section{Chances to obtain a residency position}

Another factor of how student's perception of a specialty is and was mentioned by them, is the chance to obtain a residency position. In the Netherlands, some specialties and residency positions are more popular than others and there is a skewed distribution in applications for postgraduate medical education programs and varying entrance criteria. Some programs now require a $\mathrm{PhD}$ degree. For the one student, this means to put in more effort and the opportunity to show their motivation, while other students are not prepared to invest in these 
rare changes and maybe to be disappointed not to reach their career choice. One of the medical students said:

“...It is really hard to obtain a residency position. There are so many rival competitors, you need to have a good cv. I tried to work on that, but I am not sure that is sufficient to get my residency position." (no.1, female).

\section{Discussion}

Our study focused on the factors influencing career choices of final-year medical students. The results are thematically organized through the lens of the Bland model. ${ }^{16}$ Our study was not meant to validate and weigh factors in the Bland model, but to use the model as a lens to interpret and categorize our findings and supplement the model if useful.

Senior medical students mentioned factors under three categories of the model: student characteristics, career needs, and perception of specialty characteristics. Within these categories, three new factors could be added to those in the Bland model: student-initiated information collection, patient population characteristics of a specialty, and characteristics of teams and colleagues.

Student-initiated information collection reflects how activities or information sources not offered in the regular education program influence a medical student's career choice. To promote the specialties, information events, one-day courses, or other opportunities to interact with and experience a specialty are organized to attract medical students and graduates. ${ }^{35-38}$ This aligns with Billett's learning theory. He emphasizes the role of the workplace as an implicit learning environment wherein the learner negotiates participation in work activities and so the learning process - with those individuals representing the interests of the workplace. ${ }^{39}$ Students can use the affordances offered by the workplace (and beyond it) in various ways. Student-initiated information collection is an explicit result of such agency. These experiences will contribute, even if in small ways, to changes in their ways of knowing and sense of self. Moreover, it is one more piece of evidence for an account of learning for work which acknowledges the independence of individuals acting within the interdependence of the social practice of work. Educational programs may consider how the benefits of such agency can be communicated with those who start clinical training.

'Patient population characteristics of a specialty' is not cited as a separate factor of influence in recent literature but it may be subsumed within other factors and therefore sometimes labelled differently (for example as interesting work, work content, contact with patients, or interest in relationships). ${ }^{22}$ Nevertheless, students mentioned patient population characteristics 
as an important separate factor and, therefore, it should be classified as a separate factor. Characteristics of teams and colleagues affect career choices. Being part of a team can have a positive influence. Second-year residents in the UK, interviewed about career choice, stated that experiences with one specialty team could profoundly shape their opinion of that entire specialty, and this could contribute to the attractiveness of a specialty. ${ }^{40}$ This aligns with what our medical students reported and seems to indicate that being regard as a colleague and participating in a team affects career choice.

Some of the many factors included in the Bland model were not mentioned by the medical students $^{16}$, in particular (institutional:) type of school, mission/structure, faculty composition, admission committee, faculty values, curriculum committee, student composition, institutional culture and curriculum, (student-related:) gender, study year, ethnicity, age, selfconfidence, marital status, academic performance, (profession-related) salary, psychical/ emotional workload, professional autonomy, scope of self-practice, perception of gender differences and perception of status. We attribute the absence to a lack of awareness among students or not relevant for the Dutch situation. For example, students in the Netherlands graduate with less debt than medical students in some other countries; it is possible that this is why no student in this study mentioned financial burden as a factor of any importance in career choice..$^{22,41,42}$ In the U.S.A. and New Zealand, the cost of education is significantly higher, and graduates are perhaps for this reason more likely to choose a medical career that is more highly paid. ${ }^{41,42}$ Hence, while the financial burden was not a factor of influence in this study, it should not be excluded, as previous studies with other populations attest to their importance in students' career choice.

To provide support to medical students in making career choices an overview of all factors influencing this career choice is useful. Our study adds three factors to yield a more complete model of factors of influences on career choice of medical students. It provides a better understanding of how students reflect on their career choice. Knowledge of these factors can be useful for the development of tools and strategies for career support by educators and policy makers. 
- Chapter 3

\section{Limitations}

This study has some limitations. First, this study was performed at a single institution, one medical school in the Netherlands. We have to bear in mind that the institutional environment can influence results. The Dutch situation may differ from other countries, by its transitional year and admission process for residency. ${ }^{28,43}$ Furthermore, the results of the study are predominantly a reflection of female students' experiences. The proportion of male and female students in Dutch medical schools (about $65 \%$ female) (4, $^{45}$ is different from the proportion in our study population $(83,3 \%$ female) which could result in bias in the data. In addition, participation was voluntary which may have led to a non-representative sample of the student population as a whole. However, we had a representative mix of participants as we look to their age and specialty preferences.

\section{Conclusion}

Medical students acknowledge many factors to be of influence on career choice including some factors not presented in the Bland model of medical career choice. Our study offers educators and school counsellors better insight into factors of influence and contributes to establishing a more accurate and complete model for guidance of medical students in making a career choice. This can contribute to future career satisfaction and personal well-being as well as to a better distribution of graduates across specialties. 


\section{References}

1. Walsh S, Arnold B, Pickwell-smith B, Summers B. What kind of doctor would you like me to be ? Clin Teach. 2015;12:1-4.

2. Cleland J, Johnston PW, French FH, Needham G. Associations between medical school and career preferences in Year 1 medical students in Scotland. Med Educ. 2012;46(5):473-484. doi:10.1111/j.1365-2923.2012.04218.x

3. Kaur B, Carberry A, Hogan N, Roberton D, Beilby J. The medical schools outcomes database project : Australian medical student characteristics. BMC Med Educ. 2014;14:180-190.

4. Compton MT, Frank E, Elon L, Carrera J. Changes in U.S. Medical Students ' Specialty Interests over the Course of Medical School. J Gen Intern Med. 2008;23(7):1095-1100.

5. Maudsley G, Williams L, Taylor D, Maudsley G, Williams LYN, Taylor D. Medical students' and prospective medical students' uncertainties about career intentions: Cross-sectional and longitudinal studies. 2010;32(3):e143-e151.

6. Nieuwhof MG, Rademakers JJ, Kuyvenhoven MM, Soethout MB, ten Cate TJ. Students' conceptions of the medical profession; an interview study. Med Teach. 2005;27(8):709-714. doi:10.1080/01421590500271159.

7. Soethout MBM, Heymans MW, ten Cate OTJ. Career preference and medical students' biographical characteristics and academic achievement. Med Teach. 2008;30(1):e15e22. doi:10.1080/01421590701759614.

8. Underwood MJ, Thompson M, McCaskie A. Insight of first-year medical students into their future working conditions. Med Educ. 1990;24(3):210-211. doi:10.1111/j.13652923.1990.tb00002.x.

9. Dyrbye LN, Burke SE, Hardeman RR, et al. Association of Clinical Specialty With Symptoms of Burnout and Career Choice Regret Among US Resident Physicians. 2018;320(11):1114-1130. doi:10.1001/jama.2018.12615.

10. Goldacre MJ, Laxton L, Lambert TW. Medical graduates' early career choices of specialty and their eventual specialty destinations: UK prospective cohort studies. $B M J$. 2010;340(c3199):1-9.

11. Borges NJ, Gibson DD, Karnani RM. Job satisfaction of physicians with congruent versus incongruent specialty choice. Eval Health Prof. 2005;28(4):400-413.

12. Dyrbye LN, Thomas MR, Huntington JL, et al. Personal life events and medical student burnout: a multicenter study. Acad Med. 2006;81(4):374-384. doi:81/4/374 [pii].

13. Leigh JP, Tancredi DJ, Kravitz RL. Physician career satisfaction within specialties. BMC Health Serv Res. 2009;(9):166-178. doi:10.1186/1472-6963-9-166.

14. Lepnurm R, Danielson D, Dobson R, Keegan D. Cornerstones of career satisfaction in medicine. Can J Psychiatry. 2006;51(8):512-522.

15. Roos M, Watson J, Dch MD, Wensing M. Motivation for career choice and job satisfaction of GP trainees and newly qualified GPs across Europe: a seven countries cross-sectional survey. Educ Prim Care. 2014;25:202-210. 
16. Querido SJ, Vergouw D, Wigersma L, Batenburg RS, De Rond MEJ, Ten Cate OTJ. Dynamics of career choice among students in undergraduate medical courses. A BEME systematic review: BEME Guide No. 33. Med Teach. 2015;38(1):18-29. doi:10.3109/0142159X.2015.1074990.

17. Bland C, Meurer L, Maldona G. Determinants of primary care specialty choice; A nonstatistical meta-analysis of the literature. 1995:70(7):620-641.

18. Barat A, Goldacre MJ, Lambert TW. Career choices for nephrology and factors influencing them: surveys of UK medical graduates. J R Soc Med Open. 2018;9(8):110. doi:10.1177/2054270418793024.

19. Lahad A, Bazemore A, Petek D, Phillips WR, Merenstein D. How can we change medical students' perceptions of a career in family medicine ? Marketing or substance? Isr J Health Policy Res. 2018;7(52):1-5.

20. Marshall AL, Gupta R, Grill D, et al. Identification of Factors Associated with Hematology-Oncology Fellow Academic Success and Career Choice reviewed by educational committees looking to select those. J Cancer Educ. 2018;Epub.

21. Meiboom AA, Vries H De, Soethout MBM, Hertogh CMPM, Scheele F. A career in elderly care; an option for today's medical student? Medical students' interest in elderly care medicine. Tijdschr Gerontol Geriatr. 2018;49(4):139-146. doi:10.1007/s12439-018-0255-7.

22. Goel S, Angeli F, Dhirar N, Singla N, Ruwaard D. What motivates medical students to select medical studies : a systematic literature review. BMC Med Educ. 2018;18(16):110. doi:10.1186/s12909-018-1123-4.

23. Malterud K. Qualitative research: Standards, challenges, and guidelines. Lancet. 2001;358(9280):483-488.

24. Tavakol M, Sandars J. Quantitative and qualitative methods in medical education research: AMEE Guide No 90: Part II. Med Teach. 2014;44(90):1-11.

25. Chen HC, Teherani A. Common Qualitative Methodologies and Research Designs in Health Professions Education. Acad Med. 2016;91(12):2016. doi:10.1097/ACM.0000000000001393.Additional.

26. Creswell JW. Research Design: Qualitative, Quantitative, and Mixed Methods Approaches. Fourth. Michigan: Sage Publications Inc.; 2014.

27. Wijnen-Meijer M, Burdick W, Alofs L, Burgers C, ten Cate O. Stages and transitions in medical education around the world: clarifying structures and terminology. Med Teach. 2013;35(4):301-307.

28. van den Broek WES, Wijnen-Meijer M, Ten Cate O, van Dijk M. Medical students' preparation for the transition to postgraduate training through final year elective rotations. GMS J Med Educ. 2017;34(5):Doc65.

29. Ten Cate O. Medical education in The Netherlands. Med Teach. 2007;29(8):752-757.

30. O'Brien BC, Harris IB, Beckman TJ, Reed DA, Cook DA. Standards for reporting qualitative research: A synthesis of recommendations. Acad Med. 2014;89(9):12451251.

31. Yin RK. Case Study Reserach - Design and Methods. Vol 2.; 2006. 
32. King N. Doing template analyses. In: Symon G, ed. Qualitative Organizational Research: Core Methods and Current Challenges. London: Sage Publications Inc; 2012:426-450.

33. Miles MB, Huberman M a, Saldana J. Qualitative Data Analysis. A Methods Sourcebook. 3rd ed. Arizona: Sage Publications Inc.; 2014.

34. SocioCultural Research Consultants L. Dedoose, version, 7.0.23. web application for managing, analyzing, and presenting qualitative and mixed method research data. 2016. www.dedoose.com.

35. Ahmed K, Bennett DM, Halder N, Byrne P. Medfest : the Effect of a National Medical Film Festival on Attendees 'Attitudes to Psychiatry and Psychiatrists and Medical Students' Attitudes to a Career in Psychiatry. Acad Psychiatry. 2015;39(3):335-338. doi:10.1007/s40596-014-0184-x.

36. Agyapong VIO, McLoughlin D. Promoting Psychiatry as a Career Option for Ghanaian Medical Students Through a Public-Speaking Competition. Acad Psychiatry36. 2012;36(3):229-232.

37. Bridgeman A, Findlay R, Devnani A, Lim D, Loganathan K. Inspiring the next generation of Cardiothoracic Surgeons : an easily reproducible, sustainable event increases UK undergraduate interest in the specialty. Interact Cardiovasc Thorac Surg. 2016;22(October 2015):106-108. doi:10.1093/icvts/ivv280.

38. Tesche LJ, Feins RH, Dedmon MM, et al. Simulation Experience Enhances Medical Students ' Interest in Cardiothoracic Surgery. Ann Thorac Surg. 2010;90(6):1967-1974. doi:10.1016/j.athoracsur.2010.06.117.

39. Billett S. Subjectivity, Self and Personal Agency in Learning Through and for Work. In: Malloch M, Cairs L, Evans E, O'Connor B, eds. The Sage Handbook of Workplace Learning. 1st ed. London: Sage Publications Inc.; 2011:52-62.

40. Spooner S, Pearson E, Gibson J, Checkland K. How do workplaces, working practices and colleagues affect UK doctors' career decisions? A qualitative study of junior doctors' career decision making in the UK. BMJ Open. 2017; $018462 .: 1-9$. doi:10.1136/bmjopen-2017-018462.

41. Rohlfing J, Navarro R, Maniya OZ, Hughes BD, Rogalsky DK. Medical student debt and major life choices other than specialty. Med Educ Online. 2014;11(19):1-10.

42. Verstappen A, Poole P. Rising levels of New Zealand medical student debt. $N Z$ Med J. 2017;130(1457):38-44.

43. Hoff R, Imhof S, Frenkel F, ten Cate OTJ. Flexibility in Postgraduate Medical Training in the Netherlands. Acad Med. 2018;93(3):S33-6.

44. Advisory Committee on Medical Manpower Planning. The 2013 Recommendations for Medical Specialist Training [in Dutch]. Utrecht; 2013.

https://capaciteitsorgaan.nl/app/uploads/2016/01/DEFINITIEF-2013-hoofdrapportengels-compl.pdf.

45. Advisory Committee on Medical Manpower Planning. The 2016 Recommendations for Medical Specialist Training [in Dutch]. Utrecht; 2016.

https://capaciteitsorgaan.nl/app/uploads/2016/10/2016_10_21-Revisie-3.0-

Capaciteitsplan-2016-Hoofdrapport-DEFINITIEF.pdf. 



\section{Chapter 4}

The Significance of Experiencing Clinical Responsibilities for Specialty Career Choice

Sophie Querido Marlies de Rond Lode Wigersma Sjoukje van den Broek Olle ten Cate

Published as:

The Significance of Experiencing Clinical Responsibilities for Specialty Career Choice.

Medical Science Educator 2019. doi: 10.1007/s40670-019-00832-z 
- Chapter 4

\begin{abstract}
Aim

Medical trainees make career choices in the final year of medical school or after graduation, if they do not continue with residency directly. Most Dutch medical students are trained in vertically integrated (VI) curricula, with early clinical experience and a gradual increase in clinical responsibilities. Students in such curricula have been reported to make career choices at an earlier stage than graduates from more traditionally designed curricula. Many Dutch graduates build further clinical experience after graduation as physicians-not-in-training (PNITs) before beginning residency. We explored how students make career choices, and whether pre-residency clinical responsibilities influence this choice.
\end{abstract}

\title{
Method
}

A qualitative study with a phenomenology approach was used. The authors conducted a longitudinal interview study of medical students with two intervals over a 2-year period. The interview questions covered how trainees establish career preferences and which factors affect preference and choice over time.

\section{Results}

Experiencing clinical responsibility was a key factor for career preference during all interview rounds. Being a PNIT who makes diagnostic and therapeutic decisions, having their own patients and have significant patient care responsibilities creates opportunities to build an image of a future context of employment. Some participants mentioned that their experience of having full responsibility as a PNIT was pivotal in a career preference change.

\section{Conclusion}

Clinical responsibility as a student or a PNIT appears to be important for career preference and choice. The experience of responsibility as a medical doctor forces trainees to reflect on personal needs and to consider which career preference fits best. 


\section{Introduction}

Medical trainees need to make an important career choice about a specialty when they face the transition from medical school to residency. When they feel urged to make this choice depends on the structure and length of medical training in the country. ${ }^{1}$

In the Netherlands, the duration of undergraduate medical education is usually 6 years and includes 2 to 4 years of clerkships. Most students are admitted directly from secondary school. ${ }^{2}$ After graduation, the medical graduate can either do temporary supervised clinical work before residency as a so-called physician-not-in-training (PNIT), start a PhD trajectory or start residency directly. ${ }^{1-5}$ Many of the Dutch medical graduates choose PNIT work experience in one or more specialties before residency to make a thoughtful specialty decision. ${ }^{4}$ In the United Kingdom (UK) all junior doctors have a 2 year foundation training after medical school and choose a specialty in the second year, which is at least 18 months after finishing medical school. ${ }^{1}$ Many UK junior doctors consider this period too short to make a well-founded career choice, because of insufficient clinical experience. ${ }^{6}$

Worldwide, graduates have preferences for popular specialties, such as surgery, gynaecology and dermatology, while other specialties show a shortage of interest including psychiatry and primary care..$^{7-10}$ Dutch graduates apply for a residency in an open job market system, rather than a national matching model; many preferences focus on a limited number of popular specialties, with a consequent shortage of available positions. Dutch graduates usually take an interval period of months up to a year (or even longer) to gain clinical or research experience, often to optimize chances of being selected, especially for popular specialties. ${ }^{2-5}$ This, in turn, allows programs to raise acceptance criteria, in a self-reinforcing process that further increases the interval between undergraduate and postgraduate training as graduates need time to meet these criteria. Throughout the year, approximately 2400 Dutch medical students graduate and become eligible to start residency. ${ }^{11,12}$ Graduates who do not start postgraduate medical training directly can roughly be categorized in three groups: (1) those serving in patient care to gain clinical experience as a physician; we will categorize them as 'physiciansnot-in-training' (PNITs). This group is approximately 3736 physicians $^{4}$; (2) those starting or completing a $\mathrm{PhD}$ trajectory, often in a direction aligning with their specialty preference. This group is approximately 1366 physicians $^{4}$; and (3) those employed in a non-clinical area. This group is approximately 412 physicians. ${ }^{4}$ There is no nationally coordinated placement, and most of the physicians start residency after a period of experience as a PNIT or PhD student. ${ }^{4}$ This is quite a usual pathway for Dutch graduates. 
In the period between 1975 and 2000, all Dutch medical schools have gradually developed integrated curricula, both horizontally, i.e. among the basic sciences, and vertically, intertwining clinical topics and experiences with basic sciences. Vertical integration includes a gradual increase in clinical responsibilities. ${ }^{13}$ An important feature of vertical integration is that clinical experience, such as clerkships, is offered early in the program. ${ }^{2,13,14}$

Another feature is that students are given increased responsibilities in patient care, especially in the final year of medical school. ${ }^{15-18}$ Students in most final program years of Dutch medical curricula (the 'transitional year') are called 'semi-physicians' -not students- and must do clinical ward work at the level of a junior resident, with a limited number of patients and adequate supervision. ${ }^{2,19-21}$ A survey study among graduates of two cohorts, one from traditional and the other from vertically integrated curricula, showed that graduates from the latter had made the definite career choice at an earlier stage and needed less time and fewer applications to obtain a residency position than those from the traditional, less vertically integrated, curricula ${ }^{21}$. This study did not, however, provide insight into the factors determining this positive effect of early career choice in vertically integrated curricula. In our study, we aimed to explore how students from vertically integrated curricula develop career preferences and make their career choice and whether additional pre-residency clinical experiences and increased responsibilities influence this choice.

\section{Method}

\section{Methodology}

To appreciate the development of career preferences and career choice over time, we designed a longitudinal interview study. Longitudinal research can provide a deeper understanding of how medical students develop a career preference over time and which factors influence career preference. There is a paucity of longitudinal studies focusing on the preference for medical specialties in general. The only longitudinal studies to date are specialty specific and are focused on primary care ${ }^{10}$ and surgery. ${ }^{22}$ Other longitudinal research focuses on student interest but lacks explanation of the changes of interest and uses written surveys. ${ }^{23-25}$ One recent longitudinal study performed in the UK found that when considering groups of specialties, two thirds of graduates had a stable specialty preference since year 4 of medical school. Specialty choice was reported to be strongly influenced by experiences within the specialty at medical school and during the two foundation years. ${ }^{6}$ However, the UK medical education structure differs from that of other countries, such as the Netherlands ${ }^{1}$, and therefore, more research is required. 
We conducted this longitudinal, interview-based qualitative study to gain insight into the influence of clinical responsibility on the career preference and career choice at three different moments. ${ }^{26}$ We used a phenomenological approach, as this allows for interpretation of data, extraction of meaning and understanding of data to develop deeper understanding of the concept. Phenomenology attempts to understand how individuals construct meaning from their experiences through the perception of events. ${ }^{27,28}$

\section{Context}

The study was conducted at University Medical Center Utrecht (UMC Utrecht), the Netherlands. The final year of the Utrecht curriculum is called transitional year and contains elective options and extended clerkships in which students work with increased clinical responsibilities as compared to earlier clerkships. ${ }^{16,19}$ Medical students can enter the transitional year at different times throughout the year, because of delays for any reason during previous study years. The final-year medical student as a semi-physician, can be compared to a foundation doctor in the UK system or a sub-intern or intern in the US system $^{1}$. In this final phase, medical students must consider career preferences, to enable choice in the mostly elective final-year program. We deliberately chose participants for our study from this curricular context as they explicitly have the opportunity to work with increased responsibilities in clinical practice during medical school plus one following year and consider their career choice. ${ }^{2,20}$

\section{Participants}

We interviewed the same participants three times over a 2-year period. We chose to plan the first interview at the start of the transitional year, when medical students have the possibility and are encouraged- to arrange the electives in this year according to their career preference. The second interview was at the end of the transitional year, to explore the impact of this year. The third interview was planned 1 year after graduation, to compare differences in career preference between the medical student perspective and the perspective of the recently graduated physician and explore factors that affect career choice. Dutch students at UMC Utrecht can enter the transitional year at several moments during the academic year. We invited students from one cohort initially during teaching sessions in May and October 2014. All students were also sent an information e-mail and a possibility to sign up. After 1 week, a reminder was sent to all non-responders. We used convenience sampling with the following criteria: being a medical student at Utrecht University at the start of the transitional year of the 
- Chapter 4

curriculum during the first round of data collection for this study. No new students were invited in the second and third rounds.

\section{Instrument}

The interview questions were based on what is known from the literature. ${ }^{29,30}$ The first interview guide was piloted with six transitional-year students, and was refined prior to implementation in agreement with all researchers. The second and third interview guides were adapted from the first guide in alignment with all researchers. Table 1 presents all three interview guides. 
Table 1 Interview questions

\begin{tabular}{|c|c|c|}
\hline $\begin{array}{l}\text { Start of the final year of } \\
\text { medical school } \\
\text { (interview 1) }\end{array}$ & $\begin{array}{l}\text { End of the final year of } \\
\text { medical school } \\
\text { (interview 2) }\end{array}$ & $\begin{array}{l}1 \text { year after graduation } \\
\text { (interview 3) }\end{array}$ \\
\hline $\begin{array}{l}\text { Why did you choose to } \\
\text { study medicine? } \\
\text { 2) What are your career } \\
\text { preferences? Can you } \\
\text { explain for each of these } \\
\text { why and since when? } \\
\text { 3) How familiar are you } \\
\text { with these preferences? } \\
\text { And what have you done } \\
\text { to become familiar with } \\
\text { them? } \\
\text { 4) What is the opinion of } \\
\text { your family, friends or } \\
\text { others about your career } \\
\text { preference? And what } \\
\text { does that opinion mean } \\
\text { to you? } \\
\text { 5) Which were your } \\
\text { electives during the } \\
\text { transitional year and why } \\
\text { did you choose these? } \\
\text { 6) Tell me your strategy to } \\
\text { get into the residency of } \\
\text { your choice } \\
\text { 7) What would be your } \\
\text { definite choice just for } \\
\text { the upcoming five } \\
\text { minutes? } \\
\text { 8) What else do you want } \\
\text { to tell me about your } \\
\text { career } \\
\text { preferences/choice? }\end{array}$ & $\begin{array}{l}\text { 1) What are your career } \\
\text { preferences? Can you } \\
\text { explain for each of these } \\
\text { why and since when? } \\
\text { 2) How familiar are you } \\
\text { with these preferences? } \\
\text { And what have you done } \\
\text { to become familiar with } \\
\text { them? } \\
\text { 3) Can you reflect on your } \\
\text { transitional year? } \\
\text { 4) What is the opinion of } \\
\text { your family, friends or } \\
\text { others about your career } \\
\text { preference? And what } \\
\text { does that opinion mean } \\
\text { to you? } \\
\text { 5) Tell me your strategy to } \\
\text { get into the residency of } \\
\text { your choice } \\
\text { 6) Did any changes occur in } \\
\text { your life of influence on } \\
\text { your career preference } \\
\text { over the last year? } \\
\text { 7) What would be your } \\
\text { definite choice just for } \\
\text { the upcoming five } \\
\text { minutes? } \\
\text { 8) What else do you want } \\
\text { to tell me about your } \\
\text { career } \\
\text { preferences/choice? }\end{array}$ & $\begin{array}{l}\text { What are your career } \\
\text { preferences? Can you } \\
\text { explain for each of these } \\
\text { why and since when? } \\
\text { 2) How familiar are you } \\
\text { with these preferences? } \\
\text { And what have you done } \\
\text { to become familiar with } \\
\text { them? } \\
\text { 3) Can you reflect on the } \\
\text { last year after } \\
\text { graduation? } \\
\text { 4) Are you working? And } \\
\text { does reality matches } \\
\text { your expectations? } \\
\text { 5) What is the opinion of } \\
\text { your family, friends or } \\
\text { others about your career } \\
\text { preference? And what } \\
\text { does that opinion mean } \\
\text { to you? } \\
\text { 6) Tell me your strategy to } \\
\text { get into the residency of } \\
\text { your choice or how did } \\
\text { you got your position? } \\
\text { 7) Did any changes occur in } \\
\text { your life of influence on } \\
\text { your career preference } \\
\text { over the last year? } \\
\text { 8) What would be your } \\
\text { definite choice just for } \\
\text { the upcoming five } \\
\text { minutes? } \\
\text { 9) What will be your } \\
\text { preference / career in } 1.5 \\
\text { years from now? } \\
\text { 10) What else do you want } \\
\text { to tell me about your } \\
\text { career } \\
\text { preferences/choice? }\end{array}$ \\
\hline
\end{tabular}


Elaboration was encouraged, using follow-up questions about experiences influencing career preferences. To protect the participants' privacy, all were asked to choose a pseudonym and to retain this for each interview that was used during further analysis. Original names were only known to the interviewers and were not used during analyses.

\section{Data collection}

We conducted semi-structured, in-depth interviews in a quiet studio at UMC Utrecht to stimulate respondents to mention all aspects that arose without constrictions of a predetermined questionnaire. The interviews were performed face to face by one of two researchers (SQ and SB) at UMC Utrecht, except for some third interviews performed at the participant's home or through Skype ${ }^{\circledR}$. The first three interviews at the start of the final year of medical school were conducted jointly by both researchers, to ensure consistency of interviewing. All interviews were audio recorded. During the interviews, field notes were made for the purpose of reference. Member checking was performed by sharing written summaries of each interview with the participant, with the request to check for accuracy and completeness. During follow-up interviews, participants were not provided with their answers in previous interviews, in order to assure that participants would not justify or adapt their answers based on previously given information.

\section{Data analysis}

Following a qualitative research methodology, data analysis was performed according to recently suggested standards for reporting qualitative research. ${ }^{26,28,31-33}$ The interviews were transcribed verbatim using a transcription company with participants' personal data being deidentified. Two researchers (SQ and SB) first familiarized themselves with the transcripts by multiple readings of the transcripts and checking audio recordings. Next, transcripts were first coded line by line, meaning we identified relevant text passages in the interview transcripts and assigned themes to these data units. Then, these themes were merged in a codebook. The selection of the unit of analysis involved coding for all single factors of influence mentioned by the participants and also coding their career preferences. Coding for these units was performed by reading the transcripts multiple times. For these codes, we (SQ, SB, MdR) created labels that described the essence of the themes. With this process, we identified elements that were similar. This led to an understanding of the variety of factors and the frequency with which they were mentioned. This set of themes could be used for description and interpretation of the phenomenon..$^{28,31}$ 
For analytical rigour, multiple interviews were coded by three researchers (SQ, SB and MdR). A codebook was developed based on the first interview round and was then discussed with the research team before all data were coded. The codebook was adapted throughout the coding of interview rounds 2 and 3 as needed. We assumed saturation within this sample, when no new insights and no new codes appeared and when the relationships between categories were well established. ${ }^{31,32}$ Researchers (SQ with SB and SQ with MdR) had several meetings to compare their findings of coding and themes, and differences were resolved through discussion. The final codebook and themes were discussed with all research members. All researchers met over several meetings to discuss the coding and analysis. This allowed for alignment of the researchers' individual interpretations and enhanced reflection, to increase credibility in the content and interpretations of the data. ${ }^{34}$

Data analysis started after all the interviews had taken place, and was further refined in an iterative process with constant comparison and revision of earlier interpretations and developing new themes if needed. ${ }^{31,35}$ Themes emerge naturally from the data rather than being imposed.

\section{Reflexivity}

Reflexivity in qualitative research is a researcher's ongoing reflection on possible personal biases and being accountable in reporting results. ${ }^{35} \mathrm{SQ}$ who had no medical background but had knowledge about career options, curricula and the theoretical framework was assigned the role of a researcher with an outsider approach. SB acted as a researcher with an insider approach based on her medical background, her knowledge of the Utrecht medical education program and her recent personal experience herself with medical career choice. This insider/outsider status of the researchers allowed us to understand and interpret the data and to independently perform coding, discuss and resolve any discrepancies. MdR played the role of an outsider based on her knowledge about theoretical frameworks and conducting academic research in general. LW, a family physician by training, fulfilled an insider approach as well as $\mathrm{OtC}$, being a professor of medical education. To maintain reflexivity, the final phases of analyses involved discussions with the larger study team consisting of a mix of insider/outsider approaches and having theoretical knowledge to provide additional perspectives for interpretation. Data analysis continued by importing all data by one researcher $(\mathrm{SQ})$ in a qualitative software application Dedoose ${ }^{\circledR}{ }^{36}$ 
The study was approved by the Netherlands Association for Medical Education Ethical Review Board. The participants were informed that participation was voluntary, that confidentiality was secured and that non-participation would not be held against them. They could withdraw from the study at any time without giving a reason. Written informed consent was obtained from all the participants.

\section{Results}

The teaching sessions in the first weeks of study year 6 were attended by a total of 67 medical students. A total of 26 students signed up for participation, 24 of whom were able to schedule a first interview and participated. The second interview series involved 22 of these participants and the third interview series 20 . We did not know the reasons for withdrawal by those students who failed to participate in the second and third interview processes. One student was able to attend the third interview but skipped the second interview due to medical school-related scheduling conflicts. All 24 first and 22 second interviews were all performed at UMC Utrecht. Of the 20 third interviews, 5 were performed at the participant's home and 4 through Skype ${ }^{\circledR}$ or telephone, and 11 were performed at UMC Utrecht. One of the first interview series failed to be recorded due to technical problems, yielding 23 interview transcripts. One of the second interview series failed to be recorded due to technical problems, yielding 21 interview transcripts. Of both interviews, field notes and a member check were available.

Member-checking of written interview summaries ${ }^{37}$ did not lead to essential changes; five participants made minor textual changes in the first round. For the second interview round 2 participants made minor changes and for the third round 3 participants did. Participants at the first interview ranged in age from 23 to 26 and included 20 women and 4 men. The second and third interviews included 19 women and 3 men, and 16 women and 4 men respectively. Some had partners, but there were no married or divorced students; none had children.

The first interview was conducted at the start of the final study year and all 24 participants were still attending medical school. The second interview was in the weeks before graduation. There were 22 participants, and they were all still medical students. Nine were looking for a job as a PNIT, and four already had the prospect of starting as a PNIT, a total of 13. Three could start residency, three with $\mathrm{PhD}$ training, and for three it was unknown. At the third interview, there were 20 participants and all of them had graduated. Fifteen had a PNIT position, and two had the perspective of starting residency training within 2 months. One had 
a residency position, three had started a PhD-trajectory and one was unemployed, see Table 2 . Participants with a PhD position do not work in a clinical setting and could therefore not mention the impact of responsibility for patient care or professional actions on their career choice. We excluded these three from further analyses.

Nineteen participants completed all three interviews, twenty-two participants participated in interviews 1 and 2 only and one participant participated in interviews 1 and 3 only.

Table 2 Background and number of participants at the time of the interview

\begin{tabular}{|l|c|c|c|}
\hline $\begin{array}{l}\text { Interview } \\
\text { moment }\end{array}$ & $\begin{array}{c}\text { Beginning of } \\
\text { transitional } \\
\text { year } \\
\text { (interview 1) }\end{array}$ & $\begin{array}{c}\text { End of } \\
\text { transitional } \\
\text { year } \\
\text { (interview 2) }\end{array}$ & $\begin{array}{c}\text { 1 year after } \\
\text { graduation } \\
\text { (interview 3) }\end{array}$ \\
\hline In medical school & 24 & 0 & 0 \\
\hline In a PNIT position* & 0 & 13 & 15 \\
\hline In residency training & 0 & 3 & 1 \\
\hline In PhD training & 0 & 3 & 3 \\
\hline Unemployed / unknown & 0 & 3 & 1 \\
\hline Total & 24 & 22 & 20 \\
\hline
\end{tabular}

* PNIT: physician-not-in-training position doing clinical work

In Figure 1 an overview of the different career paths of the study population as also the interview moments are illustrated by the spotted lines. This overview does not cover all possible pathways, as graduates can choose different paths and even can change. We indicated the most common paths, in a schematic fashion. 
Figure 1 Flowchart of common career paths and times of the interviews (dotted lines)

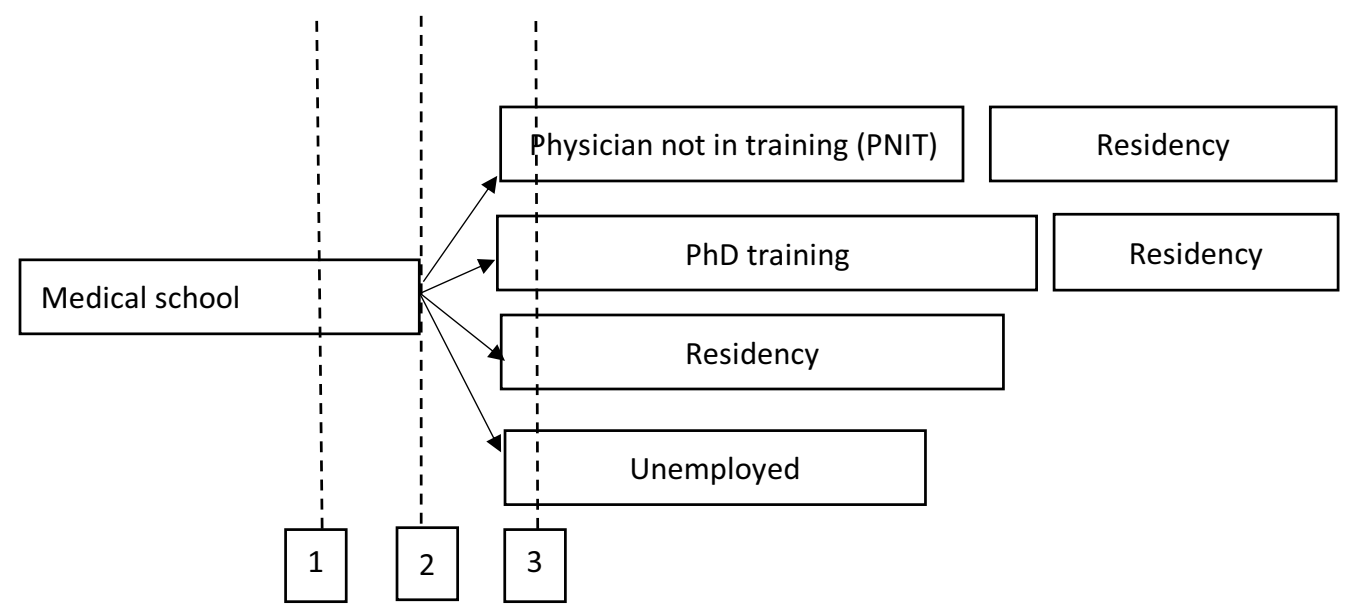

\section{Career preferences and choice}

During all three interview rounds, the participants were asked for their career preferences or choice. All participants mentioned their top list of career preferences, ranging from two to five. Two thirds of all participants $(\mathrm{N}=17)$ changed the rank order of their preferences during the interview rounds. Six participants mentioned career preferences they did not had before in interview three, when they had some experiences as a PNIT. Experiencing responsibilities in patient care was a dominant factor that contributed to the sequence of the top list of career preferences. In the examples below, we explain this further.

\section{Responsibility as a doctor}

In the interviews, several participants mentioned the dominance of (clinical) responsibility impacting career preference. They explained needing this experience to feel more "certain of their own actions", to get "more knowledge and experience as a real doctor" and "to experience working in the context of their specialty of preference" to confirm their career preference, as illustrated in three sequential interviews with a female participant (no.16).

Interview 1: "I did an extra clerkship gynaecology in Africa. In this clerkship, I was allowed to see and participate more, and maybe that is where my career preference was initiated. I thought: this is something I like. 
Why? Because you are allowed to see and perform a lot and that is how you develop more knowledge. It makes you more secure in a specific specialty. And when you know it better, you start liking it more".

Interview 2: "I got more responsibilities this final year clerkship gynaecology and they took me more seriously. I could perform so much, with the responsible doctor just next to me. I learned so much in this final study year, I think I can perform as a doctor".

Interview 3: "The real work is really something different from what you have seen during your clerkships. In a clerkship, I already felt I had a lot of responsibility and I thought oh yes, I am really in control. But at the end of the day, there is always someone else who makes the decisions. And now, of course, there is still the gynaecologist, and you always consult him. But, I am the doctor now and I have to make acute decisions myself. My career preference is still gynaecology. This year [as a PNIT] I did so much, this confirmed my interest again. In two months, I will start an ObGyn residency and I am really happy about it".

In the second interview series, participants explained that their insecurity had decreased, due to their responsibility such as performing the full tasks in patient consultations as a semiphysician. These experiences as 'almost a doctor' supported them in gaining insight into what it means to perform as a doctor and what it means to be working as a doctor in specific specialty. Several of the participants also mentioned that they looked forward to working as a PNIT and to experience responsibility for patients and activities and to be more certain of their career choice.

On the third interview, they reflected on being a PNIT and how this resulted in having the full responsibilities of a doctor. They had to make medical decisions, they had to collaborate with and instruct other nursing professionals, and they were in charge of threating and caring for patients. The subsequent interviews with a female participant (no. 8) illustrate this.

Interview 1: "If someone calls me a doctor, then I think no I am not a doctor at all. I can't imagine that I will be a doctor in one year from now".

Interview 2: "During my clerkship psychiatry, I just got so enthusiastic about everything I did. I like it when patients share their story and that I can help them. Later they came back to say that my suggestions had helped. Maybe that is an idealized view of psychiatry, and that is why I need to experience how psychiatry will be if I work there as a PNIT"'. 
Interview 3: "The difference between being a semi-physician and PNIT is huge. I felt much more responsible. The patients and colleagues expected so much more from me. Also, the shifts were stressful, sleeping with the beeper that can buzz any moment. I wanted to be a psychiatrist, but after my PNIT period I experienced what this specialty really is about and I miss the somatic part patient care. I returned to my preference for general practice”.

We analyzed to what extent additional pre-residency clinical experience and increased responsibilities had affected career choice. In the interviews, the participants explained how responsibilities in patient care, such as autonomously conducting patient consultations and assisting in medical practice, prescribing medicine, collaborating with medical staff and negotiating with families, provided a realistic view of the specialty. For some participants, it was a confirmation of their earlier career preference; for others, the PNIT experience turned out to be disappointing and led them to reconsider their career preference. Of the 15 participants with a PNIT experience, 7 changed their first preference after their experiences as a PNIT. One reason to shift preference was that reality did not match the expected image of the specialty. The opposite also occurred; by gaining more experience within an (unknown) specialty, it could turn out to be more interesting than expected. Interviews with a female participant (no.12) illustrate this.

Interview 1: "I had a clerkship in family medicine in year 5 and this was a good experience, but I would like to have confirmation that this is really my career choice. That is why a want to go for a family medicine clerkship".

Interview 2: "My family medicine clerkship was in a small practice with just one general practitioner. I was allowed to perform a lot by myself and it gave me a good insight into a regular day in practice. It confirmed that I really like this specialty”. During her clerkship internal medicine, she experienced more responsibility: "Before I started I was excited and anxious, because I felt I needed to know a lot, you have to bring a lot of knowledge. And, for me that was exciting... but it went really well. That was really positive and maybe it is a cliché, but I thought: I noticed during my clerkship that I am ready for the next step as a PNIT. I hope to become more of a real physician. It is like getting your driving license. You are allowed to drive, but you still have to learn to drive". 
Interview 3: "When I graduated I thought of specializing in family medicine, but I wanted to gain more experience. I started working as a PNIT in geriatrics. I got caught by this specialty. I cannot pinpoint any single moment or occasion how this happened, but the whole experience of working and having the responsibility [in geriatrics] turned out very successful and enjoyable”.

\section{Discussion}

We conducted a longitudinal, interview-based study to explore how students from a vertically integrated curriculum make career choices and whether the phenomenon of pre-residency clinical experiences and increased responsibilities influence this choice.

Our data reveal the importance of responsibility, both when being a medical student and as a PNIT. This responsibility is not confined to any particular specialty and encompasses a realistic experience of becoming and being a physician. This experience encourages the medical student and graduate to reflect on their actions and to translate these reflections into their preferences. With the presence of this phenomenon of 'responsibility', a medical student's or a PNIT's perception of a specialty is confirmed or changes. The student or PNIT is forced to reflect, (re)consider and possibly adjust their personal career preference. The underlying process of career choice is stimulated by these iterative reflections. This supports the validity of Bland's model of career choice. ${ }^{29}$ This model postulates that the process of choice is essentially a balance between expected future career needs and the perception of the characteristics of a specialty. The stronger the perceived similarity, the stronger the desire for this specialty as a career choice. ${ }^{29}$ To achieve a balance between the needs and perceived specialty characteristics, students must actively reflect to establish a career preference(s). We argue that students, and particularly recent graduates, use experience of responsibility to calibrate their perceptions of different specialties' characteristics with current and future personal needs.

The extent to which responsibility is present in the several phases, in which we interviewed the participants, differs. During medical school, students, even with quite some responsibility, are still limited in their performance as a doctor. Early clerkships enable medical students to experience their chosen profession, helping them to reflect on whether they have chosen the right study. ${ }^{38}$ The Dutch medical curricula have evolved, roughly since the turn of the millennium, in a vertically integrated direction ${ }^{2}$, not only by planning early clinical experiences ${ }^{38}$, but also by creating affordances in the clinical workplace that stress increased responsibility in the higher years ${ }^{15,18,20}$, such as semi-physician rotations and 
-recently- the introduction, in some programs, of entrustable professional activities. ${ }^{39}$ Our results also show that a clerkship that enables the medical student to work with more responsibility under supervision stimulates him or her to find a balance between the future career needs and the best match with a career preference. We found that pre-residency responsibilities enable medical students to reflect on their career preference in a timely manner. The effect of carrying responsibility is that the graduates can make a well-considered career choice. Not only pre-residency responsibility but also continuing and increased responsibility add to a thoughtful career consideration process. We found that particularly working as a PNIT had a strong effect on career preference considerations. Seven of the 15 graduates who had work experience as a PNIT changed their career choice because of these experiences. Therefore, we should stimulate that final-year students and graduates experience more into the field of the unpopular specialties and get more excited about these specialties. This could lead to a more balanced allocating of the available residency positions. This indicates the relevance of the PNIT period and the effect it can have on the final career choice, supporting the similar findings of Woolf and colleagues. ${ }^{6}$ These were limited to the UK, but with our results we support these statements and think they can be used for countries with different educational systems.

The final career choice is partly based on the experience of independently working as a doctor with responsibility for self-determined actions and patient care. This implies that a medical educational system starting with pre-residency clinical experience and subsequent increase of responsibility during undergraduate training enhances a thoughtful career preference development. Next, graduates significantly benefit from the advantages of working as a PNIT. With this experience as a PNIT, career preference becomes clearer. The difference between the medical student and the PNIT is the license to practice and therefore the level of responsibility for patient care. 


\section{Conclusion}

In our study, the responsibility to work as a physician, i.e. being more self-directed than as a medical student, before postgraduate training, appears to significantly affect career choice. Practicing with responsibility as a PNIT provides one's realistic view on work impact and one's reflection of their future self-image and therefore enables to match with their career preference and to make their career choice.

\section{Strengths and limitations of this study}

This study was performed in the context of one Dutch medical school. Other schools and particularly other countries may show different results. The proportion of female students in Dutch medical schools $(65 \%)^{10,40}$ is lower than that in our study population (83\%) which could have caused a bias in the data. Previous research shows that men and women differ in the motivational factors that are associated with specialty preference, regarding part-time work, status and salary. ${ }^{41,42}$ Nevertheless, the stories of the male students in our study showed similar experiences with clinical responsibility and the importance for their career choice. Future research, particularly quantitative with a large sample, is needed to substantiate our results to counteract to the physician workforce of today. 


\section{References}

1. Wijnen-Meijer M, Burdick W, Alofs L, Burgers C, ten Cate O. Stages and transitions in medical education around the world: clarifying structures and terminology. Med Teach. 2013;35(4):301-307.

2. Ten Cate O. Medical education in The Netherlands. Med Teach. 2007;29(8):752-757.

3. Hoff R, Imhof S, Frenkel F, ten Cate OTJ. Flexibility in Postgraduate Medical Training in the Netherlands. Acad Med. 2018;93(3):S33-6.

4. Van der Velde F, Wierenga M. Loopbanen En Loopbaanwensen van Basisartsen. Herhaling van Het Onderzoek Onder Basisartsen 2009 en 2012 [in Dutch]. Utrecht. KIWA; 2016.

5. van der Vleuten C, Scherpbier A. AM Last Page: medical education in the Netherlands. Acad Med. 2009;84(7):973.

6. Woolf K, Elton C, Newport M. The specialty choices of graduates from Brighton and Sussex Medical School: a longitudinal cohort study. BMC Med Educ. 2015;15:46.

7. Andlauer O, Guicherd W, Haffen E, et al. Factors influencing french medical students towards a career in psychiatry. Psychiatr Danub. 2012;24(SUPPL. 1):185-190.

8. Baller FE, Ludwig K V, Kinas-Gnadt Olivares CL, Graef-Calliess I-T. Exploring the ideas and expectations of German medical students towards career choices and the speciality of psychiatry. Int Rev Psychiatry. 2013;25(4):425-430. doi:10.3109/09540261.2013.823384.

9. Hou J, Xu M, Kolars JC, et al. Career preferences of graduating medical students in China: a nationwide cross-sectional study. BMC Med Educ. 2016;16(1):136. doi:10.1186/s12909-016-0658-5.

10. Pfarrwaller E, Sommer J, Chung C, et al. Impact of Interventions to Increase the Proportion of Medical Students Choosing a Primary Care Career: A Systematic Review. J Gen Intern Med. 2015;30(9):1349-1358.

11. Advisory Committee on Medical Manpower Planning. The 2016 Recommendations for Medical Specialist Training [in Dutch]. Utrecht; 2016. https://capaciteitsorgaan.nl/app/uploads/2016/10/2016_10_21-Revisie-3.0Capaciteitsplan-2016-Hoofdrapport-DEFINITIEF.pdf.

12. Advisory Committee on Medical Manpower Planning [in Dutch]. Personal communication with director V. Slenter. Presented at the: 2017.

13. Wijnen-Meijer M. Readiness for clinical practice - Studies about transitions in medical education, the influence of vertically integrated curricula and the assessment of readiness for practice [doctoral dissertation]. 2012.

14. Dornan T, Bundy C. What can experience add to early medical education? Consensus survey. BMJ. 2004;329(9):1-6.

15. Jonker G, Hoff RG, Max S, Kalkman CJ, ten Cate O. Connecting undergraduate and postgraduate medical education through an elective EPA-based transitional year in acute care: an early project report. GMS J Med Educ. 2017;34(5):1-6.

16. ten Cate OTJ, Borleffs JCC, Van Dijk M, Westerveld T. Training Medical Students for the 21st Century: Rationale and Development of the Utrecht Curricullum "CRU+." Med Teach. 2018;40(5):461-466. 
17. Wijnen-Meijer M, ten Cate O, van der Schaaf M, Harendza S. Graduates from vertically integrated curricula. Clin Teach. 2013;10(3):155-159. doi:10.1111/tct.12022.

18. Wijnen-Meijer M, Ten Cate O, Van Der Schaaf M, Burgers C, Borleffs J, Harendza S. Vertically integrated medical education and the readiness for practice of graduates. BMC Med Educ. 2015;15(1):1-9. doi:10.1186/s12909-015-0514-z.

19. van den Broek WES, Wijnen-Meijer M, Ten Cate O, van Dijk M. Medical students preparation for the transition to postgraduate training through final year elective rotations. GMS J Med Educ. 2017;34(5):Doc65.

20. Wijnen-Meijer M, Ten Cate OTJ, Van Der Schaaf M, Borleffs JCC. Vertical integration in medical school: Effect on the transition to postgraduate training. Med Educ. 2010;44(3):272-279. doi:10.1111/j.1365-2923.2009.03571.x.

21. Wijnen-Meijer M, Cate OTJ Ten, Rademakers JJDJM, Van Der Schaaf M, Borleffs JCC. The influence of a vertically integrated curriculum on the transition to postgraduate training. Med Teach. 2009;31(March):e528-e532.

22. Goldin SB, Schnaus MJ, Horn G, et al. Surgical interest and surgical match for thirdyear students: Results of a prospective multivariate longitudinal cohort study. J Am Coll Surg. 2012;215(5):599-606.

23. Compton MT, Frank E, Elon L, Carrera J. Changes in U.S. Medical Students ' Specialty Interests over the Course of Medical School. J Gen Intern Med. 2008;23(7):1095-1100.

24. Goldacre MJ, Laxton L, Lambert TW. Medical graduates' early career choices of specialty and their eventual specialty destinations: UK prospective cohort studies. $B M J$. 2010;340(c3199):1-9.

25. Maudsley G, Williams L, Taylor D, Maudsley G, Williams LYN, Taylor D. Medical students' and prospective medical students' uncertainties about career intentions: Cross-sectional and longitudinal studies. 2010;32(3):e143-e151.

26. Balmer DF, Richards BF. Longitudinal qualitative research in medical education. Perspect Med Educ. 2017;6(5):306-310.

27. Husserl E. Ideas: General Introduction to Pure Phenomenology. New York: Collier Books; 1962.

28. Swanwick T. Understanding Medical Education: Evidence, Theory and Practice.; 2014.

29. Bland C, Meurer L, Maldona G. Determinants of primary care specialty choice; A nonstatistical meta-analysis of the literature. 1995:70(7):620-641.

30. Querido SJ, Vergouw D, Wigersma L, Batenburg RS, De Rond MEJ, Ten Cate OTJ. Dynamics of career choice among students in undergraduate medical courses. A BEME systematic review: BEME Guide No. 33. Med Teach. 2015;38(1):18-29. doi:10.3109/0142159X.2015.1074990.

31. Creswell JW. Research Design: Qualitative, Quantitative, and Mixed Methods Approaches. Fourth. Michigan: Sage Publications Inc.; 2014.

32. Miles MB, Huberman M a, Saldana J. Qualitative Data Analysis. A Methods Sourcebook. 3rd ed. Arizona: Sage Publications Inc.; 2014. 
- Chapter 4

33. O'Brien BC, Harris IB, Beckman TJ, Reed DA, Cook DA. Standards for reporting qualitative research: A synthesis of recommendations. Acad Med. 2014;89(9):12451251.

34. Cook DA, Kuper A, Hatala R, Ginsburg S. When Assessment Data Are Words. Acad Med. 2016;XX(X):1-11.

35. Malterud K. Qualitative research: Standards, challenges, and guidelines. Lancet. 2001;358(9280):483-488.

36. SocioCultural Research Consultants L. Dedoose, version, 7.0.23. web application for managing, analyzing, and presenting qualitative and mixed method research data. 2016. www.dedoose.com.

37. Tavakol M, Sandars J. Quantitative and qualitative methods in medical education research: AMEE Guide No 90: Part II. Med Teach. 2014;44(90):1-11.

38. Kamalski DMA, Ter Braak EWMT, Ten Cate OTHJ, Borleffs JCC. Early clerkships. Med Teach. 2007;29(9):915-920.

39. ten Cate O, Graafmans L, Posthumus I, Welink L, van Dijk M. The EPA-based Utrecht undergraduate clinical curriculum: Development and implementation. Med Teach. 2018;40(5):506-513. doi:10.1080/0142159X.2018.1435856.

40. Advisory Committee on Medical Manpower Planning. The 2013 Recommendations for Medical Specialist Training [in Dutch]. Utrecht; 2013. https:/capaciteitsorgaan.nl/app/uploads/2016/01/DEFINITIEF-2013-hoofdrapportengels-compl.pdf.

41. Diderichsen S, Johansson EE, Verdonk P, Lagro-Janssen T, Hamberg K. Few gender differences in specialty preferences and motivational factors: a cross-sectional Swedish study on last-year medical students. BMC Med Educ. 2013;13(1):39. doi:10.1186/1472-6920-13-39.

42. Heikkilä TJ, Hyppölä H, Vänskä J, et al. What predicts doctors' satisfaction with their chosen medical specialty? A Finnish national study. BMC Med Educ. 2016;16(1):125. doi:10.1186/s12909-016-0643-z. 




\section{Chapter 5}

\section{Some Residents Drop Out of Specialty Training:}

\section{Are Reasons Related to Prior Physician Experience?}

Sophie Querido

Marlies de Rond

Lode Wigersma

Olle ten Cate

Submitted as:

Some residents drop out of specialty training: are reasons related to prior physician experience? 
- Chapter 5

\begin{abstract}
Objective

The drop out rate among residents across all medical specialties in the Netherlands approximates $2.5 \%$. This means capacity loss in the medical workforce and often personal damage to graduates. The aim of this study was to investigate reasons for dropout among residents from all specialties and the significance of physician work experience prior to residency.
\end{abstract}

\title{
Method
}

In cooperation with the Dutch Medical Registration Board, a nationwide survey was sent to all residents who dropped out between 1 September 2017 and 1 September 2019. The respondents were asked to indicate on a 5-point Likert scale, how they rate the 28 reasons listed for drop-out or add other reasons.

\section{Results}

The response rate was $39 \%(\mathrm{~N}=129,99$ females) representing all medical specialties. The most frequently indicated reasons for dropout were lifestyle related factors. Of the respondents, $54 \%$ (69) had prior clinical experience in the same medical specialty before residency. Most reasons for drop-out weighed heavier for respondents without this prior experience than for respondents with it.

\section{Conclusion}

An important reason to drop out of residency appears to be a limited image of the specialty of their choose for residency. One third of those who dropped out mentioned that prior physician experience within the same specialty could have prevented dropout or prevented choosing this specialty in the first place. Graduates are likely to benefit from guidance with making career choices, as lifestyle related factors are prominent reasons for drop-out, and residents may also benefit from coaching during residency. 


\section{Introduction}

After medical school, most graduates start residency training, but some do not complete it, voluntarily or not. Terminating residency has a societal and organizational impact, because dropout implies a capacity loss of the medical workforce--populations must be served with an adequate mix of medical specialists--and it may signal personal tragedies. ${ }^{1,2}$ Terminating residency training or switching to a different specialty is uncommon ${ }^{3}$ and can cause damage to residents, psychologically as well as financially. ${ }^{2}$ Students and graduates can feel pressured to make the right choice at once and to avoid the stress of dropping out of residency. ${ }^{4}$ This choice has a significant impact on career satisfaction and personal well-being in later life. ${ }^{1,2,5-8}$ Health and wellbeing of physicians have been found to relate positively to quality of care and patient satisfaction ${ }^{2,8,9}$, but the prevalence of depression or depressive symptoms is high. ${ }^{10-12}$ Insight into factors of influence on dropout from graduate medical training is limited. Studies provide valuable data on factors affecting dropout, but usually report about one specialty, with a dominance of studies among surgical residents. ${ }^{13-15}$ In the US, a 2.6\% attrition rate was found among 6.303 general surgical residents of 2007-2008, caused by a switch of specialty or true dropout. ${ }^{16}$ The main findings in this study were that the majority of attrition occurs early in residency and that a large number of those residents reenter in non-surgical residencies such as anesthesiology, radiology and family medicine or commence a non-medical career. ${ }^{16}$ Some studies investigated single factors such as gender ${ }^{17}$, motivation rate $^{18}$, burn-out ${ }^{19}$ or timing of dropout ${ }^{20}$; one recent review and meta-analysis of studies among surgical residents provided a broader insight into factors of dropout and also reported that the majority of dropouts occurs after the first postgraduate year and are related to lifestyle related issues. ${ }^{14}$

In the Netherlands, about 175 residents quit every year (2013-2017), which is approximately $2.5 \%$ of all Dutch residents. ${ }^{21,22}$ A Dutch longitudinal survey was performed between 20092019 among graduates to research the reasons for dropout. ${ }^{23-26}$ Most reasons related to lifestyle: high job pressure, long or irregular working hours, difficulty to combine the residency with a family life, personal reasons, but also content of the educational program, desire to switch to another specialty, lack of personal coaching and a conflict at work. ${ }^{23-26}$ These studies were conducted only among graduates who terminated residency training; those who switched to a different residency were not included. ${ }^{23-26}$ Another Dutch study among residents who quitted a hospital residency, did include switching residents, and found workprivate balance, work pressure and disappointing content of the specialty as main reasons. ${ }^{27}$ 
Of these graduates $65 \%$ started or intended to start a non-hospital residency as a career switch.

Specialty preference among senior Dutch medical students is dominated by a few specialties, such as pediatrics, internal medicine and surgery, with a popular second-best plan to choose family medicine. ${ }^{25,28}$ After graduation and before residency Dutch graduates can change their career choice. ${ }^{29-31}$ Nevertheless, a large group will still try to obtain a residency position in a hospital specialty or subspecialty. The Dutch Medical Registration Board registers all postgraduate medical trainees, but does not keep track of reasons for dropout. With this study, we intended to explore dropout among all those concerned. Our study aims to identify reasons why trainees quit residency, including switchers and among all specialties. In an earlier study we showed that the experience of full responsibility for patient care as a physician-not-intraining (PNIT) before residency is important to make a thoughtful career choice ${ }^{30}$, we looked especially into PNIT experiences of the graduates who dropped out. The current study aims to provide insight into the dynamics of dropout and career switch in residency and the significance of physician work experience as a PNIT before residency. This may support medical students and graduates in making optimal choices for a medical specialty and reduce dropout of residency.

\section{Method}

\section{Participants and population}

The study population consisted of all residents who terminated residency between September 1, 2017 and September 1, 2019. An email including a link to the online survey, accompanied by a letter that explained the purpose of the study, was sent, on 19 September 2019, to a total of 348 graduates who had quit residency. The email was sent by the Dutch Medical Registration Board with the request to complete the survey for the purpose of medical education research. The research team had no access to email addresses or other personal information and the Medical Registration Board had no insight in any of the collected data. The study was approved by the Netherlands Association for Medical Education Ethical Review Board, ERB number 197. The participants were informed that participation was voluntary, that confidentiality was secured and that non-participation would not be held against them. They could withdraw from the survey at any time without giving a reason. Written informed consent was obtained from all participants as the first question of the survey. Twelve days after the initial mailing, a reminder was sent. 


\section{Instrument}

To identify reasons for dropping out of residency, we designed a survey for residents who had terminated their residency. As we did not find a suitable existing survey, we composed one. We used a recommended seven-step process for survey scale design. ${ }^{32}$ The first step, literature review, provided insight into the construct of drop-out from residency. ${ }^{29,33}$ The next step, interviews, were held with three individuals who had dropped out of residency, to obtain insight in resident views of the construct. As step 3, the literature and the information of the interviews were combined to optimize the list of indicators for the construct. The factors of influence mentioned by the three respondents matched the list of the literature review. In step 4 we developed the items for the survey, using the vocabulary of the target population. This resulted in the draft survey, including 28 factors, potentially of influence for dropout, in Table 3. As it concerns a new survey, we used step 5 for content validation. We selected three experts with methodological knowledge or research experience with the subject of dropout for a panel to provide feedback on the draft survey. As step 6, one researcher (SQ), conducted three cognitive interviews to examine response process validity, i.e. assessing how prospective participants interpret the survey items. A think-aloud technique was applied, respondents verbalized all their thought regarding the questions. This led to minor language edits and the research team concluded that the survey was comprehensive. The final step 7 was a pilot test of the survey in the web-based structure of SurveyMonkey ${ }^{\circledR}{ }^{34}$ The research team and two frequent survey monkey users tested the survey. The themes in the final survey included: working experience as a professional not in residency training (PNIT), preferences during the phase of career choice, current employment and desired employment. Further, they were asked to indicate on a 5-point Likert scale how they rated 28 potential reasons for dropping-out of their residency $(1=$ not a reason to $5=$ important reason to quit residency).

\section{Analysis}

We divided our respondents into two groups according to hospital specialty or non-hospital specialty. Descriptive statistics were calculated on frequencies of baseline characteristics, such as gender, age, specialty, part-time or fulltime residency program, dropout year. Differences between subgroups were calculated using crosstabs and Chi-square test. Subgroup analyses were performed based on gender, specialty, part-time/fulltime and previous employment (PNIT-experience) in the same specialty. The results from the 28 reasons were analyzed as Likert scale means with standard deviations. Descriptive statistics and subgroup analyses were calculated for valid cases. Missing data were not substituted. 
Analysis was done by using IBM SPSS ${ }^{\circledR}$ software version 26 . The answers to the open-ended questions were analyzed by SQ, MdR and LW. First, they independently reviewed the data, followed by a discussion between the authors. All open answers were compared with the list of existing variables and new variables were appointed and added to the longlist of reasons.

\section{Results}

\section{Study population characteristics}

The email was sent to 348 graduates ( $72 \%$ females) who prematurely left specialty training. There were 10 unusable email addresses and 3 persons sent an email they should not be included (one did not start residency at all, and the other two did not quit residency), remaining a group of 335 . There were 145 respondents who participated in our online survey; 16 responses were incomplete and were excluded. The response was 39\% (129, including $77 \%$ (99) females). The mean age was 34,8. There were 54\% (70) respondents with a hospital specialty and 46\% (59) respondents of a non-hospital specialty. Of the respondents, 55\% (63 females and 8 males), had a part-time contract, while 45\% (36 females and 22 males) had a fulltime contract. For $86 \%$ respondents (111), the specialty which they left was their first choice; for $9 \%$ (12) their second choice and for 5\% (6) their third choice. Most of the them, $86 \%(101)$, left their residency position in the first three years of the training period. And, $79 \%$ (102) had made their own decision to discontinue, in $10 \%$ of the cases (13) it was a decision forced by the program and 10\% (14) it was a joint decision. Most respondents currently work as a PNIT or have started a different residency. There were 14.812 residents (including 67\% females) with a mean age of 34 in the Netherlands. The percentage part-time residents were $53 \%$. The response group is not representative for percentage females and parttime compared with the group who all dropped out and with all the residents. The study population characteristics are summarized in Table 1. Some respondents did not answer all questions, the total response group is noted. 
Table 1 Overview of study population characteristics

\begin{tabular}{|c|c|c|c|c|c|}
\hline Characteristics & $\begin{array}{c}\text { All respon- } \\
\text { dents* } \\
\mathrm{N}=129\end{array}$ & $\begin{array}{l}\text { Respondents } \\
\text { in hospital } \\
\text { specialties } \\
\mathbf{N}=\mathbf{7 0}(54 \%)\end{array}$ & $\begin{array}{c}\text { Respondents } \\
\text { in non- } \\
\text { hospital } \\
\text { specialties } \\
\mathrm{N}=59(46 \%)\end{array}$ & $\begin{array}{l}\text { All Dutch } \\
\text { residents } \\
\text { who } \\
\text { terminated } \\
\text { or switched } \\
\mathbf{N}=\mathbf{3 4 8}\end{array}$ & $\begin{array}{c}\text { All Dutch } \\
\text { residents } \\
\mathrm{N}=14812\end{array}$ \\
\hline Female & $99(77 \%)$ & $50(71 \%)$ & $49(83 \%)$ & $251(72 \%)$ & 9987 (67\%) \\
\hline Male & $30(23 \%)$ & $20(29 \%)$ & $10(17 \%)$ & $97(28 \%)$ & $4825(33 \%)$ \\
\hline $\begin{array}{l}\text { Mean age } \\
\text { (range) }\end{array}$ & $\begin{array}{c}34,8 \\
(27-63) \\
\end{array}$ & $\begin{array}{c}34,3 \\
(27-47) \\
\end{array}$ & $\begin{array}{c}35,3 \\
(28-63) \\
\end{array}$ & 36,5 & 34 \\
\hline $\begin{array}{l}\text { Part-time } \\
\text { Fulltime }\end{array}$ & $\begin{array}{l}71(55 \%) \\
58(45 \%) \\
\end{array}$ & $\begin{array}{l}35(50 \%) \\
35(50 \%) \\
\end{array}$ & $\begin{array}{l}36(61 \%) \\
23(39 \%) \\
\end{array}$ & $\begin{array}{l}131(38 \%) \\
217(62 \%) \\
\end{array}$ & $\begin{array}{l}7000(47 \%) \\
7812(53 \%) \\
\end{array}$ \\
\hline $\begin{array}{l}\text { Training year at time } \\
\text { of drop-out* } \\
1 \\
2 \\
3 \\
4 \\
5 \\
6\end{array}$ & $\begin{array}{c}33 \\
39 \\
39 \\
12 \\
4 \\
2\end{array}$ & $\begin{array}{c}* \\
\\
10 \\
21 \\
23 \\
10 \\
4 \\
2\end{array}$ & $\begin{array}{c}* * \\
\\
23 \\
18 \\
16 \\
2 \\
0 \\
0\end{array}$ & $\begin{array}{l}75 \\
88 \\
75 \\
55 \\
30 \\
25\end{array}$ & $\begin{array}{c}\text { No data } \\
\text { available }\end{array}$ \\
\hline $\begin{array}{l}\text { Decision to quit } \\
\text { residency made by } \\
(\mathrm{N}=129) \\
\text { Resident } \\
\text { Program } \\
\text { Resident \& } \\
\text { program }\end{array}$ & $\begin{array}{c}102 \\
13 \\
14\end{array}$ & $\begin{array}{c}59 \\
3 \\
8\end{array}$ & $\begin{array}{c}43 \\
10 \\
6\end{array}$ & $\begin{array}{l}\text { No data } \\
\text { available }\end{array}$ & $\begin{array}{c}\text { No data } \\
\text { available }\end{array}$ \\
\hline $\begin{array}{l}\text { Current occupation } \\
(\mathrm{N}=123) \\
\text { Other residency } \\
\text { Working as PNIT } \\
\text { Not working as } \\
\text { physician } \\
\text { Other }\end{array}$ & $\begin{array}{l}41 \\
56 \\
17 \\
\\
12\end{array}$ & $\begin{array}{l}30 \\
21 \\
13 \\
4\end{array}$ & $\begin{array}{c}11 \\
35 \\
4 \\
\\
8\end{array}$ & $\begin{array}{l}\text { No data } \\
\text { available }\end{array}$ & $\begin{array}{c}\text { No data } \\
\text { available }\end{array}$ \\
\hline
\end{tabular}

* residencies with 3 till 6 years education program

** residencies with 3 or 4 years education program

All residents $=$ all residents in the period 1 September $2017-1$ September 2019

\section{Experience related to the specialty of drop-out}

Some of the respondents had no prior experience in the same specialty, some had one or multiple. Of the 127 respondents, 2 missing, who provided information about prior work experience, $13(10 \%)$ reported having no experience in the specialty of their residency; 57 (45\%) an elective internship in medical school in the same specialty; 69 (54\%) had PNIT experience in the same specialty and $16(13 \%)$ had both. Of the respondents $29(23 \%)$ had experience as $\mathrm{PhD}$. Some of the respondents had experience during an internship and $\mathrm{PhD}$, 
- Chapter 5

PNIT and $\mathrm{PhD}$ or all three. Of the respondents $11(9 \%)$ had another kind of experience. None of the respondents had all four kind of experiences. Table 2 provides an overview.

Table 2 Overview of experience related to the specialty

\begin{tabular}{|l|l|}
\hline Kind of experience & $\begin{array}{l}\text { Number } \\
\text { (total N=127) }\end{array}$ \\
\hline None & $13(10 \%)$ \\
\hline Internship & $57(45 \%)$ \\
\hline PNIT & $69(54 \%)$ \\
\hline PhD & $29(23 \%)$ \\
\hline Internship and PNIT & $16(13 \%)$ \\
\hline Internship, and PhD & $5(4 \%)$ \\
\hline PNIT and PhD & $4(3 \%)$ \\
\hline Internship, PNIT, and PhD & $10(8 \%)$ \\
\hline Other & $11(9 \%)$ \\
\hline Missing data & 2 \\
\hline &
\end{tabular}

The respondents can be categorized into four groups of prior PNIT-experience within their specialty of residency: 0 months of experience $(\mathrm{N}=58), 1-12$ months $(\mathrm{N}=11), 13-24$ months of experience $(\mathrm{N}=28)$ and more than 24 months of experience $(\mathrm{N}=18)$. Another 12 respondents did have work experience, but did not indicate the duration.

\section{Factors determining drop-out}

Respondents were first asked to name the main reason for drop-out by an open question. The answers (in frequency of appearance) were: 1. work-life disbalance (17\%), 2. personal reason (16\%) and 3. I became interested / was caught by another specialism (14\%). Next, the respondents were asked to score the relevance of 28 reasons for their own drop-out. None of the reasons appeared dominant, as all means were below 3. Five items with a mean of 2.4 or higher were: 1) insufficient satisfaction with the nature of work, 2) work-life disbalance, 3) energy-consuming work, 4) work was different than expected and 5) lifestyle incongruence. There was no significant difference between females and males. Further analysis was performed based on having prior PNIT experience in the specialty of later residency, presented in Table 3 . Among the 28 reasons potentially affecting the decision to terminate the residency, 20 of the 28 items showed a higher score among the residents without a specialty-specific PNIT experience than those with this experience. 
Table 3 Reasons respondents checked for terminating a specialty

\begin{tabular}{|c|c|c|c|}
\hline & $\begin{array}{l}\text { All } \\
\text { respondents } \\
(\mathrm{N}=129)\end{array}$ & $\begin{array}{l}\text { All } \\
\text { respondents } \\
\text { without prior } \\
\text { PNIT } \\
\text { experience in } \\
\text { own specialty } \\
(\mathrm{N}=60)\end{array}$ & $\begin{array}{c}\text { All } \\
\text { respondents } \\
\text { with prior } \\
\text { PNIT } \\
\text { experience } \\
\text { in own } \\
\text { specialty } \\
(\mathrm{N}=69)\end{array}$ \\
\hline $\begin{array}{l}\text { Reasons for termination as listed in the survey, on a } \\
\text { 5-point Likert scale from } 1 \text { (not a reason) to } 5 \text { (most } \\
\text { important reason) }\end{array}$ & Mean (SD) & Mean (SD) & Mean (SD) \\
\hline $\begin{array}{l}\text { 1. Insufficient satisfaction with the nature of the } \\
\text { work }\end{array}$ & $2.71(1.25)$ & $3.03(1.54)$ & $2.43(1.50)$ \\
\hline 2. Work-life disbalance & $2.70(1.38)$ & $2.73(1.45)$ & $2.67(1.34)$ \\
\hline 3. Energy-consuming work & $2.59(1.32)$ & $2.87(1.20)$ & $2.35(1.37)$ \\
\hline 4. The work was different than expected & $2.53(1.32)$ & $2.85(1.35)$ & $2.26(1.24)$ \\
\hline 5. Lifestyle incongruence & $2.40(1.29)$ & $2.38(1.26)$ & $2.41(1.32)$ \\
\hline 6. I had (symptoms of) a burnout & $2.30(1.37)$ & $2.50(1.38)$ & $2.13(1.35)$ \\
\hline $\begin{array}{l}\text { 7. Professional autonomy limited by rules / limited } \\
\text { autonomy }\end{array}$ & $2.26(1.35)$ & $2.53(1.43)$ & $2.01(1.23)$ \\
\hline 8. High volume of duty hours & $2.26(1.26)$ & $2.30(1.34)$ & $2.22(1.19)$ \\
\hline 9. Emotionally too heavy for me & $1.89(1.16)$ & $1.88(1.15)$ & $1.90(1.18)$ \\
\hline $\begin{array}{l}\text { 10. The residency did not meet the expectations } \\
\text { suggested by advance information }\end{array}$ & $1.84(1.07)$ & $2.07(1.09)$ & $1.64(1.01)$ \\
\hline 11. Personal or family related reason & $1.83(1.36)$ & $1.95(1.44)$ & $1.72(1.28)$ \\
\hline $\begin{array}{l}\text { 12. Not being able to really care / mean something } \\
\text { to the patient }\end{array}$ & $1.81(1.15)$ & $1.98(1.23)$ & $1.67(1.07)$ \\
\hline 13. I became interested in another specialty & $1.81(1.39)$ & $1.63(1.21)$ & $1.96(1.52)$ \\
\hline 14. Interpersonal problems (colleagues / team) & $1.80(1.18)$ & $1.78(1.15)$ & $1.81(1.22)$ \\
\hline $\begin{array}{l}\text { 15. There was too much pressure for (medical) } \\
\text { production and less for personal development }\end{array}$ & $1.77(1.14)$ & $1.75(1.20)$ & $1.78(1.10)$ \\
\hline 16. Work setting/type of practice & $1.76(1.14)$ & $1.72(1.11)$ & $1.80(1.17)$ \\
\hline 17. I performed badly & $1.67(0.96)$ & $1.78(0.99)$ & $1.57(0.93)$ \\
\hline 18. I could not cooperate/work with my superior & $1.64(1.10)$ & $1.67(1.15)$ & $1.62(1.06)$ \\
\hline 19. Limited career perspective within this specialty & $1.54(1.05)$ & $1.57(1.11)$ & $1.52(0.99)$ \\
\hline 20. It was physically too heavy for me & $1.49(1.02)$ & $1.50(1.02)$ & $1.48(1.04)$ \\
\hline 21. I was forced by others to quit & $1.48(1.11)$ & $1.58(1.17)$ & $1.39(1.06)$ \\
\hline $\begin{array}{l}\text { 22. I could not share personal concerns with } \\
\text { someone }\end{array}$ & $1.48(0.95)$ & $1.53(1.05)$ & $1.43(0.85)$ \\
\hline $\begin{array}{l}\text { 23. I had to deal with improper or cross-border } \\
\text { treatment at work }\end{array}$ & $1.40(0.96)$ & $1.40(1.01)$ & $1.41(0.93)$ \\
\hline 24. Status of the specialty & $1.35(0.85)$ & $1.37(0.76)$ & $1.33(0.92)$ \\
\hline 25. There was no possibility to work part-time & $1.27(0.72)$ & $1.28(0.74)$ & $1.26(0.70)$ \\
\hline 26. Impact of disciplinary or legal procedures & $1.12(0.55)$ & $1.13(0.60)$ & $1.10(0.52)$ \\
\hline $\begin{array}{l}\text { 27. Opinions of others about the specialty } \\
\text { influenced me }\end{array}$ & $1.09(0.46)$ & $1.05(0.22)$ & $1.13(0.59)$ \\
\hline 28. Financial matters/problems & $1.05(0.31)$ & $1.08(0.38)$ & $1.03(0.24)$ \\
\hline
\end{tabular}




\section{Preventing dropout}

Respondents were asked what could have prevented them from quitting residency. This was an open question and answered by 42 respondents and categorized in five themes: 1) More orientation about the different specialties, mainly through experience as a PNIT (N=13), 2) More detailed information about the structure of the residency $(\mathrm{N}=9), 3)$ Personal reason $(\mathrm{N}=8)$, 4) Personal coaching $(\mathrm{N}=6)$, 5) Safer learning climate $(\mathrm{N}=2), 6)$ Various other answers $(\mathrm{N}=4)$. Respondents were also asked what could have supported them not to start with residency. This was an open question and answered by 46 respondents and categorized in four themes: 1) More orientation about the different specialties, mainly through experience as a PNIT (N=21), 2) Information about the combination of residency and having a family with children $(\mathrm{N}=5), 3)$ Detailed information about the load / type of work as a resident $(\mathrm{N}=5), 4)$ Various other answers $(\mathrm{N}=11)$.

\section{Discussion}

We conducted a nationwide survey among residents who had dropped out of specialty training, to obtain insight into the factors involved in terminating residency and to investigate whether these reasons differ among those having prior PNIT experience. Our study supports earlier findings that dropout most often takes place in the first three years of residency. ${ }^{20,27,35}$ We found five dominant factors: insufficient satisfaction with the nature of work, work-life disbalance, energy-consuming work, work was different than expected and I did not want the lifestyle needed for this specialty. These results are in line with previous research ${ }^{20,23-27,36}$ and with this study we can add to the literature that these factors are not related to a specialty or to hospital specialties only, but apply for all graduates who dropout. We consider the high mean for work-life disbalance, energy-consuming work and I did not want the lifestyle needed for this specialty in our study of major concern, because of the relation with burn-out and the effect on the physical and psychological well-being of physician's. ${ }^{10-12}$ Taking care of the physician's well-being is pivotal for our future healthcare system. ${ }^{9,12,37,38}$ Therefore, more attention to these lifestyle-related issues is crucial.

Another prominent observation from our study is that half (54\%) of our respondents had a prior experience as a PNIT in the same specialty. This figure is slightly lower compared to an earlier study among hospital specialties. ${ }^{27}$ This small difference can be explained by the fact that a PNIT experience as a family physician is not possible in the Netherlands, and some of 
our respondents dropped out of this specialty training. Of all Dutch graduates it is estimated that $64 \%$ has prior experience as a physician in a specialty. ${ }^{26}$

As these data of drop-out imply and also suggested by previous research ${ }^{14,27}$, we assume that previous experiences within the same specialty would support to provide a realistic image of the specialty and the demands of being a resident and thus would prevent dropout. ${ }^{30,39,40}$ We found that most reasons for drop-out weigh heavier for those without prior experience with the same specialty than for those with this experience (Table 3). Up to a third of the respondents suggests that better orientation and more PNIT experience could have prevented dropout. Those with realistic expectations of the demands of residency and life as a resident may be more likely to complete their residency. ${ }^{40}$ It means long days, hard working, high performance and act as a licensed physician. These findings support our hypothesis that PNIT experience in the same specialty is relevant for making a valid career choice. It is likely that graduates would benefit from having a PNIT experience to explore the full scope of a specialty and inform themselves about the structure and type of work of the residency before making their definite career choice.

We also suggest that more guidance or mentoring during residency could support trainees and possibly mitigate specialty related or personal problems. Mentoring could help prevent burn out, learn trainees to cope with high work load and to better navigate the balance between work and private life, as these seem important reasons for drop-out. Dutch family medicine and psychiatry residencies have coaching now integrated in their programs. ${ }^{41,42}$ This involves daily supervision concerning patients, medical aspects, and the residents' personal well-being. Another approach that has be applied is peer-supervision among residents. This support is perhaps needed for all residents and prevent them more from physical and psychological complaints and remain them for future workforce as healthy and satisfied specialists.

Next to support structures to assist residents individually in coping with the challenges or residency training, the training environment itself may be subject to scrutiny. Health care, with or without training, is an increasingly demanding environment, that appears to be less and less attractive for young physicians to work in. Contextual adaptations may be necessary to prevent increasing numbers of residents choosing to leave this work environment.

The focus of this study regarded reasons of drop-out by those who quit residency and the importance of previous experience as a PNIT. Nevertheless, most Dutch residents do fulfill their residency training and become a specialist. ${ }^{43}$ We advise further research about what are the reasons to fulfill residency and the importance of a PNIT experience prior to residency. 


\section{Limitations}

This study has its limitations. This was a retrospective study with residents who quitted residency within the last two years. It is possible that those who quitted some while ago perhaps forgot some details or have giving other meaning to their experiences and therefore their answers could be biased. The survey was anonymous and we could not send personal reminders. While our sample was a fair representation of the population, seven respondents exceeded the age of 45 . We initially excluded them from our sample, but as this did not lead to essential differences in the results, we included them in the results. Our study findings could have been affected by somewhat larger proportion of women in our sample: $76 \%$ in our study; $72 \%$ in the reference group and $67 \%$ in the group of all residents, and by a larger proportion of part-time respondents: $55 \%$ in our sample; $38 \%$ in the reference group and $47 \%$ in the group of all residents. Therefore, we should be careful with the interpretation of the differences between the subgroups. To further explore the differences between those subgroups more research is needed.

\section{Conclusion}

Our study shows that half of the respondents had a PNIT experience in the same specialty as their residency. There are five dominant reasons, mainly lifestyle related factors, for drop-out. Reason for drop-out weigh heavier for those without prior experience with the specialty of residency.

The results of this study support that to make a good medical career choice, graduates must have a realistic insight of their preferred specialty. Graduates are likely to benefit from a PNIT experience in their preferred specialty before making their definite career choice. Furthermore, residents may benefit from support focused on how to deal with lifestyle related issues, professional and personal development during their residency.

For this study, we collaborated with the Medical Registration Board (in Dutch: RGS) of the Royal Dutch Medical Association (KNMG). The Medical Registration Board has a complete documentation of all Dutch graduates, residents and specialists. ${ }^{44}$ The board periodically tests whether doctors and study programs comply with the rules of the Medical Specialties Board. The Medical Registration Board registers contain information about education programs, duration, qualifications, years of practice and dropout rates. 


\section{References}

1. Borges NJ, Gibson DD, Karnani RM. Job satisfaction of physicians with congruent versus incongruent specialty choice. Eval Health Prof. 2005;28(4):400-413.

2. Leigh JP, Tancredi DJ, Kravitz RL. Physician career satisfaction within specialties. BMC Health Serv Res. 2009;(9):166-178. doi:10.1186/1472-6963-9-166.

3. Goldacre MJ, Laxton L, Lambert TW. Medical graduates' early career choices of specialty and their eventual specialty destinations: UK prospective cohort studies. $B M J$. 2010;340(c3199):1-9.

4. Maudsley G, Williams L, Taylor D, Maudsley G, Williams LYN, Taylor D. Medical students' and prospective medical students' uncertainties about career intentions: Cross-sectional and longitudinal studies. 2010;32(3):e143-e151.

5. Dyrbye LN, Thomas MR, Huntington JL, et al. Personal life events and medical student burnout: a multicenter study. Acad Med. 2006;81(4):374-384. doi:81/4/374 [pii].

6. Lepnurm R, Danielson D, Dobson R, Keegan D. Cornerstones of career satisfaction in medicine. Can J Psychiatry. 2006;51(8):512-522.

7. Roos M, Watson J, Dch MD, Wensing M. Motivation for career choice and job satisfaction of GP trainees and newly qualified GPs across Europe: a seven countries cross-sectional survey. Educ Prim Care. 2014;25:202-210.

8. Williams ES, Skinner AC. Outcomes of physician job satisfaction: a narrative review, implications, and directions for future research. Health Care Manage Rev. 2003;28(2):119-139. doi:Article.

9. Kravitz RL. Physician job satisfaction as a public health issue. Isr J Health Policy Res. 2012;1(1):51-52. doi:10.1186/2045-4015-1-51.

10. Mata DA, Ramos MA, Bansal N, et al. Prevalence of Depression and Depressive Symptoms Among Resident Physicians. Jama. 2015;314(22):2373-2383. doi:10.1001/jama.2015.15845.

11. Rotenstein LS, Ramos MA, Torre M, et al. Prevalence of Depression, Depressive Symptoms, and Suicidal Ideation Among Medical Students. Jama. 2016;316(21):22142236.

12. Rotenstein LS, Torre M, Ramos MA, et al. Prevalence of Burnout Among Physicians A Systematic Review. Jama. 2019;320(11):1131-1150. doi:10.1001/jama.2018.12777.

13. Bauer JM, Holt GE. National Orthopedic Residency Attrition : Who Is At Risk? J Surg Educ. 2016;73(5):852-857. doi:10.1016/j.jsurg.2016.03.010.

14. Khoushhai Z, Hussain M, Greco E, et al. Prevalence and Causes of Attrition Among Surgical ResidentsA Systematic Review and Meta-analysis. JAMA Surg. 2017;152(3):265-272. doi:10.1001/jamasurg.2016.4086.

15. Ottenhausen M, Anetsberger S, Kleffmann J, et al. Risk factors for dropping Out of NeurosurgIcal resideNcy programs - The RONIN Survey. World Neurosurg. 2018. doi:10.1016/j.wneu.2018.07.195.

16. Yeo H, Bucholz E, Ann Sosa J, et al. A National Study of Attrition in General Surgery Training. Which Residents Leave and Where Do they Go? Trans . Meet Am Surg Assoc. 2010;252(3):529-536. doi:10.1097/SLA.0b013e3181f2789c. 
17. Myers SP, Hill KA, Nicholson KJ, et al. Association for Academic Surgery A qualitative study of gender differences in the experiences of general surgery trainees. $J$ Surg Res. 2018;228:127-134. doi:10.1016/j.jss.2018.02.043.

18. Symer MM, Abelson JS, Yeo HL, Sosa JA, Rosenthal MZ. The Surgical Personality: Does Surgery Resident Motivation Predict Attrition? J Am Coll Surg. 2018;226(5):777783. doi:10.1016/j.jamcollsurg.2018.02.007.

19. Dyrbye LN, Burke SE, Hardeman RR, et al. Association of Clinical Specialty With Symptoms of Burnout and Career Choice Regret Among US Resident Physicians. 2018;320(11):1114-1130. doi:10.1001/jama.2018.12615.

20. Yeo H, Abelson J, Symer M, et al. Association of Time to Attrition in Surgical Residency With Individual Resident and Programmatic Factors. JAMA Surg. 2018;153(6):511-517. doi:10.1001/jamasurg.2017.6202.

21. Advisory Committee on Medical Manpower Planning. The 2016 Recommendations for Medical Specialist Training [in Dutch]. Utrecht; 2016. https:/capaciteitsorgaan.nl/app/uploads/2016/10/2016_10_21-Revisie-3.0Capaciteitsplan-2016-Hoofdrapport-DEFINITIEF.pdf.

22. Medical Registration Board. Personal communication with Registration Committee the Netherlands [in Dutch]. Presented at the: 2018.

23. Velde F van der, Verijdt F, Smeets RCKC. Loopbanen En Loopbaan- Wensen van Basisartsen [in Dutch]. Utrecht. Prismant; 2009.

24. Van der Velde F, Abbink-Cornelissen M, Bloemendaal I, Van der Kwartel A. Loopbanen En Loopbaanwensen van Basisartsen, Meting 2012/2013 [in Dutch]. Utrecht, KIWA; 2013.

25. Van der Velde F, Wierenga M. Loopbanen En Loopbaanwensen van Basisartsen. Herhaling van Het Onderzoek Onder Basisartsen 2009 En 2012 [in Dutch]. Utrecht. KIWA; 2016.

26. Velde F van der, Leemkolk B van de, Lodder A. Loopbanen En Loopbaanwensen van Basisartsen Meting 2019 [in Dutch]. Utrecht. Prismant; 2019.

27. Bustraan J, Dijkhuizen K, Velthuis S, et al. Why do trainees leave hospital-based specialty training? A nationwide survey study investigating factors involved in attrition and subsequent career choices in the Netherlands. BMJ Open. 2019;9:1-8. doi:10.1136/bmjopen-2018-028631.

28. The medical student association. Research Report Career Choice 2014 [in Dutch]. Utrecht; 2014. https://degeneeskundestudent.nl/nieuws-en-standpunten/onderwerpenstandpunten/beroepskeuze.

29. Querido S, Broek S Van Den, Rond M De, Wigersma L, Cate O. Factors affecting senior medical students ' career choice. Int J Med Educ. 2018;9:332-339. doi:10.5116/ijme.5c14.de75.

30. Querido S, Rond M De, Wigersma L, van den Broek WES, Ten Cate O. The Significance of Experiencing Clinical Responsibilities for Specialty Career Choice. Med Sci Educ. 2019. doi:10.1007/s40670-019-00832-z.

31. Querido SJ, Wigersma L, Cate O. Traveling by winding roads or highways: Stability of medical students' specialty preferences over time specialty. Med Teach. 2020;0(0):1-3. doi:10.1080/0142159X.2020.1804056. 
32. Artino A, Rochelle JS La, Dezee KJ, et al. Developing questionnaires for educational research : AMEE Guide No. 87. Med Teach. 2014;36(6):463-474. doi:10.3109/0142159X.2014.889814.

33. Khoushhai Z, Hussain M, Greco E, et al. Supplementary Online Content Prevalence and Causes of Attrition Among Surgical ResidentsA Systematic Review and Metaanalysis. JAMA Surg. 2016;152(3):1-21. doi:10.1001/jamasurg.2016.4086.

34. SurveyMonkey. SurveyMonkey. 2019. www.surveymonkey.com.

35. Ottenhausen M, Anetsberger S, Kleffmann J, et al. Risk Factors for Dropping Out of Neurosurgical Residency Programs - A Survey Study. World Neurosurg. 2018;120:e100-e106. doi:10.1016/j.wneu.2018.07.195

36. Khoushhal Z, Hussain M, Greco E, et al. Prevalence and Causes of Attrition Among Surgical Residents A Systematic Review and Meta-analysis. JAMA Surg. 2017;152(3):265-272. doi:10.1001/jamasurg.2016.4086.

37. Boone S. Burnout and Satisfaction With Work-Life Balance Among US Physicians Relative to the General US Population $<$ alt-title $>$ Burnout and Satisfaction With WorkLife Balance</alt-title>. Arch Intern Med. 2012. doi:10.1001/archinternmed.2012.3199.

38. Shanafelt TD, Hasan O, Dyrbye LN, et al. Changes in Burnout and Satisfaction With Work-Life Balance in Physicians and the General US Working Population Between 2011 and 2014. Mayo Clin Proc. 2015;90(12):1600-1613. doi:10.1016/j.mayocp.2015.08.023.

39. Heikkilä TJ, Hyppölä H, Vänskä J, et al. What predicts doctors' satisfaction with their chosen medical specialty? A Finnish national study. BMC Med Educ. 2016;16(1):125. doi:10.1186/s12909-016-0643-z.

40. Abelson J, Sosa J, Symer M, et al. Association of Expectations of Training With Attrition in General Surgery Residents. JAMA Surg. 2018;153(8):712-717. doi:10.1001/jamasurg.2018.0611.

41. Draijer N. Ken u zelf; leertherapie in de Nederlandse opleiding tot psychiater 1. [in Dutch]. Tijdschr Psychiatr. 2019;61(3):164-169.

42. Gerritse F, Duvivier R, Stel A. Coaching gaat aiossen niet helpen. Med Contact [in Dutch]. 2019;(39):34-36.

43. Advisory Committee on Medical Manpower Planning. Medical Manpower Planning Main Report [In Dutch]. Utrecht; 2019.

https://capaciteitsorgaan.nl/app/uploads/2020/02/2020_02_12-Capaciteitsplan-20212024-Hoofdrapport-DEFINITIEF-EN.pdf.

44. Royal Dutch Medical Association. About the medical registration board [in Dutch]. https://www.knmg.nl/opleiding-herregistratie-carriere/rgs/over-de-rgs.htm. Published 2018 . 



\section{Chapter 6}

Traveling by winding roads or highways: Stability of medical students' specialty preferences over time

Sophie Querido

Lode Wigersma

Olle ten Cate

\section{Published as:}

Traveling by winding roads or highways: Stability of medical students' specialty preferences over time. Medical Teacher. 2020. doi: 10.1080/0142159X.2020.1804056 
- Chapter 6

\begin{abstract}
Introduction

Medical students switch career preferences during medical school and likely distinguish themselves in stability of preference over time. The purpose of our study was to gain insight in career paths stability of medical students.
\end{abstract}

\title{
Method
}

The authors conducted a longitudinal, four sessions interview study with medical students with three intervals over a three and a half-year period. From all 24 participants the first and second career preferences were documented, analyzed and we calculated a stability score, to interpret career preference stability.

\section{Results}

Three different pathways were found: a 'winding road' with low stability (0-7 points); a 'country road' with medium stability (8-14 points); and a 'highway' with high stability (15-22 points).

\section{Conclusion}

This study provides a longitudinal view of how the stability of career preference, including the first and second career preference, evolves over time. While we only studied a small sample, the characterization may hold when larger samples are studied. 


\section{Introduction}

Many students enter medical school with a career preference but few actually start a residency of that preference. ${ }^{1,2}$ With experience during medical school, career preferences shift. ${ }^{3} \mathrm{~A}$ study in the UK showed a $65 \%$ stability of medical students' career preference in year four until residency. ${ }^{4}$ Goldenberg et al. found the preference for psychiatry at the start of medical school to be $1.6 \%$, only $4.6 \%$ of which group actually chose psychiatry at graduation. ${ }^{5}$ These studies related career preference of medical students with eventual specialty choice. What studies with two moments of measurement do not show is how stable students' preferences are over time. The aim of our study was to explore the stability of career preferences of medical students over a period of several years. The study was conducted in the Netherlands where undergraduate medical education takes six years and the final year is the period where they most experience how demands of specialties match with their career preferences. ${ }^{6}$ During medical school students are not exposed to all medical specialties. Most graduates do not directly continue residency after medical school. This period contributes in making the career choice. $^{7}$

\section{Methods}

We conducted a longitudinal interview study. We interviewed the same medical students four times over a three and a half-year period. The interviews focused on the development of career preferences over time. The first interview took place at the beginning of the final study year. The second interview was at the end of the final study year, i.e. around graduation. The third interview was planned one year after graduation and the fourth was one and a half year later. This enabled following their individual career preference paths.

Our study population consisted of students at the Utrecht University Medical Center in the Netherlands. We invited students from one cohort who started the final study year during teaching sessions in May and October 2014. The participants were informed that participation was voluntary, that confidentiality was secured and that non-participation would not be held against them. They could withdraw from the study at any time without giving a reason. The research proposal was approved by the Ethical Review Board of the Dutch Association for Medical Education (NERB \#308) and included a larger study to explore students' considerations in making a career choice. ${ }^{7}$ The focus of the current study is merely on career stability over time, but the interview study provided the data to explore this stability. Participants' first and second career preferences at every interview were documented. 
Stability was defined as related to the final career preference in the 4th interview, often coinciding with a residency choice, i.e. as (a) the number of similar preferences seen in earlier interviews with (b) preference at interview 3 weighing more than at interview 2, which weighs more than the one at interview 1 . If there was no second preference, we assumed a stronger preference. The career stability choice was calculated as shown in Box 1 ("3.1" designates third interview, preference 1; "3.2" designates preference 2). This calculation is a simple formula which shows the extent of the stability of career choice. The stronger the preference over time, the higher the total points and therefore the stability score.

Box 1 Career preference stability score calculation

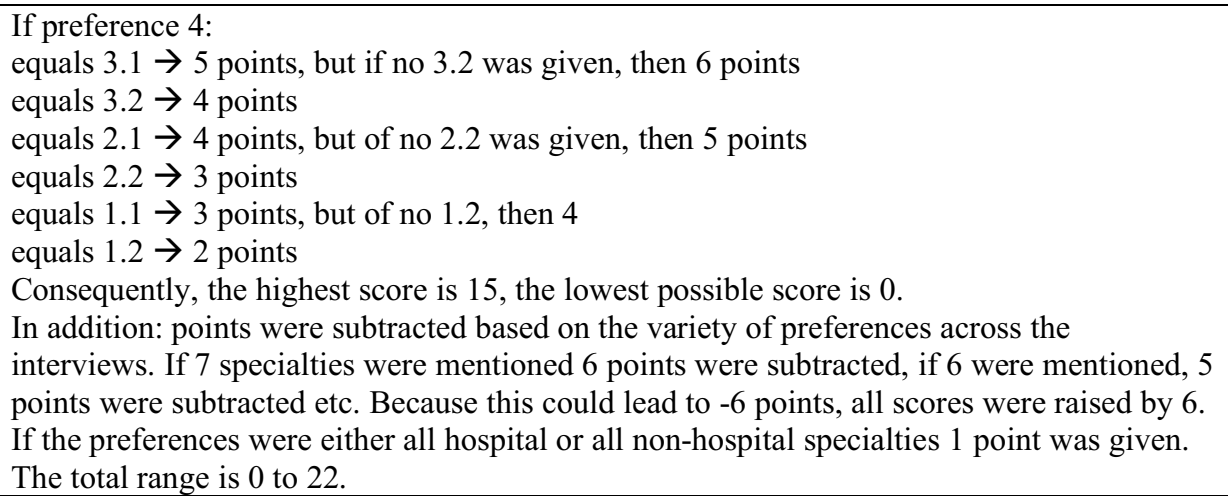

\section{Results}

A total of 24 students participated in the first interview, the second interview series involved 22 , the third interview series 20 and the fourth interview series involved 21 participants. We did not know the reasons for withdrawal by those students who failed to participate in the next interviews. Four participants were excluded from stability ranking, because they discontinued medicine after graduation or stopped participating in our study. Leaving 20 for stability calculations (4 male, 16 female) with a variety of pathways, shown in Table 1. 
Table 1 First and second specialty preferences at the four interviews

\begin{tabular}{|c|c|c|c|c|c|c|c|c|c|}
\hline Subject & 1.1 & 1.2 & 2.1 & 2.2 & 3.1 & 3.2 & 4 & $\begin{array}{l}\text { Resident at } \\
\text { interview } 4\end{array}$ & $\begin{array}{c}\text { Stability } \\
\text { score }\end{array}$ \\
\hline \multicolumn{10}{|c|}{ Traveling the 'highway' (15-22) } \\
\hline $\mathrm{S} 1$ & $\mathrm{~A}$ & & $\mathrm{~A}$ & & A & & $A$ & yes & 22 \\
\hline S2 & $\mathrm{F}$ & & $\mathrm{F}$ & S & $\mathrm{F}$ & & $F$ & no & 18 \\
\hline S3 & $\mathrm{W}$ & $\mathrm{T}$ & $\mathrm{T}$ & $\mathrm{Y}$ & $\mathrm{T}$ & & $T$ & yes & 17 \\
\hline S4 & $\mathrm{F}$ & $\mathrm{C}$ & $\mathrm{F}$ & $\mathrm{S}$ & $\mathrm{F}$ & & $F$ & yes & 17 \\
\hline S5 & $\mathrm{D}$ & S & $\mathrm{D}$ & S & $\mathrm{D}$ & S & $D$ & yes & 17 \\
\hline S6 & $\mathrm{N}$ & S & $\mathrm{N}$ & $\mathrm{S}$ & $\mathrm{N}$ & S & $N$ & yes & 17 \\
\hline S7 & B & $\mathrm{S}$ & B & $\mathrm{E}$ & B & $\mathrm{S}$ & $B$ & no & 16 \\
\hline S8 & $\mathrm{C}$ & A & $\mathrm{C}$ & A & $\mathrm{A}$ & & $A$ & no & 16 \\
\hline \multicolumn{10}{|c|}{ Traveling the 'country road' (8-14) } \\
\hline S9 & $\mathrm{L}$ & $\mathrm{S}$ & $\mathrm{V}$ & $\mathrm{S}$ & $\mathrm{S}$ & $\mathrm{V}$ & $S$ & yes & 14 \\
\hline $\mathrm{S} 10$ & $\mathrm{~K}$ & $\mathrm{O}$ & $\mathrm{S}$ & $\mathrm{O}$ & K & $\mathrm{S}$ & $K$ & yes & 12 \\
\hline S11 & $\mathrm{U}$ & $\mathrm{V}$ & V & $\mathrm{U}$ & $*$ & & $V$ & yes & 12 \\
\hline $\mathrm{S} 12$ & S & $\mathrm{O}$ & S & & E & & E & yes & 10 \\
\hline S13 & $\mathrm{S}$ & $\mathrm{E}$ & $\mathrm{S}$ & $\mathrm{E}$ & $\mathrm{V}$ & $\mathrm{S}$ & $V$ & yes & 9 \\
\hline S14 & $\mathrm{S}$ & I & $\mathrm{S}$ & I & V & $\mathrm{S}$ & $V$ & yes & 9 \\
\hline S15 & S & $\mathrm{J}$ & S & & $\mathrm{S}$ & $\mathrm{V}$ & $V$ & yes & 8 \\
\hline S16 & M & $\mathrm{C}$ & $*$ & & M & $\mathrm{T}$ & $T$ & yes & 8 \\
\hline S17 & $\mathrm{S}$ & $\mathrm{D}$ & $\mathrm{S}$ & & $\mathrm{S}$ & $\mathrm{V}$ & $V$ & yes & 8 \\
\hline S18 & $\mathrm{F}$ & $\mathrm{C}$ & $\mathrm{X}$ & $\mathrm{F}$ & $*$ & & $X$ & yes & 8 \\
\hline \multicolumn{10}{|c|}{ Traveling the 'winding road' $(0-7)$} \\
\hline S19 & $\mathrm{R}$ & $\mathrm{S}$ & $\mathrm{S}$ & $\mathrm{R}$ & $\mathrm{S}$ & $\mathrm{R}$ & $U$ & yes & 5 \\
\hline S20 & $\mathrm{F}$ & $\mathrm{S}$ & $\mathrm{F}$ & $\mathrm{P}$ & $\mathrm{G}$ & $\mathrm{F}$ & $A$ & no & 2 \\
\hline \multicolumn{10}{|c|}{$\begin{array}{l}\text { Hospital-based specialties: A - Anesthesiology, B - Cardiology, C - General surgery } \\
\text { D - Dermatology, E - Geriatrics, F - Gynaecology, G - Intensive care, H - Internal } \\
\text { medicine, I - Pediatrics, J - Otorhinolaryngology, K - Neurology, } \\
\text { L - Ophthalmology, M - Orthopedics, N - Plastic surgery, O - Rehabilitation } \\
\text { medicine, P - Emergency medicine, Q - Trauma surgery. } \\
\text { Non-hospital-based specialties: R - Physician for the mentally retarded, S - Family } \\
\text { medicine, T - Military medicine, U - Elderly care medicine, V - Psychiatry, } \\
\text { W - Sports medicine, X - Tropical medicine. } \\
\text { Y - Miscellaneous other, * No interview. }\end{array}$} \\
\hline \multicolumn{10}{|c|}{$\begin{array}{l}\text { Interview 1: beginning of final study year. } \\
\text { Interview 2: end of final study year. } \\
\text { Interview } 3: 1 \text { year after graduation. } \\
\text { Interview } 4: 2,5 \text { years after graduation. }\end{array}$} \\
\hline
\end{tabular}

The career preferences showed 24 specialties across the interviews and 12 at the final interview. Seven participants had the same first preference during all interviews, most of whom did not seriously consider many other options. Others show much more unstable 
pathways. We grouped the 20 subjects in three categories: scores 0-7 (traveling 'winding roads'), 8-14 (traveling 'country roads') and 15-22 (traveling 'highways').

\section{Discussion}

Asking career preferences four times provided insight into the variety in career preference paths and its stability. 'Traveling the highway' characterizes medical students who are quite stable in their career preference and already started residency in this direction, or perform research to require a $\mathrm{PhD}$ degree and still have the same career preference. 'Traveling the country road' were students considering two or three serious options and traveling the 'winding road' were students who did not end with the various, mainly first, career preferences earlier considered. The studies by Woolf et al. ${ }^{4}$ and Goldenberg et al. ${ }^{5}$ focused on the accordance of first career preference with residency choice. We also included second preferences and asked these multiple times, providing us with a more realistic insight into stability of preference. A stable career path can benefit a student, as a stable curriculum vitae may impress at a residency application. However, many specialties are not very visible during undergraduate medical education. Half of the students showing a 'country road' and all students, except one, showing a 'winding road' behavior chose a residency that is not experienced in early undergraduate education (such as psychiatry, elderly care medicine, tropical or military medicine). Our interview study concluded, that experiencing clinical responsibility as a student or a junior physician not yet in residency training appears to be important for career preference. ${ }^{7}$ This forces trainees to reflect on personal needs and to consider which career fits best. Individuals with a 'highway' path usually had experience within their specialty preferences during medical school and they used the period with only clinical responsibility as a conformation to make their choice. While for those with a 'country road' or 'winding road' the clinical experience after graduation was likely used to explore a variation of specialty options.

Our small sample is an important limitation of this study. The sample has an overrepresentation of females, with no males in the 'winding road' group. This should be considered by interpreting the results, as females are influenced by other factors in their career choices than males. ${ }^{8}$ We can only recommend to repeat the study with a large sample. This study provides a first longitudinal insight. Future research may consider starting earlier during medical school. 


\section{References}

1. Cleland J, Johnston PW, French FH, Needham G. Associations between medical school and career preferences in Year 1 medical students in Scotland. Med Educ. 2012;46(5):473-484. doi:10.1111/j.1365-2923.2012.04218.x.

2. Kaur B, Carberry A, Hogan N, Roberton D, Beilby J. The medical schools outcomes database project : Australian medical student characteristics. BMC Med Educ. 2014;14:180-190.

3. Scott I, Gowans M, Wright B, Brenneis F. Stability of Medical Student Career Interest. Acad Med. 2012;87(9):1260-1267. doi:10.1097/ACM.0b013e31826291fa.

4. Woolf K, Elton C, Newport M. The specialty choices of graduates from Brighton and Sussex Medical School: a longitudinal cohort study. BMC Med Educ. 2015;15:46.

5. Goldenberg MN, Sc M, Williams DK, Ph D, Spollen JJ. Stability of and Factors Related to Medical Student Specialty Choice of Psychiatry. 2017;(September):859-866. doi:10.1176/appi.ajp.2017.17020159.

6. ten Cate OTJ, Borleffs JCC, Van Dijk M, Westerveld T. Training Medical Students for the 21st Century: Rationale and Development of the Utrecht Curricullum "CRU+." Med Teach. 2018;40(5):461-466.

7. Querido S, Rond M De, Wigersma L, van den Broek WES, Ten Cate O. The Significance of Experiencing Clinical Responsibilities for Specialty Career Choice. Med Sci Educ. 2019. doi:10.1007/s40670-019-00832-z.

8. Heikkilä TJ, Hyppölä H, Vänskä J, et al. Factors important in the choice of a medical career: a Finnish national study. BMC Med Educ. 2015;15(1):169. doi:10.1186/s12909015-0451-x. 



\section{Chapter 7}

\section{General discussion}

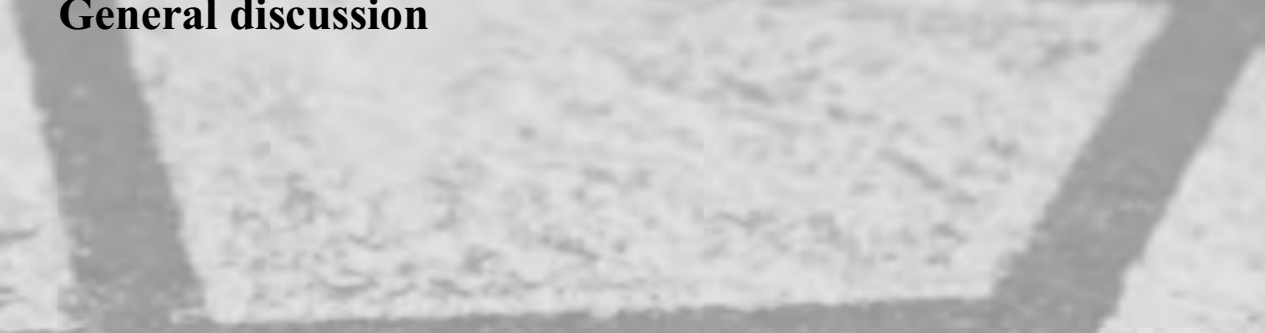


Medical graduates tend to prefer some specialties over others. This can lead to an imbalance between the needs of western society and the career choices of medical students. Medical career choice is an important and extensively studied theme. ${ }^{1-3}$ A general aim most studies share is how to establish a balanced workforce of physicians and therefore it is interesting to know how medical students make their career choice. Many students enter medical school with an idea of which specialist to become, but for most students this idea changes in the course of the study, and they actually start in another residency. ${ }^{4,5}$ A reason is that medical students appear to have misconceptions about the medical profession. ${ }^{6,7}$ As students gain experience during medical school, their career plans and preferences shift. Nevertheless, there are graduates who drop out of residency, which means capacity loss in the medical workforce and often personal damage to graduates. In this thesis we explored factors that determine the career choice of medical students and recent graduates in the Netherlands, and the reasons to drop out of residency.

The account of our study findings is organized around the five main research questions laid out in chapter 1 :

1. What is known from the literature about factors associated with career preferences and career choice?

2. Which factors determine the career choice of medical students during the final phase of medical school?

3. What is the impact of working as a physician-not-in-training (PNIT) between medical school and residency on career preferences and choice?

4. Why do residents drop out? Which factors influence their career choice?

5. How is the career choice stability of medical students over a period of time?

To answer these questions three different studies were conducted.

\section{Main findings}

\section{What is known from the literature about factors associated with career preferences and career choice?}

Career choice is a process with many interacting factors. There is a lack of a recent literature overview on medical career decision-making. We therefore, first, conducted a review about medical career decision-making in countries with a similar education system as the 
Netherlands. ${ }^{8}$ In chapter 2, we presented a more detailed model, than the former Bland model of $1997^{9}$ and especially provided an overview of the factors related to the needs and perceptions which determine the career choice. We also noticed that most studies included in this review, were cross-sectional. The review provided a longlist of factors of influence on medical career choice and supported the model of Bland, which states that medical career choice is formed by a matching of perceptions of specialty characteristics with personal needs. This review was limited to the research on medical career decision-making in educational systems with a Western European curriculum structure, which provided sufficient insight for our Netherlands-based study.

\section{Which factors determine the career choice of medical students during the final phase of medical school?}

While we established an extensive model about career choice, we also addressed the question which factors determine the career choice of medical students during the final study year and the later period. This required a longitudinal perspective, as this involved a longer period. Also, there is a lack of longitudinal studies of this kind. ${ }^{1,4,10-12} \mathrm{We}$ used the Bland model $^{9}$, with the added important factors of career choice which resulted from the review (chapter 2), as a lens to analyze the 24 interviews we performed with medical students about their career choice in the final study year (chapter 3). We interviewed them at the start of their final year. The results of this study show that students match and calibrate their perceptions of different specialty characteristics with their current personal needs and expected future needs, and also include cues from self-initiated information collection about a specialty. The results of this study produced three new factors: (1) factors arising from student-initiated information collection, (2) patient population characteristics of a specialty domain, and (3) the characteristics of teams and colleagues within a specialty. These items were not yet included in the Bland model or our review.

(1). Student-initiated information collection reflects how activities or information sources not offered in the regular education program influence a medical student's career choice. To inform medical students about the various options, many specialties use different methods, such as information events, one-day courses, or other opportunities, to attract students and let them experience a specialty. ${ }^{13-15}$ Especially for those medical specialties with no regular curricular activities and a shortage of medical specialists, this is an important possibility to show medical students their specialty and attract them. (2) Patient population characteristics of a specialty is not cited as a separate factor of influence in recent literature but it may be 
subsumed within other factors and therefore sometimes labelled differently (for example as interesting work, work content, contact with patients, or interest in relationships). ${ }^{10}$ Nevertheless, students explicitly mentioned this as separate factor. Many specialties have to deal with elderly and frail patients nowadays, whereas young medical students are often not attracted by this patient group. (3) The characteristics of teams and colleagues within a specialty are added as a separate factor because being part of a team can have a positive influence on the choice for a particular specialty. Also, team members play an important role in students' identification process and their fit with the group. ${ }^{16}$ This can result in a positive experience with the medical specialty. Second-year residents in the UK stated that experiences with one specialty team did profoundly shape their opinion of that entire specialty, and this could contribute to the attractiveness of a specialty. ${ }^{17}$ This aligns with the interviewees' opinion that the feeling of being treated and participating as a colleague in a team positively affects career choice. The results of this study were the factors of influence mentioned by medical students, the study was not meant to validate and weigh factors in the Bland model.

\section{What is the impact of working as a physician-not-in-training (PNIT) between medical school and residency on career preferences and choice?}

As we performed longitudinal research, we could compare the given answers, and notice particular trends such as having responsibility. In chapter 4 we explored if pre-residency clinical responsibilities influence career choice. We noted that the increase of responsibility as a medical student and when working as a graduate, supports having realistic experiences. Most of the participants mentioned that they needed the experience to feel more "certain of their own actions", to acquire "more knowledge and experience as a real doctor" and "to experience working in the context of their specialty of preference". This supported and sometimes confirmed their medical career preference. "The real work is really something different from what you have seen during your clerkships." They also stated that they needed these experiences to become more certain of their own actions and obtain more knowledge as a doctor. "When working as a PNIT, I learned so much in a few months. I really feel more certain to perform as a physician now. And these experiences also confirmed their preference. "This year [as a PNIT] I did so much and learned so much about the specialty, this reconfirmed my interest."

So, having a level of responsibility gives students good insight into their own needs, such as working hours, team / colleagues, content of the work. Secondly this shaped their view on the 
specialty and if and how the specialty fits with their personal future. The study concluded that clinical responsibilities stimulate to make a well-considered career choice. ${ }^{18}$ This aligns with Billett's learning theory, which emphasizes the role of the workplace as an implicit learning environment, wherein the way workplaces bring possibilities for learning and how individuals choose to participate in activities and are supported by the environment. This is called coparticipation, and provides a base for workplace learning. ${ }^{19,20}$ In particular, having the real clinical responsibilities can stimulate medical students and graduates to use the readiness of the workplace to afford opportunities for themselves to experience the specialty. This provides learning about the specialty and challenges a student or graduate to reflect if this experience contributes to either confirmation of, or changes in the career preferences.

If we look through the lens of the Bland model as used in chapter 2 and chapter 3, we see that responsibility determines ones needs through the perception of the specialty and this results in career choice. ${ }^{9}$ The Bland model already stated that the balance between the two items, needs and perceptions of the specialty, leads to career choice. With this study we would like to add to this model that more responsibilities lead to a better understanding of what a specialty requires. Responsibility is an element which exceeds this balance and can be drawn as a circle around these two elements. Perhaps responsibility is necessary to determine a sustainable choice. Self-Determination Theory (SDT) can be explanatory in this. It is a human motivation theory, that stresses that people pursue goal content through different regulatory processes. It identifies three different categories of motivation that extend on a continuum of increasing self-determination: amotivation, controlled motivation and autonomous motivation. ${ }^{21}$ Along this dimension, it is possible to distinguish specific types of regulatory styles, that vary in their degree of relative autonomy: from external to intrinsic regulation. Intrinsic motivation regulates behavior more strongly than extrinsic. SDT stipulates that intrinsic motivation is stimulated and maintained if three conditions are met, that is the need for (a) autonomy, (b) feelings of competence and (c) relatedness to a group of significant others. ${ }^{21}$ This, applied to our study, would mean that; a) autonomy can be found in experiencing a level of responsibility whereby the student or graduate can perform a task by themselves. b) responsibility strengthens the feeling to be more certain and becoming competent in this specialty. c). relatedness to belong to the team of the specialty. Providing an environment where medical students and graduates feel responsible, are valued for their competence and are part of the team is likely to stimulate the intrinsic motivation to make the specialty career choice. We therefore state that students and especially graduates need and benefit from experiences with full responsibility. The scope of the SDT-framework supports insight into 
motivations and reasons why students and graduates choose a specialty. Knowing these reasons is relevant to support student and graduate career choice. This requires a broader application of the SDT-frame in the research of medical career choice.

\section{Why do residents drop out? Which factors influence their career choice?}

Confirmation of the importance of experience and responsibilities in the preferred specialty can be found in the results in chapter 5 . The fourth research question was addressed through a survey among a large group of graduates who dropped out of residency in all specialties. This study provided information about the main reasons for drop-out: insufficient satisfaction with the nature of work, work-life disbalance, energy-consuming work, work different than expected and lifestyle incongruence. This is in line with previous research. ${ }^{22-25}$ Most reasons for drop-out weigh heavier for those without prior experience with the same specialty than for those with this experience. Of the respondents, 54\% $(\mathrm{N}=69)$ had previous experience within the same medical specialty before starting residency. This means that half of the residents started without having really experienced what a specialty is about and if this fits with their personal needs. Up to a third of the respondents suggests that better orientation and more PNIT experience could have prevented dropout. We concluded that graduates benefit from previous experience within the same specialty. They appear to need more guidance to interpret and reflect on their experiences, before making their definite career choice. Furthermore, to prevent dropout caused by the main reasons, especially the lifestyle-related issues, more guidance and mentorship for residents seems necessary about how to cope with high work load and to better navigate the balance between work and private life. We also stated that the training environment itself may be subject to scrutiny. Health care, with or without training, is an increasingly demanding environment. Residents increasingly suffer of burn-out and the effect on their physical and psychological well-being. ${ }^{26-28}$

To ensure the needed workforce by attracting and sustaining enough healthy residents we suggest that contextual adaptations of the training environment may be necessary. To ensure a balance between the demands of residency training and the challenges resident has to cope with, a healthy interplay between these is desirable.

\section{How is the career choice stability of medical students over a period of time?}

To answer this research question, chapter 6 provides a sketch of the stability of career paths of medical students. We distinguished three groups, those with a 'highway path', a 'country road' and a 'winding road'. Students with a 'highway' had a specific preference during 
medical school and explained in the interviews, that they used their experiences in the final year and especially as a graduate to be certain what this specialty requires before they would definitely choose to obtain their preferred residency position. To explain this, we might refer again to the Self-Determination Theory that says, that intrinsic motivation regulates behavior more strongly than extrinsic behavior. ${ }^{21}$ SDT stipulates that intrinsic motivation is stimulated and maintained if three conditions are met, that is the need for (a) autonomy, (b) feelings of competence and (c) relatedness to a group of significant others. ${ }^{21}$ Obviously, this group of 'highway' students has a strong intrinsic motivation, probably based on character or circumstances which stimulate autonomy and feelings of self-competence.

Students with a 'country road' or a 'winding road' paths hesitated about their preferences and used their period as a graduate to experience multiple specialties, after which they finally chose their specialty. Our impression is that those with a 'country' or 'winding road' path started residency in an 'unknown' specialty. When we look into the data of the small sample we notice that those who switched their career preferences are ultimately attracted to a specialty which was not experienced during medical school, such as elderly care physician, psychiatry and international \& tropical medicine. These students may either have less selfconfidence or are less autonomous than the 'highway' group, or on the other hand may be more adventurous.

A study in the U.K. showed a $65 \%$ stability of medical students' first career preference in year four until residency. ${ }^{29}$ While in our study just 35\% (7 of the 20) participants started residency in their first preference stated in the first interview; therefore, we also weighed in their second preference. This provided a much more realistic image of medical students' career preferences and related stability, as many students have a second-best plan.

The study in chapter 6 shows that the final study year with increased responsibilities contributes for those with a fixed ('highway') career preference. For those who are more hesitant the period after medical school is needed to choose, in order to first experience the specialty with more responsibilities, as described in chapter 4 . These findings thus suggest that experience as a graduate leads to better specialty streaming.

In the Netherlands, some specialties deal with a shortage of residents and would benefit from more graduates and future residents. ${ }^{30,31}$ In 2020, "The Dutch Blueprint", the revision of the national framework of objectives for medical education of the Dutch physician, was presented. ${ }^{32}$ This framework explicitly mentions the importance of more emphasis on, and education in specialties outside the hospital, this concerns mainly the unpopular specialties. Previous research of Coffeng et al. showed that the first clinical clerkship has more impact on 
career preference than the second (for male students). This means that the order of clerkships is relevant for career preferences. ${ }^{33}$ These results could offer universities the ability to influence career preference among medical students. As more medical students should have clerkships and internships, with a certain level of responsibility as stated in this thesis, preferences could be influenced for the benefits of specialties with shortages. Future research, as also advised by Coffeng et al. ${ }^{33}$, needs to look if the effect will be similar for female students and if this positive association is applicable for all specialties.

\section{Strengths and limitations}

The strengths of this research are the longitudinal approach, the complete dataset used for the survey and the combination of research methods.

First, the studies in this thesis are among the first to examine medical students' career choice in a longitudinal perspective. We approached career choice through the lens of the Bland model and followed the development of establishing career choice over a period of 3,5 years. ${ }^{9}$ This lens helped to understand how medical students balance their needs to satisfy and perceptions of a specialty and finally make their specialty choice.

Second, our unique data set provided by the Dutch Medical Registration Board (in Dutch: RGS) made it possible to collect information of all Dutch graduates of all medical specialties who dropped out of residency in a period of two years. With the response rate of the survey this encompasses a representative group and therefore the findings are generalizable. Previous research into dropout of residency, particular in the Netherlands, was performed for hospital specialties only. ${ }^{22}$ We extend upon this data using a complete sample of residents in hospital and non-hospital specialties who recently dropped out.

A third strength was the use of multiple methods to address our research questions; literature review, interviews, survey study and a mixed method study. We performed qualitative interviews using a phenomenology approach, conducted a national quantitative study and performed a study to extract scores from multiple longitudinal interviews to predict career paths. This combination led to deeper insights to the main research question.

The study has several limitations. Our use of the model of Bland et al. ${ }^{9}$ may be seen as limitation as well as a strength. We did use the full scope of the model, but in the interviews mainly factors related to the considerations and experiences of the students arose. The influence of the factors related to the educational program, such as sequence of clerkships, topics of education, and composition of tutor groups were limited revealed by this study. 
These factors are mainly not visible for students, while this may have played a role in their career preferences and final career choice.

The body of our results is associated with Utrecht University using one small group of medical students, and it is by no means self-evident that they apply to other medical students. Therefore, our findings should only be generalized with caution. However, we believe studying this topic at one university, which is quite similar to other Dutch universities, makes is possible to inform other countries with similar models of medical education about factors of career choice related to a particular curriculum. ${ }^{8}$ In addition, our interview study involved voluntary participation. This could have led to a limited representation of the total group of medical students. We did try to include as many students as possible, by inviting them multiple times through lectures and emails.

\section{Suggestions for the practice of medical education}

In this thesis we explored factors of influence of medical students and graduates career choice, the reasons of drop-out and the stability of career choice. Based on our findings we propose the following implications for practice for medical education.

\section{Model of career choice}

We searched for the factors of influence of career choice of medical students and graduates, in the literature and by interviews. For this research we used the scope of the theoretical model of career choice of Bland et al., as this provides a broad scope into this topic. ${ }^{9}$ This model suggests that career choice emerges from the matching of perceptions of specialty characteristics with personal and social needs. The needs are determined by the preferences and values of a student, affected by student characteristics and educational program characteristics. The stronger the perceived similarity between needs and the perceived characteristics of a specialty, the stronger the desire for this specialty as a career choice. ${ }^{9}$ With the review we started to provide a more detailed model. Next, we performed a first study about factors affecting medical career choice among medical students. The results of this study produced three new factors: (1) factors arising from student-initiated information collection, (2) patient population characteristics of a specialty domain, and (3) the characteristics of teams and colleagues within a specialty. And finally, we investigated in a second study, the impact of working as a PNIT and concluded that responsibility is needed to balance the perceptions of specialty characteristics with personal and social needs and finally to make the career choice. During this process of career choice stability of career preference 
increases as explained in our study about career paths. We summarized these findings within the Bland model and integrated the phases of medical education. This model can be used to support medical students and graduates with their career choice, presented in Figure 1.

The elements present in the literature or derived from the interviews are presented black in the model. Factors not revealed in this thesis are presented grey.

Figure 1 Model of variables that determine medical students' and graduates career choice during medical education based on Bland et al. $1995^{9}$

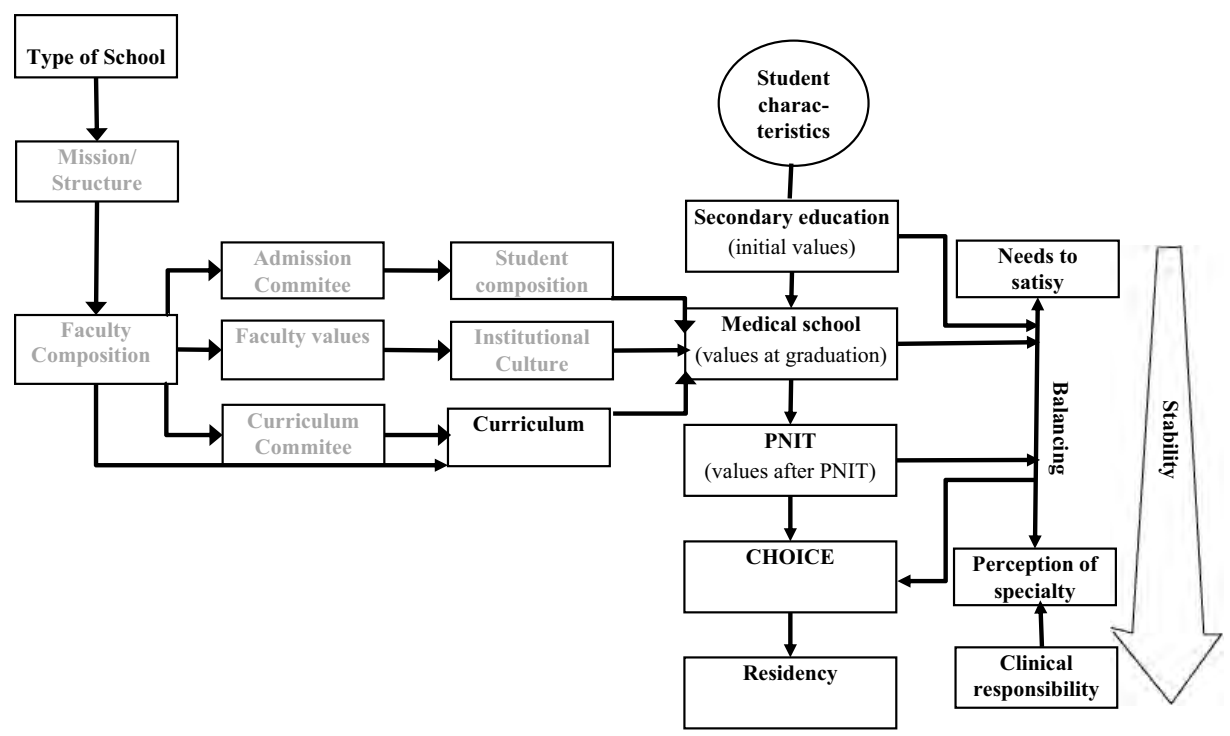

We concluded that clinical responsibility is pivotal to experience one's needs and perceptions in a real setting. This leads to a better balance between these items and to make a matching choice. This thesis was not set up to test the model, nevertheless the result broadens the applicability of the Bland model, originally created for primary care careers, to medical specialties in general.

\section{More experiences to establish career preference}

Specialty choice is an important matter of concern for the future workforce planning. As some specialties have to deal with shortage, the career preferences of medical students have to change has in order to fulfill society's healthcare needs. Most specialties which suffer from shortages, are not presented in the curriculum of all medical schools. As we know clerkship experience stimulates career preference ${ }^{34}$, or it turns out to be a confirmation of rejection of a 
specialty. Nevertheless, the experience determines one's career preference. ${ }^{18}$ Our study concluded that clinical experience is needed to make the final career choice for students and graduates. See the selected text from the interviews of Emily and Zoe in the introduction section of this thesis. They both tell their personal considerations and the relevance of the PNIT-period they experienced. We also mentioned the lack of experience by almost half of the graduates who dropped out of residency. This confirms our findings that clinical experience, especially as a PNIT, is needed to make the definite choice.

Furthermore, this study was performed in a medical school were students experience the Utrecht curricula. Other medical school curricula are designed differently and provide compulsory clerkships in specialties which have shortages in residents. For example, the Nijmegen curricula provides a clerkship elderly care medicine. The result is that more students of this university, compared to other universities, have a positive image of the specialty and more graduates from this university appeal for a residency position elderly care medicine. We consider it to be benefit that those specialties with shortages will be more integrated in the curriculum and more students can experience these specialties.

\section{Career choice support}

Another implication of this research can be found in that students' and graduates should be given more guidance in the process of making the career choice. Our study shows that graduates use their PNIT period to become more certain, to acquire more knowledge and the experience really working in the specialty. The level of responsibility provides them to discover if a specialty suits their preference. Participating in patient care and becoming part of the team of specialists allows them to get acquainted with the specialty. ${ }^{16}$ Should this finding have consequences for the guidance students and graduates receive? Many graduates can make the choice themselves, as $97,5 \%$ do complete their residency. ${ }^{30}$ Moreover, the average time from graduation to start residency is 34,2 months in the Netherlands, of which 17,5 months before the graduate starts to search for a residency position. ${ }^{30,35}$ This means that they search for 1.5 years before they know which specialty they want. Most graduates do this by themselves as graduates are not guided in making their final career choice. Can we reduce this searching time with support to reflect on their PNIT period? This will also answer the wish to shorten the total training time from student to medical specialist. ${ }^{36-38}$

We suggest more coaching for graduates before starting residency, to reflect on the experiences they have, the needs they have and which specialty fits best. This will establish a better insight in what the specialty requires for them as a professional and personally. Our 
study showed that those who drop-out missed a good image of the specialty. Having a good insight, before starting residency, can also reduce the number residents who dropout of residency.

Further, it is advisable to be aware of a graduate's motivational reasons to start residency. We stated before that motivation is stimulated and maintained if three conditions are met, that is the need for (a) autonomy, (b) feelings of competence and (c) relatedness to a group of significant others. ${ }^{21,25,39}$ How do we keep our residents motivated during residency? An increasing number of residents and specialist are less happy with their jobs. ${ }^{40-42} \mathrm{We}$ assume that mentoring and coaching about becoming a healthy and satisfied specialist is needed. Special attention to a resident's personal motivation can help to keep the balance between their professional and private life's.

This all can lead to a better balance between the needs of society and the career preferences of students and graduates.

\section{Implications for future research}

The main findings emphasized the importance of clinical responsibility in making the final career choice and the value of real experiences before starting residency. The results of this thesis lead to suggestions for further research on this topic.

First, further research needs to conduct a large and national similar longitudinal study about medical students' career preferences and development during and after medical school. This can be used to compare the reasons for career choice of medical students and graduates and provide support and guidance for all Dutch students.

Second, more research is needed to identify the impact of the single factor responsibility. This is a major finding in our longitudinal study. A further study with more focus on what kind of responsibility is needed to make the definite choice, is suggested.

Next, a study which aims to explore the concept of stability and career paths, including first and second preferences. Our study developed a first insight in the concept of stability by the 'highway road', the 'country road' and the 'winding' road. Further research can investigate if this concept is generalizable for the total population. 
More research would be advisable to perform a similar study among those how do successfully finished residency. A study with focus on what influenced their choices and how their stability of career can be described. This research needs to make a comparison about the factors of influence on career choice between those who finish residency and those who drop out.

Finally, research is needed to study the effect of the changing Dutch curricula, with more attention for the non-hospital-based specialties. Will there be a better balance between the preferences of Dutch physicians and the workforce of the society at large when a more divers curricula is offered to students?

\section{Conclusion}

This thesis aimed to contribute to identifying factors that determine the career choice of medical students and recent graduates in the Netherlands.

The research presented demonstrated that only clinical responsibilities foster deep experience of a medical specialty and awareness of one's own needs. Our findings confirmed that clinical responsibility supports medical students in determining their career preference. We also found that clinical responsibilities for graduates are pivotal to make specialty career choice. This research also distinguished three different career paths of medical students and graduates presenting stability of career choice during medical education.

Finally, we developed an extended model of career choice based on the Bland model ${ }^{9}$. We would like to suggest that medical students and recent graduates can benefit from career choice guidance. This will also support residents to cope with the high work load and to better navigate the balance between work and private life. Furthermore, we want to suggest that Dutch postgraduate education boards consider to reconsider the demands of the training environment to complete residency by healthy residents. 


\section{References}

1. Pfarrwaller E, Sommer J, Chung C, et al. Impact of Interventions to Increase the Proportion of Medical Students Choosing a Primary Care Career: A Systematic Review. J Gen Intern Med. 2015;30(9):1349-1358.

2. Shadbolt N, Bunker J. Choosing general practice: A review of career choice determinants. Aust Fam Physician. 2009;38(1-2):53-55.

3. Soethout M, Ten Cate TJ, van der Wal G. Factors associated with the nature, timing and stability of the specialty career choices of recently graduated doctors in European countries, a literature review. Med Educ. 2004;9(24):1-9.

4. Cleland JA, Johnston PW, Anthony M, Khan N, Scott NW. A survey of factors influencing career preference in new-entrant and exiting medical students from four UK medical schools. BMC Med Educ. 2014;14(1):151. doi:10.1186/1472-6920-14151 .

5. Kaur B, Carberry A, Hogan N, Roberton D, Beilby J. The medical schools outcomes database project: Australian medical student characteristics. BMC Med Educ. 2014;14:180-190.

6. Soethout MBM, Heymans MW, ten Cate OTJ. Career preference and medical students' biographical characteristics and academic achievement. Med Teach. 2008;30(1):e15e22. doi:10.1080/01421590701759614.

7. Underwood MJ, Thompson M, McCaskie A. Insight of first-year medical students into their future working conditions. Med Educ. 1990;24(3):210-211. doi:10.1111/j.13652923.1990.tb00002.x.

8. Wijnen-Meijer M, Burdick W, Alofs L, Burgers C, ten Cate O. Stages and transitions in medical education around the world: clarifying structures and terminology. Med Teach. 2013;35(4):301-307.

9. Bland C, Meurer L, Maldona G. Determinants of primary care specialty choice; A nonstatistical meta-analysis of the literature. 1995:70(7):620-641.

10. Goel S, Angeli F, Dhirar N, Singla N, Ruwaard D. What motivates medical students to select medical studies : a systematic literature review. BMC Med Educ. 2018;18(16):110. doi:10.1186/s12909-018-1123-4.

11. Creswell JW. Educational Research. Planning, Conducting and Evaluating Quantitative and Qualitative Research. fourth. (Smith P, ed.). Boston: Pearson; 2016.

12. Soethout M. Career preference of medical students and career choice of recent graduates general and in public health in particular [doctoral dissertation]. 2007.

13. Ahmed K, Bennett DM, Halder N, Byrne P. Medfest : the Effect of a National Medical Film Festival on Attendees ' Attitudes to Psychiatry and Psychiatrists and Medical Students ' Attitudes to a Career in Psychiatry. Acad Psychiatry. 2015;39(3):335-338. doi:10.1007/s40596-014-0184-x.

14. Agyapong VIO, McLoughlin D. Promoting Psychiatry as a Career Option for Ghanaian Medical Students Through a Public-Speaking Competition. Acad Psychiatry36. 2012;36(3):229-232. 
15. Bridgeman A, Findlay R, Devnani A, Lim D, Loganathan K. Inspiring the next generation of Cardiothoracic Surgeons : an easily reproducible, sustainable event increases UK undergraduate interest in the specialty. Interact Cardiovasc Thorac Surg. 2016;22(October 2015):106-108. doi:10.1093/icvts/ivv280.

16. Broek S Van Den, Querido S, Wijnen-meijer M, van Dijk van M, ten Cate O. Social Identification with the Medical Profession in the Transition from Student to Practitioner. Teach Learn Med. 2020;32(3):271-281. doi:10.1080/10401334.2020.1723593.

17. Spooner S, Pearson E, Gibson J, Checkland K. How do workplaces, working practices and colleagues affect UK doctors' career decisions? A qualitative study of junior doctors ' career decision making in the UK. BMJ Open. 2017;e018462.:1-9. doi:10.1136/bmjopen-2017-018462.

18. Querido S, Rond M De, Wigersma L, van den Broek WES, Ten Cate O. The Significance of Experiencing Clinical Responsibilities for Specialty Career Choice. Med Sci Educ. 2019. doi:10.1007/s40670-019-00832-z.

19. Billett S. Learning through work: Workplace affordance and individual engagement. $J$ Work Learn. 2001;13(5):209-214.

20. Billett S. Subjectivity, Self and Personal Agency in Learning Through and for Work. In: Malloch M, Cairs L, Evans E, O'Connor B, eds. The Sage Handbook of Workplace Learning. 1st ed. London: Sage Publications Inc.; 2011:52-62.

21. Ryan RM, Deci, Edward L. Self-determination theory. Self-Determination Theory Facil Intrinsic Motiv Soc Dev Well-Being. 2000;55(1):68-78. doi:10.1037??0003066X.55.1.68.

22. Bustraan J, Dijkhuizen K, Velthuis S, et al. Why do trainees leave hospital-based specialty training? A nationwide survey study investigating factors involved in attrition and subsequent career choices in the Netherlands. BMJ Open. 2019;9:1-8. doi:10.1136/bmjopen-2018-028631.

23. Khoushhal Z, Hussain M, Greco E, et al. Prevalence and Causes of Attrition Among Surgical Residents A Systematic Review and Meta-analysis. JAMA Surg. 2017;152(3):265-272. doi:10.1001/jamasurg.2016.4086.

24. Velden L, Batenburg R. Results Internal Efficiency Post-Graduate Trainings 2019 [in Dutch]. Utrecht; 2019.

25. Symer MM, Abelson JS, Yeo HL, Sosa JA, Rosenthal MZ. The Surgical Personality: Does Surgery Resident Motivation Predict Attrition? J Am Coll Surg. 2018;226(5):777783. doi:10.1016/j.jamcollsurg.2018.02.007.

26. Mata DA, Ramos MA, Bansal N, et al. Prevalence of Depression and Depressive Symptoms Among Resident Physicians. Jama. 2015;314(22):2373-2383. doi:10.1001/jama.2015.15845.

27. Rotenstein LS, Ramos MA, Torre M, et al. Prevalence of Depression, Depressive Symptoms, and Suicidal Ideation Among Medical Students. Jama. 2016;316(21):2214 2236.

28. Rotenstein LS, Torre M, Ramos MA, et al. Prevalence of Burnout Among Physicians A Systematic Review. Jama. 2019;320(11):1131-1150. doi:10.1001/jama.2018.12777. 
29. Woolf K, Elton C, Newport M. The specialty choices of graduates from Brighton and Sussex Medical School: a longitudinal cohort study. BMC Med Educ. 2015;15:46.

30. Advisory Committee on Medical Manpower Planning. Medical Manpower Planning Main Report [In Dutch]. Utrecht; 2019. https:/capaciteitsorgaan.nl/app/uploads/2020/02/2020_02_12-Capaciteitsplan-20212024-Hoofdrapport-DEFINITIEF-EN.pdf.

31. The medical student association. Underexposed Residencies [in Dutch]. Utrecht; 2018. https://degeneeskundestudent.nl/nieuws-en-standpunten/onderzoeksrapporten-2018.

32. Pol M van de, Hacfoort M, Laan R. The Dutch Framework 2020 [in Dutch]. Utrecht; 2020.

33. Coffeng LE, Visscher AJE, Ten Cate OTJ. The influence of early clinical experiences on career preference of male and female medical students. 2009;31:e323-e326. doi:10.1080/01421590802650084.

34. Kamalski DMA, Ter Braak EWMT, Ten Cate OTHJ, Borleffs JCC. Early clerkships. Med Teach. 2007;29(9):915-920.

35. Velde F van der, Leemkolk B van de, Lodder A. Loopbanen En Loopbaanwensen van Basisartsen Meting 2019 [in Dutch]. Utrecht. Prismant; 2019.

36. Cangiarella J, Fancher T, Jones B, et al. Three-Year MD Programs: Perspectives from the Consortium of Accelerated Medical Pathway Programs (CAMPP). Acad Med. 2017;92(4):483-490. doi:10.1097/ACM.0000000000001465.

37. (NFU) NF van UMC. Vormgeving van het dedicated schakeljaar [in Dutch]. http://www.nfu.nl/programma/dedicated-schakeljaar/status/. Published 2015.

38. Dutch Federation of Universities (NFU in Dutch). Dedicated Schakeljaar [in Dutch]. Utrecht; 2020.

39. Roos M, Watson J, Dch MD, Wensing M. Motivation for career choice and job satisfaction of GP trainees and newly qualified GPs across Europe: a seven countries cross-sectional survey. Educ Prim Care. 2014;25:202-210.

40. Kravitz RL. Physician job satisfaction as a public health issue. Isr J Health Policy Res. 2012;1(1):51-52. doi:10.1186/2045-4015-1-51.

41. Leigh JP, Tancredi DJ, Kravitz RL. Physician career satisfaction within specialties. BMC Health Serv Res. 2009;(9):166-178. doi:10.1186/1472-6963-9-166.

42. Williams ES, Skinner AC. Outcomes of physician job satisfaction: a narrative review, implications, and directions for future research. Health Care Manage Rev. 2003;28(2):119-139. 


Appendices

Appendix 1 Total table of literature review

Appendix 2 Interview questions used for interviews

Appendix 3 Survey questions about drop-out of residency 
- Appendix 1

Appendix 1 Total table of study characteristics and methodological quality of included studies of literature review, available as supplement, Querido et al. 2015.

\begin{tabular}{|c|c|c|c|c|c|c|c|c|c|c|c|c|c|c|}
\hline & & & & & & & & & eth & odo & ogi & cal & qua & \\
\hline $\mathrm{Nr}$ & First author & $\begin{array}{l}\text { Pub. } \\
\text { Year }\end{array}$ & $\begin{array}{l}\text { Cou } \\
\text { ntry }\end{array}$ & $\begin{array}{l}\text { Desi } \\
\text { gn }\end{array}$ & $\begin{array}{l}\text { Sample } \\
\text { size }(\mathrm{N}) \\
\end{array}$ & $\begin{array}{l}\text { Resp. } \\
(\%)\end{array}$ & $\mathbf{A}$ & B & $\mathrm{C}$ & D & $\mathbf{E}$ & $\mathbf{F}$ & G & Sum \\
\hline 1 & Cleland & 2012 & GBR & $\mathrm{CS}$ & 1005 & 88 & 2 & 2 & 3 & 3 & 3 & 2 & 2 & 17 \\
\hline 2 & Takeda & 2013 & JPN & $\mathrm{CS}$ & $3089 / 1370$ & $80 / 70$ & 2 & 2 & 3 & 3 & 3 & 2 & 2 & 17 \\
\hline 3 & Cleland & 2014 & GBR & $\mathrm{CS}$ & $1657 / 1628$ & $80 / 81$ & 2 & 2 & 3 & 2 & 3 & 2 & 2 & 16 \\
\hline 4 & Lefèvre & 2010 & FRA & $\mathrm{CS}$ & 2588 & 67 & 2 & 2 & 2 & 3 & 3 & 2 & 2 & 16 \\
\hline 5 & Lefèvre & 2010 & FRA & $\mathrm{CS}$ & 2588 & 67 & 2 & 2 & 2 & 3 & 3 & 2 & 2 & 16 \\
\hline 6 & Lempp & 2012 & GER & $\mathrm{CS}$ & 610 & 94 & 2 & 2 & 3 & 2 & 3 & 2 & 2 & 16 \\
\hline 7 & Bindal & 2011 & GBR & $\mathrm{CS}$ & 131 & 97 & 2 & 2 & 3 & 1 & 3 & 2 & 2 & 15 \\
\hline 8 & Coulston & 2012 & AUS & $\mathrm{CS}$ & 580 & 100 & 2 & 2 & 3 & 1 & 3 & 2 & 2 & 15 \\
\hline 9 & Diderichsen & 2013 & SWE & $\mathrm{CS}$ & 421 & 87 & 2 & 2 & 3 & 1 & 3 & 2 & 2 & 15 \\
\hline 10 & Lampe & 2010 & AUS & $\mathrm{CS}$ & 82 & 93 & 2 & 2 & 3 & 1 & 1 & 2 & 2 & 15 \\
\hline 11 & Kuhnigk & 2009 & GER & $\mathrm{CS}$ & 341 & 87 & 2 & 2 & 3 & 1 & 3 & 2 & 2 & 15 \\
\hline 12 & Malhi & 2011 & AUS & $\mathrm{CS}$ & 580 & 99 & 2 & 2 & 3 & 1 & 3 & 2 & 2 & 15 \\
\hline 13 & Tambyraja & 2008 & GBR & $\mathrm{CS}$ & 223 & 87 & 2 & 2 & 3 & 1 & 3 & 2 & 2 & 15 \\
\hline 14 & Tay & 2009 & GBR & $\mathrm{CS}$ & 72 & 83 & 2 & 2 & 3 & 1 & 3 & 2 & 2 & 15 \\
\hline 15 & $\begin{array}{l}\text { van } \\
\text { Tongeren- } \\
\text { Alers } \\
\end{array}$ & 2011 & NLD & $\mathrm{CS}$ & 657 & 94 & 2 & 2 & 3 & 1 & 3 & 2 & 2 & 15 \\
\hline 16 & Coffeng & 2009 & NLD & LRC & 488 & 99 & 2 & 2 & 3 & 1 & 2 & 2 & 2 & 14 \\
\hline 17 & Davis & 2009 & GBR & LPP & 121 & 77 & 2 & 2 & 2 & 3 & 1 & 2 & 2 & 14 \\
\hline 18 & Deutsch & 2014 & GER & LPC & 1398 & 64 & 2 & 2 & 2 & 1 & 3 & 2 & 2 & 14 \\
\hline 19 & Gibis & 2012 & GER & $\mathrm{CS}$ & 79929 & 16 & 2 & 2 & 0 & 3 & 3 & 2 & 2 & 14 \\
\hline 20 & Heiligers & 2012 & NLD & $\mathrm{CS}$ & 4100 & 36 & 2 & 2 & 0 & 3 & 3 & 2 & 2 & 14 \\
\hline 21 & Heinz & 2012 & GER & $\mathrm{CS}$ & 79929 & 16 & 2 & 2 & 0 & 3 & 3 & 2 & 2 & 14 \\
\hline 22 & Hughes & 2008 & GBR & $\mathrm{CS}$ & $169 / 120$ & $99 / 88$ & 2 & 2 & 3 & 1 & 2 & 2 & 2 & 14 \\
\hline 23 & Kumar & 2012 & IND & $\mathrm{CS}$ & 356 & 79 & 2 & 2 & 2 & 1 & 3 & 2 & 2 & 14 \\
\hline 24 & Maiorova & 2008 & NLD & LPC & 206 & 89 & 2 & 2 & 2 & 1 & 3 & 2 & 2 & 14 \\
\hline 25 & Mehmood & 2013 & SAU & $\mathrm{CS}$ & 590 & 92 & 2 & 2 & 3 & 1 & 2 & 2 & 2 & 14 \\
\hline 26 & Ravindra & 2011 & GBR & $\mathrm{CS}$ & 320 & 65 & 2 & 2 & 2 & 1 & 3 & 2 & 2 & 14 \\
\hline 27 & Svirko & 2013 & GBR & $\mathrm{CS}$ & 18489 & 52 & 2 & 2 & 1 & 3 & 2 & 2 & 2 & 14 \\
\hline 28 & Soethout & 2008 & NLD & $\mathrm{CS}$ & 4019 & 77 & 2 & 2 & 2 & 1 & 3 & 2 & 2 & 14 \\
\hline 29 & Thapper & 2013 & GBR & $\mathrm{CS}$ & - & - & 2 & 2 & 0 & 3 & 3 & 2 & 2 & 14 \\
\hline 30 & Budd & 2011 & GBR & $\mathrm{CS}$ & - & - & 2 & 2 & 0 & 2 & 3 & 2 & 2 & 13 \\
\hline 31 & Deutsch & 2013 & GER & LPP & 140 & 95 & 2 & 2 & 3 & 1 & 1 & 2 & 2 & 13 \\
\hline 32 & Rabadan & 2010 & ESP & LPP & 81 & $54 / 97$ & 2 & 2 & 1 & 1 & 3 & 2 & 2 & 13 \\
\hline 33 & Gedrose & 2012 & GER & $\mathrm{CS}$ & 2107 & 48 & 2 & 2 & 0 & 2 & 3 & 2 & 2 & 13 \\
\hline 34 & Hermann & 2012 & GER & $\mathrm{CS}$ & 12062 & 11 & 2 & 2 & 0 & 2 & 3 & 2 & 2 & 13 \\
\hline 35 & Kiolbassa & 2011 & GER & $\mathrm{CS}$ & 12062 & 11 & 2 & 2 & 0 & 2 & 3 & 2 & 2 & 13 \\
\hline 36 & Maudsley & 2010 & GBR & LPC & - & - & 2 & 0 & 3 & 1 & 3 & 2 & 2 & 13 \\
\hline 37 & Robertson & 2009 & AUS & LPP & 1103 & 11 & 2 & 2 & 0 & 1 & 3 & 2 & 2 & 13 \\
\hline 38 & Steinhäuser & 2013 & GER & $\mathrm{CS}$ & 12062 & 11 & 2 & 2 & 0 & 2 & 3 & 2 & 2 & 13 \\
\hline 39 & Abdulghani & 2013 & SAU & $\mathrm{CS}$ & 1300 & 67 & 2 & 0 & 2 & 1 & 3 & 2 & 2 & 12 \\
\hline 40 & Al-Nuaimi & 2008 & GBR & $\mathrm{CS}$ & 1988 & 20 & 2 & 2 & 0 & 1 & 3 & 2 & 2 & 12 \\
\hline
\end{tabular}




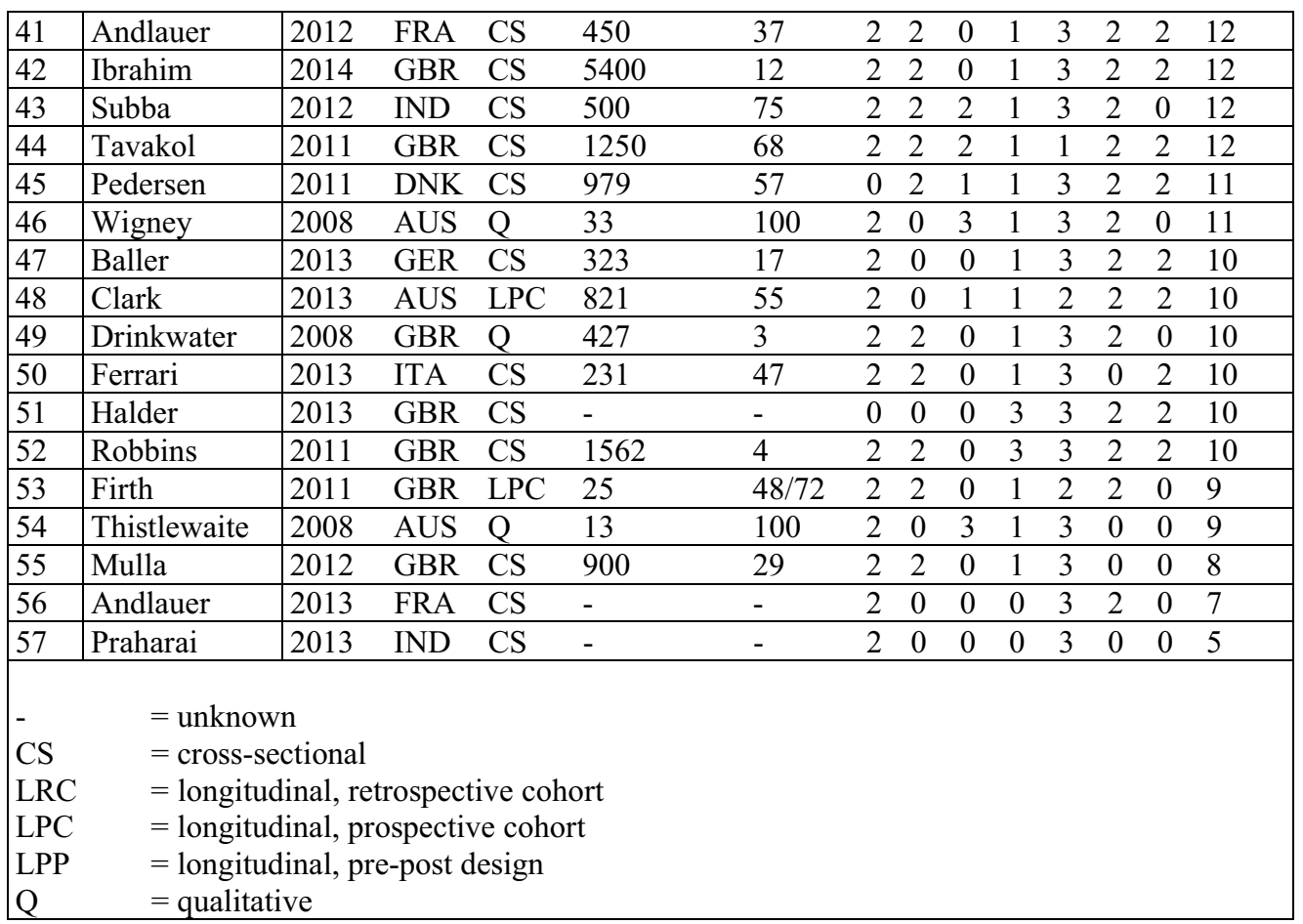

\section{Detailed information of the quality rating list}
A: Study Purpose
B: Study design
C: Response rate

D: Kind of survey

E: Number of investigated factors

F: Career or profession

G: Statistical analysis
2 pts if a specific purpose was clearly described, 0 pts if not/ unknown

2 pts if the study design was clearly described, 0pts if not/ unknown

3 pts if the response rate was at least $80 \%$ or the response rate of the study was between $65 \%$ and $80 \%$ and survey was carried out, $2 \mathrm{pts}$ if the response rate was between $65 \%$ and $80 \%$ or the response rate was between $50 \%$ and $65 \%$ and a survey was carried out, $1 \mathrm{pt}$ if the response rate was between $50 \%$ and $65 \%$, and 0 pts if unknown

3 pts if data were collected from a national survey, 2 pts if data were collected from a regional survey, $1 \mathrm{pt}$ if data were collected from a local survey, and 0pts if unknown

3 pts if more than 2 factors associated with the choice of medical career were investigated, 2 pts if 2 factors associated with the choice of medical career were investigated, $1 \mathrm{pt}$ if 1 factor associated with the choice of medical career was investigated, and $0 \mathrm{pts}$ if unknown

2 pts if actual medical career or profession was investigated, 0pts if not/ unknown

2 pts if a statistical analysis was performed for the outcome, 0pts if not/ unknown 
Appendix 2 Interview questions used for multiple interviews of

$$
\text { longitudinal study }
$$

\begin{tabular}{|c|c|c|c|}
\hline $\begin{array}{l}\text { Start of the final } \\
\text { year of medical } \\
\text { school (interview 1) }\end{array}$ & $\begin{array}{l}\text { nd of the final } \\
\text { car of medical } \\
\text { hool (interview 2) }\end{array}$ & $\begin{array}{l}1 \text { year after } \\
\text { graduation } \\
\text { (interview } 3 \text { ) }\end{array}$ & $\begin{array}{l}\text { 2,5 years after } \\
\text { graduation } \\
\text { (interview 4) }\end{array}$ \\
\hline $\begin{array}{l}\text { 1) Why did you } \\
\text { choose to study } \\
\text { medicine? } \\
\text { 2) What are your } \\
\text { career preferences? } \\
\text { Can you explain for } \\
\text { each of these why and } \\
\text { since when? } \\
\text { 3) How familiar are } \\
\text { you with these } \\
\text { preferences? And } \\
\text { what have you done to } \\
\text { become familiar with } \\
\text { them? } \\
\text { 4) What is the opinion } \\
\text { of your family, friends } \\
\text { or others about your } \\
\text { career preference? } \\
\text { And what does that } \\
\text { opinion mean to you? } \\
\text { 5) Which were your } \\
\text { electives during the } \\
\text { transitional year and } \\
\text { why did you choose } \\
\text { these? } \\
\text { 6) Tell me your } \\
\text { strategy to get into the } \\
\text { residency of your } \\
\text { choice } \\
\text { 7) What would be } \\
\text { your definite choice } \\
\text { just for the upcoming } \\
\text { five minutes? } \\
\text { 8) What else do you } \\
\text { want to tell me about } \\
\text { your career } \\
\text { preferences/choice? }\end{array}$ & $\begin{array}{l}\text { 1) What are your } \\
\text { career preferences? } \\
\text { Can you explain for } \\
\text { each of these why } \\
\text { and since when? } \\
\text { 2) How familiar are } \\
\text { you with these } \\
\text { preferences? And } \\
\text { what have you done } \\
\text { to become familiar } \\
\text { with them? } \\
\text { 3) Can you reflect on } \\
\text { your transitional } \\
\text { year? } \\
\text { 4) What is the } \\
\text { opinion of your } \\
\text { family, friends or } \\
\text { others about your } \\
\text { career preference? } \\
\text { And what does that } \\
\text { opinion mean to } \\
\text { you? } \\
\text { 5) Tell me your } \\
\text { strategy to get into } \\
\text { the residency of your } \\
\text { choice } \\
\text { 6) Did any changes } \\
\text { occur in your life of } \\
\text { influence on your } \\
\text { career preference } \\
\text { over the last year? } \\
\text { 7) What would be } \\
\text { your definite choice } \\
\text { just for the } \\
\text { upcoming five } \\
\text { minutes? } \\
\text { 8) What else do you } \\
\text { want to tell me about } \\
\text { your career } \\
\text { preferences/choice? }\end{array}$ & $\begin{array}{l}\text { 1) What are your } \\
\text { career preferences? } \\
\text { Can you explain for } \\
\text { each of these why } \\
\text { and since when? } \\
\text { 2) How familiar are } \\
\text { you with these } \\
\text { preferences? And } \\
\text { what have you done } \\
\text { to become familiar } \\
\text { with them? } \\
\text { 3) Can you reflect on } \\
\text { the last year after } \\
\text { graduation? } \\
\text { 4) Are you working? } \\
\text { And does reality } \\
\text { matches your } \\
\text { expectations? } \\
\text { 5) What is the } \\
\text { opinion of your } \\
\text { family, friends or } \\
\text { others about your } \\
\text { career preference? } \\
\text { And what does that } \\
\text { opinion mean to } \\
\text { you? } \\
\text { 6) Tell me your } \\
\text { strategy to get into } \\
\text { the residency of your } \\
\text { choice or how did } \\
\text { you got your } \\
\text { residency position? } \\
\text { 7) Did any changes } \\
\text { occur in your life of } \\
\text { influence on your } \\
\text { career preference } \\
\text { over the last year? } \\
\text { 8) What would be } \\
\text { your definite choice } \\
\text { just for the } \\
\text { upcoming five } \\
\text { minutes? } \\
\text { 9) What will be your } \\
\text { preference / career in }\end{array}$ & $\begin{array}{l}\text { 1) What are your } \\
\text { career preferences? } \\
\text { Can you explain for } \\
\text { each of these why } \\
\text { and since when? } \\
\text { 2) How familiar are } \\
\text { you with these } \\
\text { preferences? And } \\
\text { what have you done } \\
\text { to become familiar } \\
\text { with them? } \\
\text { 3) Can you reflect on } \\
\text { the last } 1,5 \text { year after } \\
\text { graduation? } \\
\text { 4) Are you working? } \\
\text { And does reality } \\
\text { matches your } \\
\text { expectations? } \\
\text { 5) What is the } \\
\text { opinion of your } \\
\text { family, friends or } \\
\text { others about your } \\
\text { career preference? } \\
\text { And what does that } \\
\text { opinion mean to } \\
\text { you? } \\
\text { 6) Tell me your } \\
\text { strategy to get into } \\
\text { the residency of your } \\
\text { choice or how did } \\
\text { you got your } \\
\text { residency position? } \\
\text { 7) Did any changes } \\
\text { occur in your life of } \\
\text { influence on your } \\
\text { career preference } \\
\text { over the last } 1,5 \\
\text { year? } \\
8 \text { ) What would be } \\
\text { your definite choice } \\
\text { just for the } \\
\text { upcoming five } \\
\text { minutes? } \\
\text { 9) What else do you }\end{array}$ \\
\hline
\end{tabular}




\begin{tabular}{|l|l|l|l|}
\hline & $\begin{array}{l}1.5 \text { years from now? } \\
\text { 10) What else do } \\
\text { you want to tell me } \\
\text { about your career } \\
\text { preferences/choice? }\end{array}$ & $\begin{array}{l}\text { your career } \\
\text { preferences/choice? }\end{array}$ \\
\hline
\end{tabular}




\section{Appendix 3 Survey question about reasons why resident prematurely left their} residency

1. Informed consent (check box)

2. What is your age? (open question)

3. What is gender? (male/female)

4. How was your personal situation when you quit residency? (alone without children, alone with children, relation and living apart, relation and without children, relation and with children, other.

5. Did you had children when you quit residency? $(0,1,2$ or more then 2$)$.

6. What was your contract during residency? (part-time/fulltime).

7. Which residency did you quit? (open question)

8. Was this residency your first, second, third (or more) choice? $\left(1^{\text {st }}, 2^{\text {nd }}\right.$ or $3^{\text {rd }}$ or more).

9. When did you graduate medical school? (dd/mm/yyyy).

10. When did you start residency? (dd/mm/yyyy).

11. When did you quit residency? (dd/mm/yyyy).

12. Which year of residency did you quit? (year 1, year 2, year 3, year 4, year 5, year 6).

13. Was it your choice or the supervisor's choice to quit residency? (own choice, supervisor's choice, made choice together)

14. What was the main reason to quit residency? (open question).

15. Can you indicate of the following factors how they influenced the decision to quit residency? (28 specialism and personal related items on a 5-point Likert scale to indicate relevance).

16. Are there other factors that influenced the choice to quit residency? (open question).

17. What could have pursued you to continue residency? (open question).

18. Did you had any work-related experience in the specialty of your residency before you started? (no work experience, work experience as final year student, work experience as graduate, work experience as $\mathrm{PhD}$, work experience as other option).

19. Can you describe this work experience? (open question).

20. Which information, experience or support before starting residency could have prevent that you had to quit residency? (open question).

21. Which information, experience or support before starting residency could have prevent that you had start this residency? (open question).

22. What is your current job position? (other residency, other job as graduate, other job not as graduate, orientation, other).

23. Do you have any comments or suggestions regarding this survey? (open question). 




\section{Summary}

\section{Samenvatting}

Dankwoord

Curriculum vitae 


\section{Summary}

\section{Chapter 1}

Chapter 1 is the general introduction of the thesis. It introduces the subject of career choice of medical students. The purpose of medical school is to train students to become medical doctors and to supply enough doctors to fulfill the needs of society. Medical graduates tend to prefer some specialties over others. This can lead to an imbalance between the needs of western society and the career choices of medical students. An important question that has to be answered in order to establish a balanced workforce of physicians is how they make their career choice. What are the factors that influence this? We used the Bland model of career choice as a lens to provide insight into the career choice process with all the interacting factors.

Chapter 1 provides a general overview of the Dutch medical education continuum, from undergraduate education until residency. It also states what is known about the medical career choice process. It also addresses the consequences of the fact that nowadays career choices lead to a mismatch with the needs of society. This chapter also introduces the research questions of this thesis.

\section{Chapter 2}

Due to the lack of a systematic overview of the recent literature on medical career decisionmaking, a literature review was performed. Since differences in educational routes in medical education are likely to affect career choice, this review focused on medical career decisionmaking in educational systems with a Western European curriculum structure, as the Netherlands have. Chapter 2 describes the results of the review.

A systematic search of electronic databases was conducted to identify recent studies. A panel of seven reviewers performed the data extraction, quality assessment and data synthesis using the Bland model of medical specialty choice as a reference.

In total fifty-seven studies met the inclusion criteria for the review. Factors associated with specialty preference or career choice were classified in five main categories, derived from the Bland model: (1) medical school characteristics, (2) student characteristics, (3) student values, (4) career needs to be satisfied, and (5) perception of specialty characteristics. An important finding of the review was that especially career needs and perceptions of specialty characteristics are often associated with medical career decision-making. The results support that medical career decisions are formed by a matching of perceptions of specialty 
characteristics with personal needs. The review in chapter 2 provided a deeper insight into the factors of influence, yet the process of career choice needs more research.

\section{Chapter 3}

To gain insight into factors affecting career preference and career choice during the final phase of medical school, we performed a study among medical students starting their final study year. This study, as described in chapter 3, was conducted in the Netherlands where undergraduate medical education takes six years and the final year is called transitional year. The transition towards working as a licensed medical doctor is prepared in this year. Medical students experience how demands of specialties match with their career preferences. A qualitative study was conducted. One-hour semi-structured interviews were conducted with final-year medical students about career preference and the factors influencing preference and choice. The interviews were transcribed and a thematic analysis was applied, to identify patterns and interrelationships in the data and to compare and contrast these with the Bland model.

We used the framework of the review study as a lens to analyze the 22 interviews we performed with medical students about their career choice. Three critical sets of factors, not present in the Bland model, emerged from the interviews: (a) factors arising from studentinitiated information collection, (b) patient population characteristics of a specialty domain, and (c) the characteristics of teams and colleagues within a specialty.

Students appear to actively match and calibrate perceptions of different specialty characteristics with their current personal needs and expected future needs, and to include cues from self-initiated information collection about a specialty. Next, specialty patient population features appear to be taken into account; this was not unexpected but not included in the Bland model yet. Finally, the characteristics of teams and colleagues of a specialty were stressed in the interviews. These three components, and the confirmation of other factors, broaden the applicability of the Bland model--originally created for primary-care careers--to medical specialties in general.

\section{Chapter 4}

Medical trainees make career choices in the final year of medical school or after graduation, if they do not continue with residency directly after medical school. Most Dutch medical students are trained in vertically integrated (VI) curricula, with early clinical experience and an increase in clinical responsibilities. Students in such curricula have been reported to make 
- Summary

career choices at an earlier stage than graduates from more traditionally designed curricula. Many Dutch graduates build further clinical experience after graduation as physicians-not-intraining (PNITs) before beginning residency. In the study of chapter 4, we explored how students make career choices, and whether pre-residency clinical responsibilities influence this choice.

A qualitative study with a phenomenology approach was used. The authors conducted a longitudinal interview study of medical students with two intervals over a 2-year period. The first interview was at the beginning of the final study year, the second interview at the end of the final study year and the third interview one year after graduation. The interview questions covered how trainees establish career preferences and which factors affect preference and choice over time.

Experiencing clinical responsibility was a key factor for career preference during all interview rounds. Respondents explained that being a PNIT who makes diagnostic and therapeutic decisions, has their own patients and has significant patient care responsibilities, creates opportunities to build an image of a future context of employment. Some participants mentioned that their experience of having full responsibility as a PNIT was pivotal in a career preference change.

Clinical responsibility as a student or as a PNIT appears to be important for career preference and choice. The experience of responsibility as a medical doctor forces trainees to reflect on personal needs and to consider which career preference fits best.

\section{Chapter 5}

The dropout rate among residents across all medical specialties in the Netherlands approximates $2.5 \%$. This means capacity loss in the medical workforce and often personal damage to graduates. The aim of the study in chapter 5 was to investigate reasons for drop-out among residents from all specialties and the significance of physician work experience prior to residency.

In cooperation with the Dutch Medical Registration Board, a nationwide survey was sent to all residents who dropped out between 1 September 2017 and 1 September 2019. The respondents were asked to indicate on a 5-point Likert scale, how they rate the 28 reasons listed for drop-out or add other reasons.

The response rate was $39 \%(\mathrm{~N}=129,99$ females $)$ representing all medical specialties. The most frequently indicated reasons for drop-out were life-style related factors. Of the respondents, $54 \%$ (69) had prior clinical experience in the same medical specialty before 
residency. Most reasons for drop-out weighed heavier for respondents without this prior experience than for respondents with it.

An important cause to dropout of residency appears to be a limited image of the specialty of the chosen residency. One third of those who dropped out mentioned that prior physician experience within the same specialty could have prevented dropout or prevented choosing this specialty in the first place. Graduates are likely to benefit from guidance in making career choice. Graduates and residents need more guidance in coping with lifestyle related factors.

\section{Chapter 6}

Medical students switch career preferences during medical school and likely distinguish themselves in stability of preference over time. The purpose of our study in chapter 6 , was to gain insight in career paths stability of medical students.

We conducted a longitudinal, four sessions interview study with medical students. The first interview was at the beginning of the final study year, the second interview at the end of the final study year, the third interview one year after graduation and the fourth interview was 2.5 year after graduation. A three and a half-year period in total. From all 24 participants the first and second career preferences were documented, analyzed and we calculated a stability score, to interpret career preference stability.

Three different pathways were found: a 'winding road' with low stability (0-7 points); a 'country road' with medium stability (8-14 points); and a 'highway' with high stability (15-22 points).

This study provides a longitudinal view of how the stability of career preference evolves over time. The stronger the preference over time, the stronger the stability of career preference and therefore the 'faster' the type of career path. Students with a 'highway' had a preference during medical school and explained they used their experiences in the final year and especially as a graduate to be sure what this specialty requires before they could definite choose. Those with 'country' and 'winding roads' hesitated about their preferences and used their period as a graduate to experience multiple specialties and finally choose their specialty. A result of this study is that those who switch their preferred specialty started residency in a specialty which was not presented during medical school. While we only studied a small sample, but the characterization may hold when larger samples are studied. 
- Summary

\section{Chapter 7}

Finally, chapter 7 summarizes the key findings of this thesis. The main conclusion is that only clinical responsibilities foster deep experience of a medical specialty and awareness of one's own needs. Our findings confirmed that clinical responsibility supports medical students determining their career preference. We also found that clinical responsibilities for graduates are pivotal to making a specialty career choice. This research also distinguished three different career paths of medical students and graduates presenting stability of career choice during medical education.

Finally, we developed an extended model of career choice based on the Bland model. For future research it would be interesting to conduct a nationwide study into medical students' career preferences and their development during and after medical school. Next, the results of this study investigated dropout, we suggest to perform a similar study among those who successfully finished residency.

Specialty choice is an important matter of concern for the future workforce planning. As some specialties have to deal with shortages, the career preferences of medical students and recent graduates have to change to fulfill society healthcare needs. We consider practical implications of these findings, and suggest medical students and recent graduates to experience clinical responsibilities, especially within their preferred specialty. They can benefit from career choice guidance and this will support them to make their career choice. Chapter 7 further addresses the strengths and limitations of this thesis. 


\section{Samenvatting}

\section{Hoofdstuk 1}

Hoofdstuk 1 is de algemene inleiding van dit proefschrift. Het introduceert het onderwerp beroepskeuze van geneeskundestudenten. Het doel van de geneeskundestudie is om studenten op te leiden tot arts en om voldoende artsen op te leiden zodoende te kunnen voldoen aan de maatschappelijke zorgvraag. Geneeskundestudenten en basisartsen hebben voorkeur voor een aantal populaire specialismen en verkiezen deze boven een aantal andere specialismen. Dit leidt tot een disbalans tussen de behoeften van de westerse samenleving en de beroepskeuzes van geneeskundestudenten en basisartsen. Centrale onderzoeksvraag van deze studie is wat er nodig is om een evenwichtige balans te creëren tussen de behoefte aan voldoende artsen voor alle specialismen en de voorkeuren en keuzes die artsen hebben voor een specialisme. Wat zijn de factoren die hierop van invloed zijn? Dit onderzoek richt zich op het verkrijgen van inzicht in het beroepskeuzeproces van geneeskundestudenten en hierbij is gebruik gemaakt van het Bland model over het keuzeproces voor een medische vervolgopleiding.

Hoofdstuk 1 geeft een overzicht van het opleidingscontinuüm van de medische opleiding in Nederland, van basisopleiding tot de medische vervolgopleiding. Ook wordt uiteengezet wat er bekend is over het beroepskeuzeproces. Tot slot wordt ingegaan op de gevolgen van de huidige voorkeuren en hoe dit nu leidt tot de mismatch met de behoeften van de samenleving.

\section{Hoofdstuk 2}

Door het ontbreken van overzicht van de meest recente literatuur over beroepskeuze is een reviewstudie uitgevoerd. De structuur en opbouw van een opleidingscontinuüm verschilt per land en heeft waarschijnlijk invloed op het beroepskeuzeproces. De studie in hoofdstuk 2 is gericht op de beroepskeuze voor een medische vervolgopleiding in landen met een WestEuropese curriculumstructuur, zoals Nederland dat heeft.

Er is een systematisch zoekstrategie in elektronische databanken uitgevoerd, gericht op het vinden van recente studies. Een panel van zeven reviewers heeft de gegevensextractie, kwaliteitsbeoordeling en datasynthese uitgevoerd, met het Bland model van medische beroepskeuze als referentie.

In totaal voldeden zevenenvijftig studies aan de inclusiecriteria voor het review. Factoren die verband houden met specialismevoorkeur of beroepskeuze zijn ingedeeld in vijf hoofdcategorieën, die zijn afgeleid van het Bland model: (1) kenmerken van de medische 
universiteit, (2) kenmerken van de student, (3) waarden van de student, (4) carrière behoeften en (5) perceptie van specialistische kenmerken. Een belangrijke bevinding van het review was dat met name de carrière behoeften en perceptie van specialiteitskenmerken vaak samenhangen met de uiteindelijke beroepskeuze. De resultaten ondersteunen dat beroepskeuze beslissingen bepaald worden door een match tussen percepties van specialistische kenmerken met de persoonlijke behoeften. De review in hoofdstuk 2 geeft een overzicht van de factoren die van invloed zijn op de uiteindelijk keuze, maar het gehele proces van beroepskeuze behoeft meer onderzoek.

\section{Hoofdstuk 3}

Om inzicht te krijgen in factoren die van invloed zijn op de beroepsvoorkeur en -keuze tijdens de laatste fase van de geneeskundestudie, hebben we een studie uitgevoerd onder geneeskundestudenten die starten met hun laatste studiejaar. Deze studie, zoals beschreven in hoofdstuk 3, is uitgevoerd in Nederland, waar de geneeskundestudie zes jaar duurt en het laatste jaar 'schakeljaar' wordt genoemd. De transitie naar het werken als basisarts wordt in dit jaar voorbereid. Geneeskundestudenten ervaren hoe de kenmerken van het specialisme zijn en hoe deze passen bij hun persoonlijk voorkeuren.

Er is een kwalitatieve studie uitgevoerd met 1 uur durende semi-gestructureerde interviews. Onderwerpen waren de factoren die van invloed zijn op de beroepsvoorkeur en -keuze van geneeskundestudenten. De interviews zijn getranscribeerd en er is een thematische analyse toegepast om patronen en onderlinge verbanden in de data te identificeren en deze te vergelijken met het Bland model.

We gebruikten het kader van het reviewonderzoek als lens om de 22 interviews over de beroepsvoorkeuren en -keuze van geneeskundestudenten te analyseren. Uit de interviews kwamen drie kritische sets van factoren naar voren die niet in het Bland model aanwezig waren: (a) factoren die voortkomen uit studentgerichte informatieverzameling, (b) kenmerken van de patiëntenpopulatie van een specialisme en (c) kenmerken van teams en collega's binnen een specialisme.

Uit deze studie bleek dat studenten hun percepties van een specialisisme proberen te vergelijken en afwegen met hun persoonlijke behoeften en verwachte toekomstige behoeften die zij nastreven voor hun beroepsuitoefening. Zij gebruikten hiervoor zelf verkregen informatie over een specialisme, de kenmerken van de patiëntenpopulatie van een specialisme en tot slot de kenmerken van teams en collega's van een specialisme. Dit waren 
geen onverwachte uitkomsten, maar deze waren nog niet weergegeven in het Bland model. Met deze aanvulling en de bevestiging van vele andere factoren, is de toepasbaarheid van het Bland model, oorspronkelijk ontwikkeld voor de beroepskeuze voor de huisartsgeneeskunde, verbreed naar alle medische specialismen.

\section{Hoofdstuk 4}

Geneeskundestudenten maken hun beroepskeuze in het laatste jaar van de geneeskundestudie of enkele jaren na afstuderen, als zij niet direct met een medische vervolgopleiding starten. De meeste Nederlandse geneeskundestudenten worden opgeleid in verticaal geïntegreerd (VI) curricula, gericht op het verkrijgen van vroege klinische ervaring en een toename van de klinische verantwoordelijkheden gedurende de opleiding. Van studenten in dergelijke curricula is onderzocht dat zij eerder beroepskeuzes maken dan afgestudeerden van meer traditionele curricula. Veel Nederlandse afgestudeerden gaan na hun afstuderen werken als arts niet in opleiding (anios) om klinische werkervaring op te doen, voordat ze een medische vervolgopleiding starten. In de studie beschreven in hoofdstuk 4 hebben we onderzocht hoe studenten beroepskeuzes maken en of klinische verantwoordelijkheden van invloed zijn op deze keuze.

Het was een kwalitatieve studie met een fenomenologische benadering. We hebben een longitudinaal interviewonderzoek uitgevoerd met drie meetmomenten bij geneeskundestudenten. Het eerste interview was aan het begin van het laatste studiejaar, het tweede interview aan het einde van het laatste studiejaar en het derde interview een jaar na het afstuderen. In het interview werden vragen gesteld over de manier waarop studenten en basisartsen hun beroepsvoorkeuren en -keuze bepalen en welke factoren hierop in de loop van de tijd van invloed zijn geweest.

Resultaat van dit onderzoek was dat het ervaren van klinische verantwoordelijkheid een belangrijke factor is voor de beroepsvoorkeur en -keuze. Werken als anios die medische beslissingen neemt, eigen patiënten heeft en belangrijke verantwoordelijkheden voor de patiëntenzorg heeft, zijn bepalend in het verkrijgen van een reëel beeld over de toekomstige werksetting. Sommige geïnterviewden benoemden dat hun ervaring met het hebben van volledige verantwoordelijkheid als arts cruciaal was voor een verandering van de beroepsvoorkeur.

Klinische verantwoordelijkheid als student of als anios blijkt belangrijk te zijn voor de beroepsvoorkeur en -keuze. De ervaring om klinische verantwoordelijkheid te hebben dwingt 
- Samenvatting

studenten en artsen om na te denken over hun persoonlijke behoeften en te bepalen bij welk specialisme deze het beste passen.

\section{Hoofdstuk 5}

Ongeveer 2,5\% van de artsen in opleiding valt uit gedurende hun medische vervolgopleiding. Dit betekent capaciteitsverlies van artsen en vaak ook persoonlijke schade voor hen. Het doel van de beschreven studie in hoofdstuk 5 was het onderzoeken van de redenen voor uitval uit een medische vervolgopleiding en de invloed van eerder opgedane werkervaring.

In samenwerking met de Registratie Geneeskundige Specialisten (RGS) van de KNMG is een landelijk enquête verstuurd naar alle artsen die zijn gestopt met hun medische vervolgopleiding tussen 1 september 2017 en 1 september 2019. Aan de respondenten is gevraagd om op een 5-punts Likert-schaal aan te geven hoe zij de 28 genoemde redenen voor uitval waarderen of andere redenen toe te voegen.

De respons was 39\% ( $\mathrm{N}=129,99$ vrouwen) en de resultaten waren representatief voor alle medische specialismen. De meest genoemde redenen voor uitval waren leefstijl gerelateerde factoren. Van de respondenten had 54\% ( $\mathrm{N}=69)$ eerder opgedane klinische ervaring in hetzelfde medische specialisme voor start van de medische vervolgopleiding. De meeste redenen voor uitval wogen zwaarder voor respondenten zonder vooraf opgedane ervaring dan voor respondenten met wel vooraf opgedane werkervaring binnen het hetzelfde specialisme. Een belangrijke oorzaak voor uitval uit de medische vervolgopleiding bleek dat sommige aios een beperkt beeld hebben van het gekozen specialisme. Een derde van de uitvallers gaf aan dat met het hebben van eerdere ervaring binnen hetzelfde specialisme uitval voorkomen had kunnen worden of ze hadden zelfs niet gekozen voor het specialisme. Basisartsen hebben waarschijnlijk baat bij begeleiding in het maken van hun beroepskeuze. Basisartsen en artsen in opleiding hebben meer coaching nodig in het omgaan met leefstijl gerelateerde factoren.

\section{Hoofdstuk 6}

Geneeskundestudenten veranderen hun beroepsvoorkeuren gedurende de geneeskundestudie en de voorkeuren worden gedurende de tijd steeds stabieler. Het doel van onze studie beschreven in hoofdstuk 6 was om inzicht te krijgen in de stabiliteit van beroepsvoorkeuren van geneeskundestudenten. Dit is onderzocht middels een longitudinale interviewstudie met geneeskundestudenten. Het eerste interview was aan het begin van het laatste studiejaar, het tweede interview aan het eind van het laatste studiejaar, het derde interview een jaar na het afstuderen en het vierde interview 2,5 jaar na afstuderen. Een periode van totaal drie en een 
half jaar. Van alle 24 deelnemers werden de eerste en tweede beroepsvoorkeuren gedocumenteerd, geanalyseerd en de stabiliteitsscore berekend, om de stabiliteit van de beroepsvoorkeur te interpreteren.

Er werden drie routes gevonden met verschillende stabiliteit: een 'kronkelweg' met lage stabiliteit (0-7 punten); een 'landweg' met gemiddelde stabiliteit (8-14 punten); en een 'snelweg' met hoge stabiliteit (15-22 punten).

Deze studie geeft een beeld van hoe de stabiliteit van de beroepsvoorkeur zich in de loop van de tijd ontwikkelt. Hoe sterker de voorkeur in de tijd, hoe sterker de stabiliteit van de beroepsvoorkeur en dus hoe 'sneller' de route. Studenten met een 'snelweg' hadden tijdens de geneeskundestudie een voorkeur en gebruikten hun ervaringen in het laatste jaar en vooral als afgestudeerde om zeker te zijn van wat deze specialiteit vereist, voordat ze een definitieve keuze konden maken. Degenen met 'landwegen' en 'kronkelwegen' aarzelden over hun voorkeuren en gebruikten hun periode als afgestudeerde arts om meerdere specialismen te ervaren en uiteindelijk hun specialisme te kiezen. Een resultaat van deze studie is dat de meeste die van voorkeur wisselden, kozen voor een specialisme waar zij geen ervaring in hadden opgedaan tijdens de geneeskundestudie. Deze studie betrof slechts een kleine steekproef van de Nederlandse geneeskundestudenten en nader onderzoek is nodig.

\section{Hoofdstuk 7}

In hoofdstuk 7 worden de belangrijkste bevindingen van dit proefschrift samengevat. De belangrijkste conclusie is dat klinische verantwoordelijkheid stimuleert om een medisch specialisme te ervaren en om goed inzicht te krijgen in de eigen behoeften. Onze bevindingen bevestigen dat het hebben van klinische verantwoordelijkheid als geneeskundestudent en/of basisarts ondersteunt bij het bepalen van de beroepsvoorkeuren en voor het maken van de beroepskeuze voor een medische vervolgopleiding. Dit onderzoek onderscheidde ook drie paden die verschillende stabiliteit van beroepskeuze toont van geneeskundestudenten. Tot slot hebben we het huidige Bland model van beroepskeuze uitgebreid met een aantal elementen. Voor toekomstig onderzoek kan het interessant zijn om de beroepsvoorkeuren en ontwikkeling hiervan bij geneeskundestudenten tijdens en na de geneeskundestudie nader te onderzoeken middels een landelijke studie. Ook het nader onderzoeken van factoren die hebben bijgedragen aan het afronden van de medische vervolgopleiding kunnen inzichten bieden om het percentage uitval van aios te verlagen.

De beroepskeuze van artsen is een belangrijk onderwerp voor de beschikbaarheid van voldoende artsen voor de maatschappij. Gezien het feit dat sommige specialismen te maken 
- Samenvatting

hebben met tekorten, dienen er veranderingen in de beroepsvoorkeuren van studenten en artsen te komen om te voldoen aan de maatschappelijke behoeften in de gezondheidszorg. Om geneeskundestudenten en basisartsen de juiste beroepskeuze te laten maken is het nodig hen hierin te begeleiden. Verder is het opportuun de huidige aios te ondersteunen in het omgaan met de hoge werkdruk en om de balans tussen werk en privéleven te behouden. Hoofdstuk 7 gaat verder in op de sterke punten en aandachtspunten van dit proefschrift. 


\section{Dankwoord}

Op deze pagina's achterin het proefschrift wil ik graag iedereen bedanken die mij de afgelopen jaren heeft gesteund en geholpen. Heel veel mensen samen hebben deze promotie mogelijk gemaakt. Aan allen van jullie: Dank je wel! Een aantal hoofdpersonen wil ik graag persoonlijk noemen, omdat het zonder jullie niet gelukt was.

Dank aan Olle. Het begon aan jouw tafel waar we een overleg hadden over het medische profielenboek en dat ik de grap maakte 'ik ben de enige niet gepromoveerde in dit gesprek'. De dagen erna begon ik na te denken hierover en snel daarna hebben we met elkaar gesproken over dit onderwerp voor mijn promotieonderzoek. Je bent een bijzondere promotor, ik heb enorm veel van je mogen leren en werd vaak meegezogen in je passie voor het medisch onderwijs. Mijn dank voor de kansen die je mij gedurende dit traject geboden hebt en ik hoop dat ik ze goed benut heb. Ik vond het een eer om bij je te mogen promoveren. Ik hoop dat ik de vaardigheden en kennis heb voor de volgende stap in de wetenschappelijke wereld.

Mijn twee copromotoren. Lode, je staat voor mij als een goede coach en sterke schrijver in dit gehele traject. Vanaf het eerste moment hebben we vele uren zitten brainstormen over de relevante inhoudelijke richting en mijn wens om beter te kunnen schrijven. Jouw advies; doen en doen! En kijk waar het mij gebracht heeft. Ik vond het super dat je ondanks je vertrek bij de KNMG mijn copromotor wilde blijven. Dank voor je steun en bereidheid mij te coachen in het leren wetenschappelijk schrijven en je enorme inhoudelijke bijdrages aan de artikelen. En natuurlijk ook mijn copromotor en oud-collega Marlies. Altijd kon ik met je overleggen en wilde je met mij meedenken hoe het aan te pakken. Fijn om samen te werken met iemand die zo de ervaring heeft van het zwoegen op een artikel en precies weet hoe je de promovendus on-going houdt. Ook tijdens het laatste stukje, na mijn KNMG-tijd, was je er. Ik ga het missen en hopelijk blijven we elkaar nog vaak zien!

Sjoukje dank voor onze fantastische, leerzame en ook gezellige samenwerking. Ik vond het waardevol om onze onderzoeken in het begin zo te integreren. De wederzijdse hulp en vele kopjes thee die we daarbij dronken waren voor mij motiverend. Je bent een goede onderzoeker en altijd meedenkend. Bijna jammer dat onderzoek doen klaar is, want ik had 
- Dankwoord

veel plezier van onze samenwerking. Ik ben blij je dat ik je heb leren kennen en ik hoop dat we nog lang bevriend blijven.

Natuurlijk was het niet gelukt zonder de 24 toen geneeskundestudenten en nu artsen. Bekend als: Alice, Anna, Emily, Eric, Eva, Femke, Fiona, James, Jonna, Jozefien, Julia, Kiki, Lizzy, Maria, Noor, Olivia, Sander, Sarah, Simone, Susan, Tess, Theo, Xavier en Zoë. 'Mijn populatie'. Bijzonder dat jullie, in jullie ontzettende drukke bestaan tijd hebben vrij gemaakt om deel te nemen aan de interviews. Het was zo mooi om een paar jaar in jullie levens te mogen 'meekijken' en jullie persoonlijke overwegingen en keuzes als basis te gebruiken voor dit onderzoek. Ik dank jullie en wens jullie een prachtige artsencarrière!

Ook dank aan alle aios die zijn gestopt met de opleiding en hebben deelgenomen aan de enquête.

Het Nivel, en in het bijzonder Ronald, dank voor je bijdrage aan de systematische review die we gezamenlijk hebben uitgevoerd. Ook voor het plaatsnemen in de beoordelingscommissie van mijn gehele proefschrift. En David, dank voor het samen sparren en mij de eerste kneepjes van wetenschappelijk publiceren mee te geven.

Victor, wat leerzaam om met jou te sparren over de analyses van de enquête. Door de samenwerking met jou heb ik nog meer kennis gekregen over de samenhang tussen factoren die bepalend zijn in het beroepskeuzeproces van geneeskundestudenten en basisartsen. Dank!

De leden van de beoordelingscommissie, Prof. dr. R.S. Batenburg, Prof. dr. G. Croiset, Prof. dr. R.A.M. Damoiseaux, dhr. dr. R.G. Hoff en mw. dr. M. van de Pol, wil ik bedanken voor het lezen en beoordelen van mijn manuscript en het zitting nemen in de oppositie. Ik kijk ernaar uit om met $u$ van gedachten te wisselen over dit proefschrift.

Het lezen, presentaties maken en het leren over onderwijs theorieën was niet mijn favoriete tijdsbesteding, maar de CTL-bijeenkomsten hebben mij enorm veel geleerd. Sjoukje, Rianne, Feikje, Anouk, Thijs, Marijn, Chantal, Gersten, Carrie, Lieselotte, Marijn, Eugene, Margot, bedankt voor de leerzame bijeenkomsten en daarmee verbreding van mijn medisch onderwijs kennis. Ik ga het denk ik toch wel missen, hopelijk blijf ik jullie op congressen tegenkomen.

Dank aan de $K N M G$ die mij de tijd heeft gegeven mijzelf wetenschappelijk te ontwikkelen. 
Ook dank aan mijn team en bestuur bij SOON, Raymond, Martin, Anne, Victor, Eric, Babette, Carien, Corinne, Eveline, Ilse, Jan, Kristen, Marianne, Peter, Sabine en Til. Vanaf de eerste dag heb ik mij welkom gevoeld in ons team en ik krijg energie van samenwerken met jullie. Dank voor jullie interesse.

Mede door de financiële steun van Stichting $S W G$ was het uitvoeren van dit onderzoek mogelijk. In het bijzonder dank ik ook Loes $v / d$ Linden voor je tip om de subsidie aan te vragen.

Dan om zeker niet te vergeten in dit dankwoord mijn vrienden en familie.

Anne-Marie, Cynthia, Hanna, Hanneliek, Kim, Peter, Veerle en jullie partners, dank voor de interesse en de lieve reacties als ik weer eens een voor jullie saai en wetenschappelijk artikel had gepubliceerd. Al die jaren hebben jullie belangstelling gehad voor mijn onderzoek. Dank voor jullie steun. Nu hoef ik geen nee meer te zeggen, omdat ik moet schrijven, maar er is volop tijd om af te spreken en wijn te drinken. Ik kijk ernaar uit.

Arieke, Britt, Floor, Jorien, Maartje, Nienke, Sandra en ook de Vrijmarkt mannen natuurlijk, ik kan weer vaker een bakkie doen en gezellig aanschuiven 's avonds bij de BBQ, ik zie jullie in de binnentuin!

Mijn paranimfen, jullie zijn twee belangrijke en bijzondere vrienden.

Britt, lieve vriendin, wat ben ik blij met jou. Een vriendin die zo dichtbij woont en dichtbij voelt. Dank je wel dat jij mijn paranimf wilt zijn, dikke knuffel.

Peter, jij betekent veel voor mij, dat hoef ik hier niet uit te leggen. Jij bent er altijd voor mij en daarom heb ik je graag aan mijn zijde bij dit bijzondere moment.

Anita, wat fijn dat je zo lief en zorgzaam voor ons alle vijf bent. Dank je.

Tante Hadassa, wat fijn om een tante te hebben die weet hoe zwaar het is om te schrijven voor mij. Als ik zat te schrijven heb ik vaak teruggedacht aan de zomer op jouw werkkamer. Dank voor de basisvaardigheden in de kunst van het schrijven. 
- Dankwoord

Papa en mama, dank voor jullie steun en stimulans tijdens dit promotietraject. Dank dat jullie er altijd voor mij zijn. Ik hoop dat jullie trots zijn op dit proefschrift. Geen dokter Querido, maar doctor Querido!

Henri, lieve schat, dank voor je steun en het overnemen van de dingen in huis, zodat ik weer kon interviewen of schrijven. Al die vele momenten dat ik je probeerde uit te leggen waar ik toch mee bezig was en dat ik nu echt de laatste versie van dat ene artikel had geschreven. Wat fijn dat je de foto's hebt gemaakt van mijn proefschrift. Lieverd, nu is het klaar!

Davine, Levy en Yva, lieve kleintjes, vanaf het moment in de buik hebben jullie wat meegekregen van het promoveren. Met een dikke buik deed ik interviews, analyses en schreef ik aan de artikelen. Jullie hebben een prachtige tekening voor de cover gemaakt, dank jullie wel! Het is klaar en het is tijd voor het feest. Er is weer veel tijd om koekjes te bakken, te knutselen en leuke dingen te doen in het weekend. Of gewoon langer op te blijven en samen nog een spelletje te doen. Ik ben trots op jullie alle drie, jullie maken mij een gelukkige mama! 


\section{List of publications}

\section{Publications related to this thesis}

- Querido SJ, Vergouw D, Wigersma L, Batenburg RS, de Rond MEJ, ten Cate T. Dynamics of career choice among students in undergraduate medical courses. A BEME systematic review: BEME guide No. 33. Med Teach. 2015.

- Querido SJ, van den Broek WES, de Rond MEJ, Wigersma L, ten Cate T. Factors affecting senior medical students' career choice. Int J Med Educ. 2018. doi:10.5116/ijme.5c14.de75.

- Querido SJ, de Rond MEJ, Wigersma L, van den Broek WES, ten Cate T. The significance of experiencing clinical responsibility for specialty career choice. Medical Science Education 2019. doi:10.1007/s40670-019-00832-z.

- Querido SJ, de Rond MEJ, Wigersma L, Cate O. Some residents drop out of specialty training: are reasons related to prior physician experience? 2020. Submitted.

- Querido SJ, Wigersma L, Cate O. Traveling by winding roads or highways: Stability of medical students' specialty preferences over time. Med Teach [Internet]. 2020;0(0):1-3. doi:10.1080/0142159X.2020.1804056.

\section{Other publications}

- Querido SJ, Brouwer T, Buiten M, Kleine Schaars I. The same, but different. GMS Z Med Ausbild. 2010;27(2).

- Soethout MBM, Querido SJ, De Rond MEJ, ten Cate T. Snijdende specialismen meest tevreden met hun werk. [in Dutch]. Medisch Contact. 2014:1800-1802.

- Van den Broek WES, Querido SJ, Wijnen-Meijer M, ten Cate T, van Dijk MR. Social identification with the profession in the transition from medical student to practioner. Teaching and Learning in Medicine. 2020: doi:10.1080/10401334.2020.1723593. 


\section{Conference presentations}

- Querido SJ, Vergouw D, Wigersma L, Batenburg RS, de Rond MEJ, ten Cate T. Dynamiek van de beroepskeuze onder geneeskunde studenten in de initiële basisopleiding. Een systematische BEME review. 13-11-2015 as paper: Nederlandse vereniging voor Medisch Onderwijs, in Rotterdam.

- Dolmans DHJM, Querido SJ, Bendermacher, G. Een review studie opzetten: Hoe doe je dat? 17-11-2016 as workshop: Nederlandse vereniging voor Medisch Onderwijs, in Egmond aan Zee.

- Querido SJ, van den Broek WES, de Rond MEJ, Wigersma L, ten Cate T. Factoren van invloed op de beroepsvoorkeuren; een kwalitatieve studie van zesdejaars studenten geneeskunde. 18-11-2016 as poster presentation: Nederlandse vereniging voor Medisch Onderwijs, in Egmond aan Zee.

- Querido SJ, van den Broek WES, de Rond MEJ, Wigersma L, ten Cate T. Clinical responsibility before residency: a significant factor enhancing career choice. 27-082018 as poster presentation: Association for Medical Education in Europe (AMEE), Basel, Switzerland.

- Querido SJ, van den Broek WES, de Rond MEJ, Wigersma L, ten Cate T. Impact van aniosperiode op de beroepskeuze. 15-11-2018 as paper: Nederlandse vereniging voor Medisch Onderwijs, in Egmond aan Zee.

- Querido SJ. Beroepskeuze in Nederland. 05-10-2019 as workshop: Koninklijke Nederlandsche Maatschappij der Geneeskunst (KNMG), Nieuwegein. 


\section{Curriculum vitae}

Sophie Querido was born in 1982 in Utrecht, the Netherlands. She studied Health Care Management at Erasmus University Rotterdam. She graduated in 2007.

In 2009, she started working at KNMG - the Royal Dutch Medical Association, in Utrecht, the Netherlands. She worked as policy advisor on several projects, initially with the career counseling of medical students, graduates and residents. During these years, she acquired experience in issues concerning strategic and policy advice on health workforce and an expert opinion on career choice of medical students and graduates.

In 2012, she started the research described in this Ph.D. thesis, under the supervision of Prof. dr. Olle ten Cate, dr. Lode Wigersma and dr. Marlies E.J. de Rond.

As of 2018, Sophie is working as director at SOON (Central Board for Specialty training for Elderly Care Medicine in the Netherlands), Utrecht, the Netherlands. 

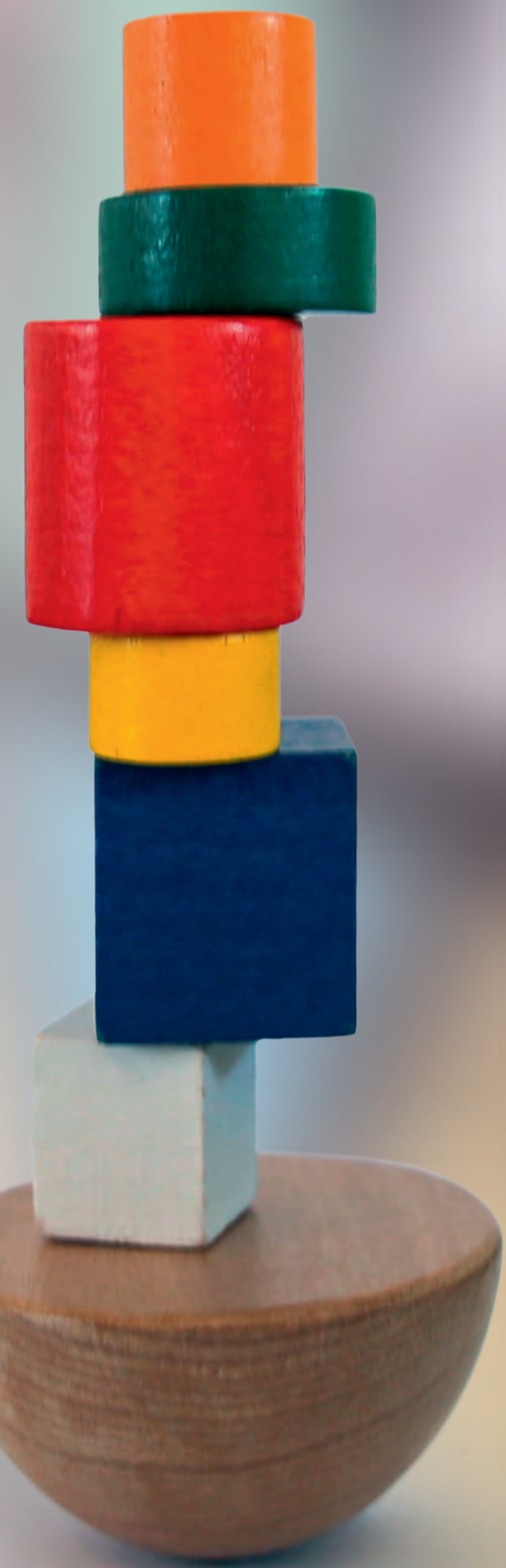